Portland State University

PDXScholar

$1-1-2012$

\title{
Interpersonal Conflict and Employee Well-Being: The Moderating Role of Recovery Experiences
}

Caitlin Ann Demsky

Portland State University

Follow this and additional works at: https://pdxscholar.library.pdx.edu/open_access_etds

Let us know how access to this document benefits you.

\section{Recommended Citation}

Demsky, Caitlin Ann, "Interpersonal Conflict and Employee Well-Being: The Moderating Role of Recovery Experiences" (2012). Dissertations and Theses. Paper 766.

https://doi.org/10.15760/etd.766

This Thesis is brought to you for free and open access. It has been accepted for inclusion in Dissertations and Theses by an authorized administrator of PDXScholar. Please contact us if we can make this document more accessible: pdxscholar@pdx.edu. 
Interpersonal Conflict and Employee Well-Being:

The Moderating Role of Recovery Experiences

by

Caitlin Ann Demsky

A thesis submitted in partial fulfillment of the requirements for the degree of

Master of Science

in

Psychology

Thesis Committee:

Charlotte Fritz, Chair

Leslie Hammer

Robert Roeser

Portland State University

(C)2012 


\begin{abstract}
Recovery during nonwork time is essential for restoring resources that have been lost throughout the working day (Sonnentag \& Fritz, 2007). Recent research has begun to explore the nature of recovery experiences as boundary conditions between various job stressors and employee well-being (Kinnunen, Mauno, \& Siltaloppi, 2010; Sonnentag, Binnewies, \& Mozja, 2010). Interpersonal conflict is an important work stressor that has been associated with several negative employee outcomes, such as higher levels of psychosomatic complaints (Pennebaker, 1982), anxiety, depression, and frustration (Spector \& Jex, 1998). This study contributes to recovery research by examining the moderating role of recovery experiences on the relationship between workplace interpersonal conflict and employee well-being. Specifically, it was hypothesized that recovery experiences (e.g., psychological detachment, mastery, control, relaxation, negative work reflection, positive work reflection, and social activities) would moderate the relationship between interpersonal conflict and employee well-being (e.g., job satisfaction, burnout, life satisfaction, and general health complaints). Hierarchical regression was used to examine the hypotheses. Relaxation was found to be a significant moderator of the relationship between self-reported interpersonal conflict and employee exhaustion. Additional analyses found mastery experiences to be a significant moderator of the relationship between coworker reported interpersonal conflict and both dimensions of burnout (exhaustion and disengagement). Several main relationships between recovery experiences and employee well-being were found that support and extend earlier research on recovery from work. Practical implications for future research are discussed.
\end{abstract}




\section{Acknowledgements}

I would like to thank my committee for their insightful comments and suggestions that have helped strengthen my thesis project. Without your input and expertise, this document would not be what it is today. In particular, I would like to thank my advisor, Charlotte Fritz, for providing me with invaluable assistance and advice over the course of this project. I would also like to thank my cohort and classmates for their emotional support, feedback, and help over the past year. Finally, I would like to thank my family and friends for their continued support of my educational pursuits. 
Table of Contents

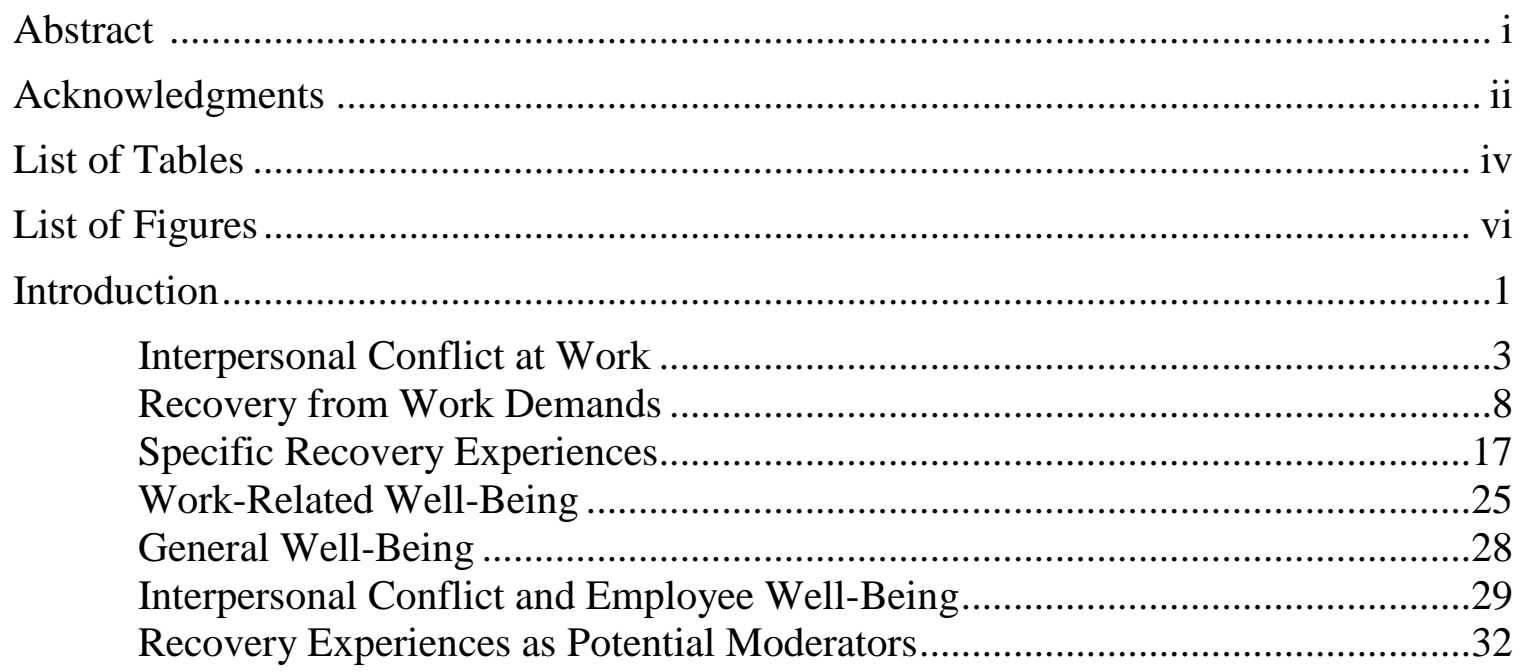

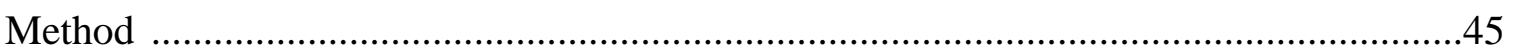

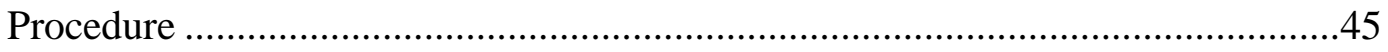

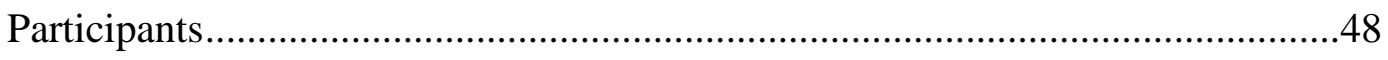

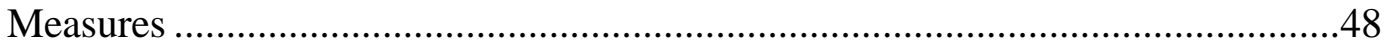

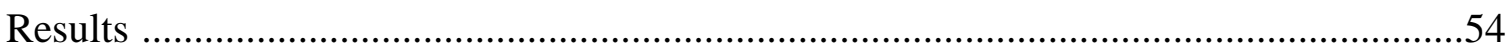

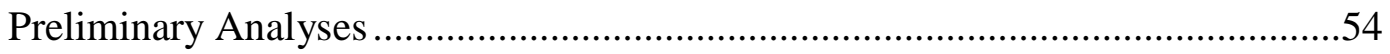

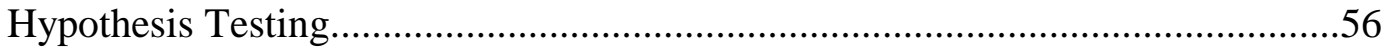

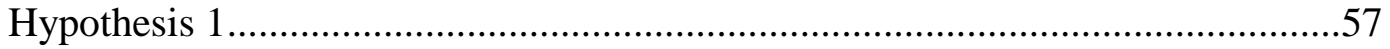

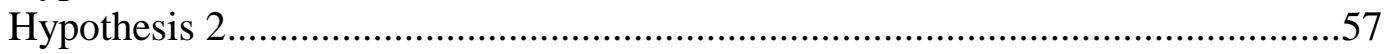

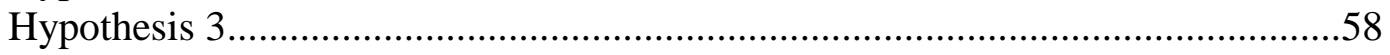

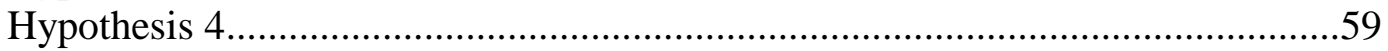

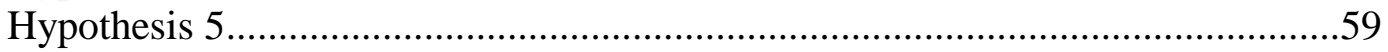

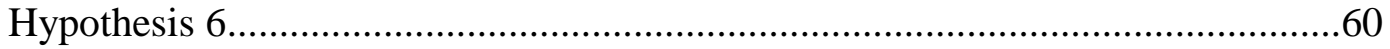

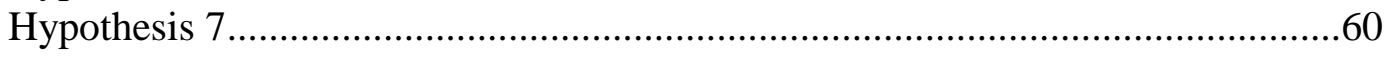

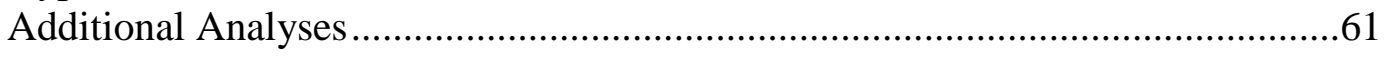

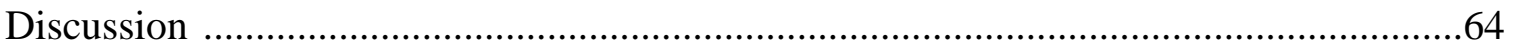

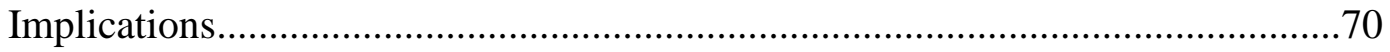

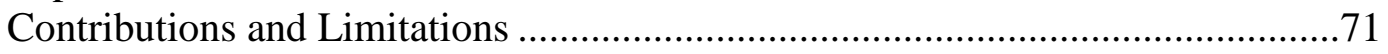

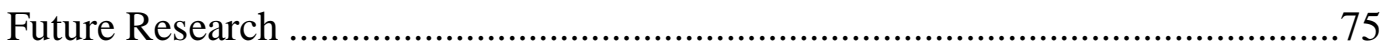

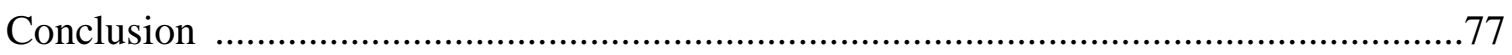

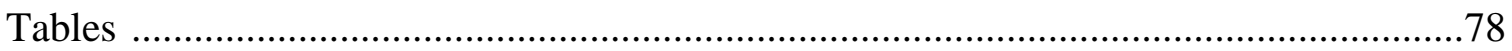

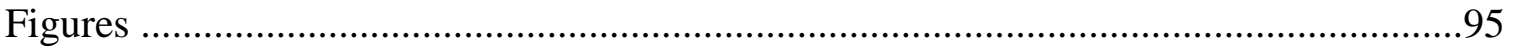

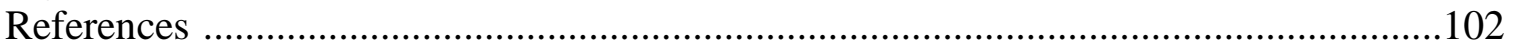

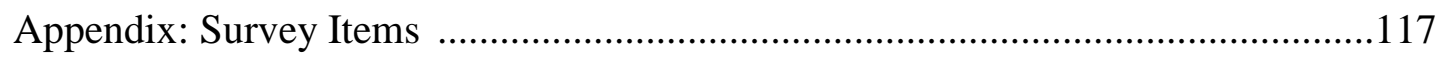




\section{List of Tables}

Table 1: Table of Variables and Measurement Scales .78

Table 2: Correlations between Study Variables

Table 3: Hierarchical Regression Results for Psychological Detachment as a Moderator of the Relationship between Interpersonal Conflict and Work-Related Well-Being .81

Table 4: Hierarchical Regression Results for Psychological Detachment as a Moderator of the Relationship between Interpersonal Conflict and General Well-Being .82

Table 5: Hierarchical Regression Results for Relaxation as a Moderator of the Relationship between Interpersonal Conflict and Work-Related Well-Being

Table 6: Hierarchical Regression Results for Relaxation as a Moderator of the Relationship between Interpersonal Conflict and General Well-Being

Table 7: Hierarchical Regression Results for Mastery Experiences as a Moderator of the Relationship between Interpersonal Conflict and Work-Related Well-Being Outcomes .85

Table 8: Hierarchical Regression Results for Mastery Experiences as a Moderator of the Relationship between Interpersonal Conflict and General Well-Being .86

Table 9: Hierarchical Regression Results for Control as a Moderator of the Relationship between Interpersonal Conflict and Work-Related Well-Being

Table 10: Hierarchical Regression Results for Control as a Moderator of the Relationship between Interpersonal Conflict and General Well-Being

Table 11: Hierarchical Regression Results for Social Activities as a Moderator of the Relationship between Interpersonal Conflict and Work-Related Well-Being

Table 12: Hierarchical Regression Results for Social Activities as a Moderator of the Relationship between Interpersonal Conflict and General Well-Being

Table 13: Hierarchical Regression Results for Positive Work Reflection (PWR) as a Moderator of the Relationship between Interpersonal Conflict and Work-Related Well-

Being

Table 14: Hierarchical Regression Results for Positive Work Reflection (PWR) as a Moderator of the Relationship between Interpersonal Conflict and General Well-Being

Table 15: Hierarchical Regression Results for Negative Work Reflection (NWR) as a Moderator of the Relationship between Interpersonal Conflict and Work-Related WellBeing 
Table 16: Hierarchical Regression Results for Negative Work Reflection (NWR) as a Moderator of the Relationship between Interpersonal Conflict and General Well-Being 


\section{List of Figures}

Figure 1: Hypothesized Model of the Relationship between Relationships between

Interpersonal Conflict and Well-Being with Recovery Experiences as Moderators

Figure 2: Relaxation as a Moderator of the Relationship between Self-Reported Interpersonal Conflict and Exhaustion

Figure 3: Additional Analyses: Mastery Experiences as a Moderator of the Relationship between Coworker-Reported Interpersonal Conflict and Exhaustion

Figure 4: Additional Analyses: Mastery Experiences as a Moderator of the Relationship

between Coworker-Reported Interpersonal Conflict and Disengagement. .98

Figure 5: Additional Analyses: Psychological Detachment as a Moderator of the Relationship between Coworker-Reported Interpersonal Conflict and Exhaustion (Controlling for Age, Gender, and Job Status).....

Figure 6: Additional Analyses: Psychological Detachment as a Moderator of the Relationship between Coworker-Reported Interpersonal Conflict and Disengagement (Controlling for Age, Gender, and Job Status).

Figure 7: Additional Analyses: Relaxation as a Moderator of the Relationship between Coworker-Reported Interpersonal Conflict and Life Satisfaction (Controlling for Age, Gender, and Job Status) 


\section{Interpersonal Conflict and Employee Well-Being:}

\section{The Moderating Role of Recovery Experiences}

In today's fast-paced society, it is common to interact with numerous individuals throughout a workday, including supervisors, coworkers, and customers. While one may hope that each of these interactions is pleasant and meaningful, this is not always the case. For various reasons, employees who interact with a variety of people throughout the workday may occasionally experience interpersonal conflict at work. Interpersonal conflict at work is a common source of work stress that can be associated with adverse outcomes for its victims. Most commonly, interpersonal conflict at work manifests itself in petty arguments, spreading rumors, and gossiping (Spector \& Jex, 1998). More specifically, interpersonal conflict has been defined by researchers as an organizational stressor consisting of disagreements between individuals in the workplace (Spector \& Jex, 1998). Conflict in the workplace can create hostile environments that add additional demands for employees. Victims of interpersonal conflict at work often use emotion regulation and rational thinking to cope with feelings of frustration and anger that arise from the conflict. These strategies may leave them feeling drained and unable to cope with additional demands at work or at home (Grandey, 2000).

Past research has indicated several negative outcomes associated with interpersonal conflict at work. For example, experienced interpersonal conflict at work is related to higher levels of anxiety, depression, frustration, and intention to quit (Spector \& Jex, 1998). These findings suggest that interpersonal conflict is associated with substantial negative outcomes for employees. While it is important that organizations 
address interpersonal conflict in the workplace, it is also essential that employees who encounter conflict at work have strategies that facilitate their ability to cope with the conflict. Much of the research surrounding interpersonal conflict has focused on identifying antecedents and outcomes, however, few studies have offered suggestions for possible strategies to ameliorate the negative impacts of interpersonal conflict at work. It can be assumed that even in the case of an organization that has been proactive in eliminating interpersonal conflict, these contentious encounters are often inevitable.

One possible way for employees to lessen potential negative impacts of workplace stressors is to intentionally spend time recovering from work during nonwork time. Several specific recovery experiences have been identified as ways for individuals to recover from work stress (Sonnentag \& Fritz, 2007). Through recovery from work individuals are able to separate themselves from work demands, enabling them to return to work feeling refreshed and rejuvenated. In the context of interpersonal conflict at work, recovery may lessen the possible negative impacts of workplace conflicts. For example, mentally distancing oneself from work may help individuals disengage from the conflict they experienced at work that day. Similarly, spending time with others outside of work may allow individuals to seek social support from friends and family.

The current study is an examination of the relationship between interpersonal conflict and employee well-being outcomes. Specifically, I focus on well-being outcomes that are both job-related (job satisfaction and burnout) and general (life satisfaction and general health). In line with past research, I propose that there will be negative relationships between interpersonal conflict and indicators of well-being. However, this 
study moves beyond previous research by examining recovery experiences as possible moderators of the relationship between workplace interpersonal conflict and employee well-being. The results of this study will provide insights for individuals dealing with interpersonal conflict at work, as well as for organizations seeking to implement interventions to counteract the negative associations between interpersonal conflict and employee well-being.

\section{Interpersonal Conflict at Work}

Job stressors. There is a substantial body of research dedicated to examining the various employee-level effects of job stressors. Individuals monitor and appraise events in their environment (Lazarus, 1991). Events that are seen as threats to well-being are considered job stressors and may induce negative emotional reactions like anger or anxiety (Spector, 1998). Various workplace conditions have been identified as job stressors, including role conflict and ambiguity (Kahn, Wolfe, Quinn, Snoek, \& Rosenthal, 1964), situational constraints (Peters \& O’Connor, 1980), low autonomy (Spector, 1986), and workload (Spector, 1987). These work stressors have been associated with a variety of employee outcomes, including both job performance and well-being. Additionally, as will be described below, interpersonal conflict is another job stressor that has received attention in the research literature (Spector \& Jex, 1998).

Workplace interpersonal conflict. Interpersonal conflict at work can manifest itself in several ways, and can range in severity from spreading rumors to physical assault. Conflict at work can consist of covert behaviors that are indirect and less 
identifiable, or overt behaviors with very direct and obvious intentions (Spector \& Jex, 1998). While a wide variation of interpersonal conflict may be found across and within organizations, the majority of interpersonal conflicts include petty arguments and gossip, and not actual physical attacks (Schat, Frone, \& Kelloway, 2006). Regardless of the interpersonal conflict manifestation, can elicit anger and frustration in employees who encounter it (Keenan \& Newton, 1985). As a result, employees who encounter interpersonal conflict at work may have difficulties disengaging from thoughts of the conflict and may ruminate about the experience even after leaving the workplace at the end of the day. They may also be less engaged in their work out of fear of future conflicts. Over time, these continued thoughts of the experienced conflict may lead to detrimental outcomes for employees, such as higher levels of anxiety, frustration, and burnout (De Dreu, Dierendonck, \& Dijkstra, 2004b).

While the current study utilizes Spector and Jex's (1998) explanation of interpersonal conflict, it is important to consider other operationalizations of the construct. Past research has examined various forms of conflicts in the workplace, using terms such as incivility, bullying, aggression, and counterproductive work behaviors (e.g., Schat et al., 2006; Bowling \& Beehr, 2006; Barling, Dupre, \& Kelloway, 2009; Hershcovis \& Barling, 2009; Hershcovis, 2011). Barki and Hartwick (2004) note that even within studies pertaining explicitly to interpersonal conflict, researchers rarely agree on one single definition of interpersonal conflict, or avoid defining the construct altogether. Barki and Hartwick (2004) define interpersonal conflict as "a dynamic process that occurs between interdependent parties as they experience negative emotional 
reactions to perceived disagreements and interference with the attainment of their goals" (p. 234). Additionally, they discuss three general themes used to describe conflict: disagreement, interference, and negative emotion. Each of these three themes is thought to represent cognitive, behavioral, and affective manifestations of conflict, respectively. Disagreement occurs when parties involved think that a divergence of needs, thoughts, opinions, or goals exists. Interference occurs when one party's behaviors interfere with, or oppose another party's attainment of its own objectives, needs, or goals. Lastly, negative emotions such as fear, jealously, anger, anxiety, and frustration have been used to characterize interpersonal conflict.

Several organizational and individual factors have been linked to increased incidents of interpersonal conflict in the workplace. The Dollard-Miller frustrationaggression theory (Dollard, Doob, Miller, Mowrer \& Sears, 1939) suggests that frustration occurs when an instigated goal sequence or behavioral sequence is interrupted. When this occurs an individual may respond with aggression, especially when a substitute response for the prevented goal sequence is not available. Later research expanded the theory by including the mediating presence of an emotional reaction (Spector, 1978; Spielberger, Reheiser \& Sydeman, 1995). In this expanded model, the frustration of a task performance or personal goal by one of a number of possible sources (e.g., supervisors, subordinates, coworkers, procedures, or formal structure) leads to an emotional response of frustration or anger. These emotional reactions are associated with behavioral outcomes, with severe frustration and no expectation of punishment being 
linked to organizational and interpersonal aggression, as well as eventual withdrawal and goal abandonment.

Fox and Spector (1999) proposed a theoretical model of counterproductive work behaviors pertaining to interpersonal and organizational aggression, which is relevant in the current context of interpersonal conflict. The work of Fox and Spector (1999) expands the original Dollard-Miller frustration-aggression theory, by including both emotional and behavioral reactions to frustration. In the work context, certain stressors, such as situational constraints, may serve to block an intended organizational goal, causing individuals to become frustrated (Peters \& O'Connor, 1980). Behavioral reactions to frustration on the job, pertinent to the current study, include lowered job performance, absenteeism, turnover, and both organizational and interpersonal aggression (Spector, 1978). Accordingly, Fox and Spector (1999) found that events in the workplace (e.g., situational constraints) were related to organizational counterproductive behaviors (including workplace aggression) and were mediated by affective responses to frustration.

Spector and Jex (1998) conducted a meta-analysis of 13 studies utilizing the Interpersonal Conflict at Work Scale. The results of this meta-analysis demonstrated that interpersonal conflict at work was most strongly related to several job stressors (e.g., role conflict, role ambiguity, and low autonomy). This meta-analysis further supports the model of frustration-aggression presented by Fox and Spector (1999), which suggests that situational constraints as well as individual factors contribute to affective and behavioral reactions, one of which is increased interpersonal aggression. 
Affective events theory. Weiss and Cropanzano (1996) posited affective events theory (AET) as an alternative explanation to theories that focus on satisfaction with one's job as an evaluative judgment process. Instead, Weiss and Cropanzano (1996) argue that job satisfaction is a consequence of affective events in the workplace that direct attention away from features of the work environment and toward events or proximal causes of affective reactions. Additionally, they suggest that patterns of affect will influence both overall feelings about one's job as well as discrete work behaviors. Importantly, AET also acknowledges the multidimensional nature of affect-employees can feel angry, proud, frustrated, or joyful. Each of these different reactions has different behavioral implications in the workplace.

At the core of AET are affective reactions, which occur in response to work events. These affective reactions can be influenced by one's disposition, and lead to both attitudinal and behavioral outcomes. Affective reactions to workplace events influence work attitudes (e.g., job satisfaction). Behavioral outcomes are grouped into two categories: affect driven behaviors and judgment driven behaviors. Affect driven behaviors follow directly from affective reactions and are influenced by processes like coping and mood management (Weiss \& Cropanzano, 1996). Judgment driven behaviors, on the other hand, are mediated by satisfaction.

In the context of workplace interpersonal conflict, AET is useful for explaining the potential linkage between interpersonal conflict and job satisfaction, one of the several dependent variables in the current study. Experiencing conflict would be one work event that would elicit an affective reaction. This affective reaction would in turn 
lead to attitudinal and behavioral outcomes. The attitudinal outcomes may include lowered levels of job satisfaction, frustration, or anger.

\section{Recovery from Work Demands}

Recovery from work refers to a process during which individual functional systems that have been called upon during the workday return to their prestressor levels (Meijman \& Mulder, 1998). Recovery can be described as a psycho-physiological process (Meijman \& Mulder, 1998), and has been conceptualized as being the opposite of the strain process, in which prolonged activation results in stress reactions. During recovery from work (e.g., during evenings or weekends) employees are able to disengage from work demands and focus on nonwork activities, which allow time for emotional and cognitive systems that were activated during work to restabilize. One's personal resources (e.g., feelings of self-efficacy, energy, etc.) are depleted throughout the workday in response to work demands. It is essential that employees engage in recovery experiences during nonwork time so that resources exhausted throughout the workday can be regenerated. Recovery is necessary for one's health and well-being, as prolonged exposure to stressors without sufficient recovery can lead to health deterioration (McEwen, 1998). Recovery from work demands can be described in the context of different theoretical frameworks. Several of these frameworks are described below.

Effort-recovery model. The effort-recovery model (Meijman \& Mulder, 1998) outlines the process of responding to cognitive demands. The model identifies three determinants: work demands, work potential, and decision latitude. These three factors together determine two specific outcomes: the work product, and short-term 
physiological and physical reactions. The work product refers to the goods or services that are a direct outcome of the work, while short-term reactions are seen as adaptive responses at the physiological, behavioral, and subjective level, and are manifested as lowered employee health. When exposure to work stressors ceases, the engaged psychobiological systems stabilize at pre-stressor levels, a process described as recovery. When these same systems are called upon outside of work, the opportunity for recovery is significantly decreased. In these instances, individuals are required to engage in compensatory mechanisms, further drawing upon reserves of resources. Extended exposure to work demands without significant time for recovery is therefore assumed to impair individual well-being.

Conservation of resources theory. Hobfoll's (1989) conservation of resources (COR) theory posits that individuals strive to maintain, build, and protect their resources. Resources are defined as objects, personal characteristics, conditions, or energies that an individual values or that serve as a means for obtaining further objects, energies, conditions, or personal characteristics (Hobfoll, 1989). Psychological stress occurs in response to three potential situations: (a) a threat to an individual's resources, (b) actual loss of resources, or (c) failure to gain resources after investment of resources.

The COR model identifies four types of resources. Object resources are valuable due to their actual nature, or their potential to be used as a status symbol (e.g., luxury items). Personal characteristics can also be seen as resources, in that they aid in the stress resistance process (e.g., self-efficacy, positive sense of self; Hobfoll, 1989; Hobfoll \& Lilly, 1993). Building personal characteristic resources may also allow for the 
development of more resources in other categories. Conditions are subjective resources, in the sense that they are sought after and valued (e.g., marriage and job seniority). Lastly, energies (e.g., time, money, and knowledge) are seen as resources in that they aid in the quest for additional resources.

Resources may be viewed as more or less valuable depending on various individual, group, and societal factors. Furthermore, various environmental factors may threaten these resources. The actual or possible loss of resources is seen as a threat because, at the most basic level, resources are instrumental to individuals, and because individuals often find self-worth in the resources they have at their disposal. Hobfoll (1989) argues that loss is central to many of the theories of psychological stress, and points to numerous studies that have examined significant life events, specifically loss events, that cause stress (Dohrenwend, 1978; Holmes \& Rahe, 1967; Sarason, Johnson, \& Siegel, 1978). Additionally, more ambiguous life events can be seen as stressful in the extent to which they are perceived as "undesirable." Furthermore, research indicates that the loss of resources is much more salient and detrimental to individuals than resource gains (Hobfoll \& Lilly, 1993).

The COR model predicts that those confronted with stress will seek to minimize resource loss (Hobfoll, 1989), and those who are not presented with stress will seek to build and develop new resources, so as to offset the possibility of future resource loss. When people develop new resources, they may experience positive well-being (Cohen \& Wills, 1985). Those that are unable to build new resources, however, are particularly 
vulnerable and may be more likely to develop self-protective styles in the hopes of preventing future resource loss (Arkin, 1981; Cheek \& Buss, 1981).

In the context of COR theory, engaging in recovery experiences outside of work allows individuals to restore resources that were lost while at work. It is also possible that some recovery experiences may allow one to build new resources, which is a key feature of COR theory. For example, taking time to relax after work may allow individuals to restore emotional energy that was depleted during a particularly trying day at work. The same may be said for cognitive resources that were called upon during the workday. While employees may feel exhausted at the end of the workday, which would signal a decreased level of resources, taking time to relax, detach from work, or engage in social activities with friends and family may leave one feeling rejuvenated by the end of the evening. Additionally, particular recovery strategies entail engaging in learning experiences (e.g., mastery experiences), which offer the opportunity for building new resources. For example, learning a new language or rock climbing during nonwork time may facilitate the development of a new skill or the increase of such personal resources as self-efficacy and a positive sense of self.

Ego depletion model. Past research on recovery from work has also included the concept of ego depletion. The theory of ego depletion assumes that the self's various acts of volition draw on a similar limited resource, such that acts of volition will have a negative impact on subsequent acts of volition (Baumeister, Bratslavsky, Muraven, \& Tice, 1998). Baumeister and colleagues (1998) found support for this explanation over the course of four unique experiences. In each of these cases, individuals who were 
required to exert self-control and conscious acts of volition were more likely to give up or persist for a shorter period of time on subsequent tasks than those who were not required to exert self-control. Additional support for the ego depletion model has been demonstrated for cases in which participants are asked to regulate and suppress emotional responses. Those who were asked to regulate and control their emotions were again linked to subsequent decreases in physical stamina (measured by the length of time participants could continuously squeeze a handgrip) and the ability to regulate further emotional responses (Muraven, Tice, \& Baumeister, 1998).

Ego depletion is relevant to the process of recovery from work, such that reacting to work stressors may require conscious acts of volition (e.g., engagement in a work task). The acts of volition in response to these stressors reduce one's self-regulatory resources, which in turn may impair subsequent acts of volition (e.g., decreased effort in the second task). The lack in self-control may also impair individual well-being (e.g., increased levels of fatigue, burnout, etc.). By engaging in recovery experiences, employees are able to rebuild the resources that were lost by engaging in multiple acts of volition during the workday. For example, by relaxing or mentally distancing oneself from work, an individual is able to regain self-regulatory resources necessary for work.

Mood regulation. Recovery from work also provides opportunities to restore positive affect that may have been diminished during the workday as a result of various work stressors. One's ability to self-regulate mood is crucial to maintaining social relationships, particularly under stressful situations. For example, Larsen (2000) 
describes mood regulation as a series of control processes in which individuals act directly to control their mood.

Some research has suggested that mood repair may be one of the core functions of recovery (Fuller, Stanton, Fisher, Spitzmuller, Russell, \& Smith, 2003). Individuals may undertake various strategies in the process of mood regulation, including both cognitive and behavioral approaches (Parkinson, Totterdell, Briner, \& Reynolds, 1996; Thayer, Newman, \& McClain, 1994). Parkinson and Totterdell's (1999) research on mood regulation strategies provides insight into the ways in which individuals actively seek to control their moods. Two particular types of strategies were suggested by Parkinson and Totterdell (1999): diversionary and engagement strategies. Diversionary strategies involve avoiding negative and stressful situations and seeking distractions from such situations (e.g., relaxation-oriented, pleasure-oriented, or mastery-oriented experiences). Engagement strategies involve actively confronting or accepting stressful situations. Both of these forms of engagement strategies involve an affect-directed and situation-directed component. Diversionary strategies appear to be most related to recovery experiences, as they allow an individual to disengage from stressful experiences and regain lost resources. In contrast, engagement experiences may keep individuals cognitively occupied with stressors, which would lead to continued resource losses (Sonnentag \& Fritz, 2007). This framework is directly relevant to research on recovery from work, as an active component of recovery is the process of regulating one's mood and responses to daily stressors, which will become apparent in employee well-being. 
Recent research has demonstrated an association between recovery experiences and emotional states. For example, Fritz, Sonnentag, Spector, and McInroe (2010a) found that recovery experiences (e.g., psychological detachment, relaxation, mastery, and control) during the weekend were related to affective states during the following work week. Specifically, relaxation was associated with increased positive affect and decreased negative affect during the following work week. Mastery was associated with higher levels of positive affect at the end of the weekend, and psychological detachment was associated with positive affective states both at the end of the weekend and at the end of the following work week. Additionally, a recent diary study by Sonnentag, Binnewies, and Mozja (2008) found an association between a lack of psychological detachment in the evening and negative activation and fatigue the following morning. On the other hand, evening relaxation was associated with morning serenity, and mastery experiences in the evening were related to positive activation in the morning.

Mechanisms linking work and nonwork domains. While it is necessary to discuss in detail the several theoretical frameworks used to support the notion of recovery during nonwork time, it is also important to acknowledge work being done in the area of work-family research that offers alternative explanations for the impacts of work on home life. Edwards and Rothbard (2000) discuss several mechanisms that link the work and family domains. They define a linking mechanism as "a relationship between a work construct and a family construct. Linking mechanisms can exist only when work and family are conceptually distinct" (p. 180). The six general categories of linking mechanisms include: spillover, compensation, segmentation, resource drain, congruence, 
and work-family conflict. These linking mechanisms are relevant to the research being done on recovery from work, as several of these mechanisms may be useful for explaining the necessity of recovery during nonwork time.

Spillover refers to effects of work and family on one another that generate similarities between the two domains (Edwards \& Rothbard, 2000), and consists of two versions: one in which spillover is characterized as a similarity between a work domain construct and a distinct but related family domain construct, and another version in which spillover consists of experiences between domains. This spillover between domains can be either positive or negative. Recovery from work may be increasingly necessary in situations of negative spillover to prevent negative experiences in one domain from affecting the other domain as well. For example, recovery after work may prevent increased levels of fatigue due to work from negatively impacting one's involvement in family domain activities. In their recent chapter on the quality of work life, Hammer and Zimmerman (2010) provide an overview of positive spillover and health outcomes. Work-family positive spillover has been linked with lower risks of mental illness, depression, and problem drinking. Furthermore, Hammer and Zimmerman point out recovery from work as a new direction in the work-family field. While spillover is particularly relevant to the concept of recovery from work, there are several other linking mechanisms that may be important as well.

Compensation, another linking mechanism, consists of efforts to offset dissatisfaction in one domain by seeking satisfaction in another domain, and comes in two forms: the reallocation of importance, and supplemental compensation. Recovery 
from work may be particularly relevant to this second type of compensation, in which individuals seek to engage in recovery experiences as a way of offsetting less than satisfactory work experiences. Segmentation refers to "an active process whereby people maintain a boundary between work and family" (Edwards \& Rothbard, 2000, p. 181). This linking mechanism may be most relevant to the process of mentally and physically distancing oneself from work during nonwork time in an attempt to disengage from work demands. Resource drain is another linking mechanism that refers to the transfer of personal resources (e.g., time, attention, energy) from one domain to another. Recovery from work may decrease employees' experience of resource drain, as engaging in recovery experiences allows for the rebuilding of resources necessary for both work and family domains. Congruence, another linking mechanism, refers to the "similarity between work and family, owing to a third variable that acts as a common cause" (p. 182). For example, overarching life values or general aptitudes and intelligence may affect both the work and family domains. Lastly, work-family conflict refers to a form of interrole conflict in which the demands of work and family are incompatible, in which meeting the demands of one domain makes it difficult to meet demands in the other domain. Work-family conflict has been separated into three forms: time-based, strainbased, and behavior-based (Greenhaus \& Beutell, 1985). In this context, recovery from work may be most relevant to forms of strain-based work-family conflict. Strain-based work-family conflict refers to a process by which strain (e.g., dissatisfaction, anxiety, fatigue) from one domain makes it difficult to meet demands of the other domain. By engaging in recovery experiences during nonwork time, employees may be able to lessen 
the detrimental outcomes associated with work demands, thereby allowing for increased resources to be allocated to the family domain.

\section{Specific Recovery Experiences}

Various experiences outside of the work domain have been suggested to contribute to recovery from work. Building on past research on recovery from work I will focus on several specific recovery experiences that will be described in more detail below.

Psychological detachment. Psychological detachment can be described as physically and mentally separating oneself from the working environment. Detachment can result from the simple physical act of leaving work and going home, or refraining from thinking about work-related problems or issues while at home (Sonnentag \& Fritz, 2007). In the context of the effort-recovery model, psychological detachment may help individuals restore resources lost while at work. After work, it is important that the same systems that were activated by work stressors are no longer called upon, so that an individual's psychobiological systems are able to return to prestressor levels. By psychologically detaching from work, an individual is no longer exposed to the demands of various work stressors, and is able to recover the resources that were lost in response to the work demands of that day. Additionally, in accordance with the theory of mood regulation, psychologically detaching from work can allow individuals to remove themselves from work situations associated with negative emotions.

Several empirical studies have suggested that psychological detachment from work during nonwork time is an important factor in recovery from work demands. 
Psychological detachment from work has been linked to positive mood and low fatigue in the evening before bedtime and the next morning (Sonnentag \& Bayer, 2005; Sonnentag et al., 2008). Psychological detachment has also been linked to lower levels of health complaints, emotional exhaustion, depressive symptoms, need for recovery, and sleep problems and higher levels of life satisfaction (Sonnentag \& Fritz, 2007). A recent study also found that higher levels of self-reported psychological detachment were associated with higher levels of significant-other reported life satisfaction and lower levels of emotional exhaustion (Fritz, Yankelevich, Zarubin, \& Barger, 2010b). Additionally, low levels of psychological detachment were associated with high levels of emotional exhaustion and need for recovery, and also partially mediate the relationship between job stressors and strain reactions (Sonnentag, Kuttler, \& Fritz, 2010). Psychological detachment during the weekend has also been associated with certain aspects of positive affect during the following workweek (e.g., joviality and serenity; Fritz et al., 2010a).

Relaxation. Relaxation is associated with low activation and positive affect (Stone, Kennedy-Moore, \& Neale, 1995), and can result from various leisure activities, including meditation, a light walk, or casual social activities. According to COR theory, individuals strive to maintain, build, and protect their resources (Hobfoll, 1989). Relaxation as a recovery experience is helpful for those individuals who are in need of maintaining and protecting their resources, particularly after having lost resources at work. In this case, relaxation may expedite the process by which systems that were activated by work stressors return to prestressor levels. Relaxation may also foster mood regulation, as engaging in relaxation after work may help reduce high activation negative 
affect (e.g., anger) that may have resulted as a response to various work stressors. Through relaxation experiences such as taking a walk or reading a book, an individual may be able to both reduce negative mood as well as restore positive mood.

Relaxation during nonwork time has been linked to lower levels of health problems, emotional exhaustion, need for recovery, and sleep problems and higher levels of life satisfaction (Sonnentag \& Fritz, 2007). In addition, Sonnentag and colleagues (2008) showed that higher levels of relaxation in the evening were related to serenity the following morning. Keeping in line with mood regulation theory, relaxation during the weekend has also been associated with higher levels of joviality, self-assurance, and serenity and lower levels of fear, hostility, and sadness at the end of the weekend as well as at the end of the following work week (Fritz et al., 2010a).

Mastery. Engaging in mastery experiences is another form of recovery during which an individual seeks to build new internal resources. This may be accomplished by seeking out new and challenging activities and learning experiences (Sonnentag \& Fritz, 2007). Mastery experiences are assumed to challenge the individual without overtaxing his or her capabilities (Siltaloppi, Kinnunen, \& Feldt, 2009). While these mastery experiences may put additional demands on the individual, they also enhance recovery by allowing for the development of new resources such as skills, competencies, and selfefficacy (Bandura, 1997; Hobfoll, 1998). Mastery experiences would allow individuals to build new resources of their own choosing. These additional resources are helpful in confronting subsequent stressors, and in many cases, may increase an individual's feelings of self-worth and self-efficacy. Engaging in mastery experiences during nonwork 
time may also allow individuals to regulate their mood, particularly in response to negative affective states that may have been elicited by interpersonal conflicts at work. Mood regulation theory posits that individuals are able to actively engage in strategies in the process of mood regulation, and mastery experiences typify an engagement strategy in which individuals select activities that will increase positive affect and feelings of selfefficacy.

Mastery experiences during vacation have been found to be negatively related to exhaustion after vacation (Fritz \& Sonnentag, 2006). Mastery has also been shown to be negatively related to emotional exhaustion, depressive symptoms, and need for recovery, and positively related to life satisfaction (Sonnentag \& Fritz, 2007). Furthermore, mastery experiences during the weekend have been associated with higher levels of positive affect (e.g., joviality, self-assurance, and serenity) at the end of the weekend (Fritz et al., 2010a).

Nonwork control. Nonwork control refers to an individual's ability to decide what leisure experiences he or she will partake in during recovery from work (Sonnentag \& Fritz, 2007). Control over one's recovery experiences may be particularly important for mood regulation. As Parkinson and Totterdell (1999) describe, there are various strategies individuals engage in to change their own moods in response to particular situational experiences. As diversionary strategies have been suggested as being most related to recovery experiences (Sonnentag \& Fritz, 2007), it is possible that engaging in control over one's recovery experiences will allow an individual to select activities that elicit recovery experiences that will be most helpful in improving one's mood. In 
addition, while diversionary strategies should be most related to recovering from work experiences, it is also possible that control is utilized to engage in other recovery experiences that are more related to engagement strategies as a means of coping with the negative outcomes of workplace stressors. As individuals strive to maintain and protect resources, engaging in control over one's experiences may allow an individual to target specific resources for rebuilding, which will prevent future resource loss.

Control over one's experiences allows for a positive reevaluation of potentially stressful situations and has been found to be positively related to individual well-being (Lazarus, 1966; Bandura, 1997). Conversely, low levels of control have been linked to psychological distress and anxiety (Rosenfield, 1989). In situations of low control, one's ability to react to and influence the surrounding environment is diminished, which may in turn lead to negative self-evaluations and lowered self-worth. For example, research by Griffin, Fuhrer, Stansfeld, and Marmot (2002) indicates that women who had low levels of control at home experienced higher levels of depression five years later than women high in control. Similarly, men low in control at home showed higher depression and anxiety levels than men with high levels of control (Griffin et al., 2002).

Control during leisure time may satisfy an individual's need for control, and in turn increase feelings of self-efficacy and competence (Sonnentag \& Fritz, 2007). It is also possible that control over leisure experiences allows individuals to select recovery experiences that will be most helpful for the restoration of resources. Sonnentag and Fritz (2007) demonstrated links between control and lower levels of health complaints, 
emotional exhaustion, depressive symptoms, need for recovery, and sleep problems, and higher levels of life satisfaction.

Social activity during nonwork time. Engaging in social activities includes meeting new people and spending time with friends and family. Social activities offer an opportunity to seek and receive social support from others (Sonnentag, 2001). Engaging in social activities may allow individuals to halt the process of resource loss that occurs in response to work stressors. Engaging in positive social activity may also allow individuals to regain emotional resources through social support from friends and family. This gain in resources will bolster reactions to future threats of resource loss. It is also likely that various social activities result in the creation of new resources (e.g., selfesteem, extended social network), which also helps individuals to cope with future resource threats and losses. Furthermore, in line with mood regulation theory, engaging in social activities with friends and family allows individuals to regulate their moods in such a way that increases positive affect. Engaging in pleasant activities with social contacts allows an individual to disengage from work and possible negative impacts of interpersonal conflict at work.

Seeking social support is beneficial for individual health (Viswesvaran, Sanchez, \& Fisher, 1999), and can serve as a vehicle to replenish one's depleted physical and emotional resources (Westman, 1999). Research further suggests that engaging in social activities with friends and family may call for less self-regulation than engaging in social interactions with coworkers, supervisors, or customers (Grandey, 2000). Nonwork experiences such as social activity have also been associated with positive individual 
outcomes. Fritz and Sonnentag (2005) found positive relationships between social activities on the weekend and well-being at the beginning of the following work week. Engaging in social activities in the evening after work has also been associated with higher levels of well-being before going to sleep (Sonnentag, 2001).

Work reflection. Reflecting on one's work has been examined as another potential recovery experience. Fritz and Sonnentag (2005) specifically examined positive work reflection, which refers to reflecting on one's job in a positive way during nonwork time. Engaging in positive work reflection may act as a type of reappraisal of stressful work situations (Lazarus \& Folkman, 1984). In positively reappraising work, stress reactions may be reduced, which leads to the restoration of resources. Additionally, positively reflecting on one's work allows an employee to focus on the positive aspects of the job, and the things that one enjoys about their work. Thus, it may allow for the creation of new resources, or the increase of existing resources. For example, thinking about the work goals that one has already accomplished may lead to greater self-efficacy, which in turn may be associated with increased well-being (Westman, 1999; Fritz \& Sonnentag, 2005). Positive work reflection may also be related to the development of new goals concerning an individual's work.

Fritz and Sonnentag (2005) found that positively reflecting on one's work over the weekend significantly and negatively predicted burnout at the beginning of the following work week. The findings on positive work reflection suggest that it is not only limited to the work or nonwork domain, but that it may have important implications for both life domains (Edwards \& Rothbard, 2000; Fritz \& Sonnentag, 2005). 
It may also be the case that individuals reflect negatively on their jobs while away from work. Contrary to positive work reflection, negative work reflection entails thinking about the undesirable aspects of one's job, such as those aspects that are not enjoyable (Fritz \& Sonnentag, 2006). Thinking negatively about one's job may in turn consume resources or prevent necessary regeneration processes, which in turn may lead to decreased well-being and performance (Etzion, Eden, \& Lapidot, 1998; Sonnentag \& Bayer, 2005). Negative work reflection during vacation has been shown to be associated with higher health complaints and exhaustion after vacation (Fritz \& Sonnentag, 2006).

Related to negative work reflection, rumination is a particular response style in which individuals repetitively think about their negative emotions, focus on their symptoms, and worry about the meaning of their negative emotions (Lyubomirsky, Caldwell, \& Nolen-Hoeksema, 1998; Nolen-Hoeksema, 1991). Rumination appears to contribute to feelings of hopelessness for the future and uncertainty. Engaging in negative work reflection would be very similar to employees ruminating about their work experience. In the context of mood regulation, negative and positive work reflection can be seen as examples of engagement strategies. Though engagement strategies are less indicative of recovery experiences, reflecting on work is an example of actively confronting and accepting work stressors. Regarding positive work reflection, an individual may actively accept work stressors as a challenge and use thoughts about work to develop future work goals and strategies. Conversely, negative work reflection results in the continued use of resources needed at work, instead of creating strategies or goals 
for dealing with stressors, or disengaging from them altogether as with diversionary strategies.

\section{Work-Related Well-Being}

As mentioned previously, I will view well-being variables as belonging to one of two domains: work-related well-being and general well-being. Work-related well-being will include job satisfaction and burnout, which will be discussed below.

Job satisfaction. Job satisfaction is one of the most widely studied attitudes in Industrial \& Organizational Psychology (Kinicki, McKee-Ryan, Schriesheim \& Carson, 2002), and is defined as a multidimensional attitudinal response to one's job that has cognitive, affective, and behavioral components (Smith, Kendall \& Hulin, 1969; Hulin \& Judge, 2003). Weiss (2002) defined job satisfaction as "a positive (or negative) evaluative judgment one makes about one's job or job situation" (p. 175).

Both antecedents and outcomes of job satisfaction have been studied extensively. For example, self-esteem, generalized self-efficacy, internal locus of control, emotional stability, and negative affect have been linked to job satisfaction (Judge \& Bono, 2001; Siu, $\mathrm{Lu}, \&$ Cooper, 1999). In the work context, a variety of factors have been linked to job satisfaction, such as specific job characteristics, pay (Brasher \& Chen, 1999), and justice perceptions (Cohen-Charash \& Spector, 2001). Specifically, research has linked each of the five core characteristics of job tasks (Hackman \& Oldham, 1976): skill variety, task identity, task significance, autonomy, and task feedback to job satisfaction.

Job satisfaction also seems to be related to more general indicators of well-being, such as anxiety, depression, burnout, cardiovascular disease, subjective physical illness, 
strain, higher levels of self-esteem and general mental health (Faragher, Cass, \& Cooper, 2005) and sleep problems (Spector, 2006). A meta-analysis focusing on business outcomes of job satisfaction showed relationships between job satisfaction and customer satisfaction-loyalty, profitability, productivity, employee turnover, and safety outcomes (Harder, Schmidt, \& Hayes, 2002). Furthermore, a recent meta-analysis indicated a modest but significant relationship between job satisfaction and job performance $(r=.20$; Judge, Thoreson, Bono, \& Patton, 2001; Harrison, Newman, \& Roth, 2006). Lastly, several studies have demonstrated a link between job satisfaction and another outcome variable of this study, life satisfaction. Generally, individuals who are more satisfied with their jobs tend to be more satisfied with their life as well, and several possible explanations (e.g., spillover, compensation, and segmentation) have been given for this relationship (Spector, 2006).

Burnout. When individuals are exposed to work stressors over a significant period of time without the opportunity to recover, burnout is often a likely outcome. Maslach (1982) originally conceptualized burnout as a syndrome affecting service workers, consisting of emotional exhaustion, depersonalization, and reduced personal accomplishment. Burnout, generally speaking, is a response to chronic work stressors, in which individuals feel depleted and unable to further cope with work demands.

Subsequent research on burnout has identified two relevant dimensions of burnout, namely, exhaustion and disengagement (Demerouti, Bakker, Vardakou, \& Kantas, 2003). While Maslach's (1982) initial conceptualization of burnout had important psychometric and theoretical limitations (Kalliath, 2001), Demerouti's and colleagues' 
(2003) revised conceptualization of burnout was not only applicable to a wide range of occupations, but had stronger theoretical and psychometric properties (e.g., Halbesleben \& Demerouti, 2005). According to Demerouti and colleagues (2003), exhaustion is a reaction to prolonged exposure to work stressors, and in this context refers to emotional, physical, and cognitive forms of exhaustion. This definition of exhaustion is similarly applicable to employees who engage in prolonged physical labor or information processing. Disengagement is a physical and emotional response that can manifest itself as distancing oneself from one's work, or having negative feelings towards one's work. The relevant scale measuring disengagement refers to emotions toward the work tasks as well as to a devaluation and mechanical execution of the work (Demerouti et al., 2003). According to the effort-recovery model, burnout is a likely outcome of prolonged activation, specifically when individuals are unable to regain resources that were lost to dealing with work stressors.

For example, burnout has been found to be associated with a variety of work stressors. Specifically, burnout has been linked to low levels of perceived control at work, high levels of role conflict, and work overload (Spector, 2006). It is important to include burnout in the conceptualization of employee well-being, as it is a likely outcome of dealing with chronic work stressors, particularly if individuals are lacking an outlet in which they are able to recover from such stressors. 


\section{General Well-Being}

In addition to the domain of work-related well-being, I will also be addressing more general indicators of well-being, including life satisfaction and general health complaints. Both of these constructs will be discussed in more detail below.

Life satisfaction. Life satisfaction is a global indicator of an individual's perceptions of their quality of life, and is seen as a cognitive-judgmental aspect of individual happiness. Each individual assesses his or her own quality of life with a different and unique set of standards (Diener, Emmons, Larsen, \& Griffin, 1985), meaning that different individuals may place varying levels of importance on different aspects of life (e.g., health and finances).

Life satisfaction can be seen as a result of satisfaction across various domains, one of which would include work. As such, it has been positively (Judge \& Watanabe, 1993) associated with job satisfaction. It is important to note that confirmatory factor analyses did identify the two scales of satisfaction as separate constructs (Judge \& Watanabe, 1993). Additionally, a meta-analysis (Kossek \& Ozeki, 1998) found a negative relationship between work-family conflict and life satisfaction further supporting the notion that life satisfaction is affected by multiple domains. Accordingly, life satisfaction was shown to be lower among dual-career couples suggesting work can have a significant impact on one's level of life satisfaction.

Health complaints. Past research indicates that prolonged exposure to stressors is associated with decreased levels of physical health. Health complaints have been viewed as an overall indicator of poor well-being and refer to physical symptoms of stress or 
minor problems (Watson \& Pennebaker, 1989) such as headaches and sleep disturbances. Chronic work stress has been linked to a number of detrimental health outcomes, such as heart disease, ulcers, headaches, cancer, and diabetes. Additionally, under high levels of work stressors, individuals are more prone to engage in negative health behaviors such as smoking, drug and alcohol use, and violence. Lastly, work stress has also been linked to higher levels of family conflict, sleep disturbances, and depression (see Greenberg \& Baron, 2008 for a review).

According to the effort-recovery model, if an individual is unable to recover after prolonged activation due to work stressors, negative outcomes such as reduced wellbeing and health are often the case. In the case of failing to recover, an individual continually taxes the psychological and physiological systems that are called into action as a result of dealing with such work stressors. When these systems fail to recover to prestressor levels, compensatory mechanisms are often called upon, further draining resource reserves. It is this continual activation and further taxation on one's systems that often leads to negative health outcomes for those dealing with chronic work stress. For example, the depletion of one's resources often becomes apparent in the form of increased psychosomatic complaints (Pennebaker, 1982).

\section{Interpersonal Conflict and Employee Well-Being}

Research has demonstrated that interpersonal conflict is a work stressor that may come in various forms, including overt and covert behaviors by coworkers (Spector \& Jex, 1998). Employees experiencing interpersonal conflict may experience a host of 
negative outcomes as a response including impaired well-being (Stoetzer et al., 2009). Conflict in itself is inherently stressful. Negative emotions, threatened self-esteem, and heightened cognitive effort as a result of interpersonal conflict can impact an individual's physiological resources in a multitude of ways (De Dreu et al., 2004b). The ego depletion model has been offered as a possible explanation for these relationships. Specifically, research indicates that asking individuals to regulate and control their emotions is associated with subsequent decreases in physical ability and the ability to regulate further emotional responses (Baumeister et al., 1998; Muraven et al., 1998). For these reasons, it is important to further examine the negative impacts of interpersonal conflict at work, and to investigate factors that may help alleviate negative outcomes.

An overview of possible negative outcomes of interpersonal conflict at work indicates that dealing with conflict at work is associated with higher levels of stress hormones which deplete the physiological system (McEwen, 1998; De Dreu, Van Dierendonck, \& Best-Waldhober, 2004a). This depletion of one's systems may become manifest as psychosomatic complaints, such as persistent headaches and upset stomachs (Pennebaker, 1982). Additionally, enduring conflict at work may lead to decreased individual well-being through increased rumination, alcohol intake and low-quality sleep (Cooper \& Marshall, 1976; Danna \& Griffin, 1999).

One meta-analysis (Spector \& Jex, 1998) further indicates that interpersonal conflict at work is associated with higher levels of anxiety, depression, frustration and doctor visits. Workplace aggression, a similar construct, has also been linked to employee 
health and well-being (Herschovis \& Barling, 2009). Specifically, workplace aggression, regardless of the source, was related to higher levels of emotional exhaustion and depression and lower levels of physical well-being and general health. According to the results of Hershcovis and Barling's (2009) meta-analysis, supervisor, co-worker, and outsider aggression were all related to general health, emotional exhaustion, depression, and physical well-being. Supervisor aggression was shown to have stronger adverse impact on general health than co-worker aggression. On the other hand, co-worker aggression had a greater adverse impact than supervisor aggression on physical wellbeing. In comparing co-worker aggression and outsider aggression, co-worker aggression had a stronger adverse impact than outsider aggression on physical well-being. Lastly, in comparing supervisor aggression to outsider aggression, supervisor aggression had a stronger adverse impact on general health than outsider aggression.

In addition to the meta-analytic evidence for the detrimental consequences of workplace interpersonal conflict and workplace aggression, a recent longitudinal study also examined problematic interpersonal relationships at work and their effects on employee depression levels (Stoetzer et al., 2009). This study examined a cohort of Swedish employees over two years. In addition to looking at interpersonal conflict, the researchers also examined social support, exclusion by superiors, and exclusion by coworkers. All four of these variables, including conflict at work, were related to higher levels of depression among employees. Previous depression was controlled for, suggesting that interpersonal conflict is associated with subsequent lowered well-being, 
above and beyond lowered well-being being a possible predictor of conflict. In summary, interpersonal conflict at work has been associated with a variety of well-being outcomes, which implies that it is an important workplace stressor that necessitates further study.

It is important to note that while this study conceptualizes interpersonal conflict at work as leading to detrimental health outcomes, it is also possible that lowered levels of well-being lead to workplace interpersonal conflict. In this case, employees would come to work with lowered levels of resources, which would potentially result in a lowered ability to engage in emotion regulation, and subsequently, higher levels of interpersonal conflict. However, this process poses a separate and unique research question that could potentially be addressed with longitudinal research designs. In the context of COR theory (Hobfoll, 1989), it is possible that interpersonal conflict in the workplace is associated with lowered well-being, and for those with lowered levels of resources, may set off a 'loss spiral,' which would in turn be associated with subsequent higher levels of interpersonal conflict. For the purposes of the current study, interpersonal conflict will be conceptualized as an antecedent to lowered well-being.

\section{Recovery Experiences As Potential Moderators}

As the previous section suggests, there have been numerous studies linking interpersonal conflict at work to potential individual outcomes, including employee wellbeing. Additionally, interpersonal conflict is only one of many work stressors, many of which (including role conflict, role ambiguity, lack of control, and perceived workload) have been examined in detail with respect to employee well-being outcomes (e. g., 
Jackson \& Schuler, 1985; Spector, 1986; Spector, Dwyer, \& Jex, 1988; Jex \& Beehr, 1991; Spector \& Jex, 1998). Recent research has also examined the benefits of various recovery experiences outside of work on employee well-being and performance (Fritz \& Sonnentag, 2005; 2006; Sonnentag \& Bayer, 2005; Sonnentag \& Fritz, 2007). Only recently, however, have particular recovery experiences been examined as possible boundary conditions in the relationship between work stressors and well-being outcomes (Siltaloppi et al., 2009; Kinnunen et al., 2010; Sonnentag et al., 2010).

A recent study examined the direct and moderator roles of psychological detachment, relaxation, mastery, and control in the relationship between time demands, job control, and justice of the supervisor and work-related well-being (Siltaloppi et al., 2009). In this study, work-related well-being was measured as need for recovery, job exhaustion, and work engagement. Psychological detachment and mastery were found to moderate the relationship between job control and need for recovery; additionally, relaxation was shown to moderate the relationship between time demands and job exhaustion. More specifically, higher levels of detachment and mastery were associated with lower need for recovery, both generally and particularly in a low control situation, compared to those low in detachment. Secondly, job exhaustion was higher in situations of high time demands and low relaxation. Employees high in relaxation expressed a weaker negative association between time demands and job exhaustion.

Furthermore, a recent study examining recovery experiences as moderators of the relationship between job insecurity and well-being outcomes indicated differential effects 
of recovery experiences as buffers against the negative outcomes of work stressors (Kinnunen et al., 2010). Specifically, across a sample of 527 employees from various occupations, relaxation moderated the relationship between an insecure job situation and need for recovery, such that individuals with low relaxation experienced higher need for recovery in conditions of high job insecurity. Control was also found to moderate the relationship between job insecurity and need for recovery. Individuals with high levels of control experienced significantly lower need for recovery under conditions of low job insecurity, though under conditions of high job insecurity, individuals with both high and low control experienced similar levels of need for recovery. Lastly, psychological detachment was found to moderate the relationship between job insecurity and vigor at work, such that individuals with high psychological detachment experienced similar levels of vigor at work under both low and high conditions of job insecurity, while those with low psychological detachment experienced lower vigor at work under conditions of high job insecurity. Job insecurity is just one of many daily stressors faced by employees, and it is possible that recovery experiences will play differing roles as moderators depending on the form of work stressor.

A recent longitudinal study by Sonnentag and colleagues (Sonnentag et al., 2010) examined the role of psychological detachment during nonwork time as a moderator of the relationship between job demands and psychological well-being and work engagement. Among a sample of 309 human service employees, psychological detachment was shown to moderate the relationship between job demands and 
psychological well-being and work engagement, such that those with high levels of job demands and low levels of psychological detachment experienced higher levels of psychosomatic complaints and decreased levels of work engagement. In the present study, various recovery experiences may buffer against negative outcomes of interpersonal conflict at work. Thus, the current study seeks to extend recent research examining recovery experiences as moderators, particularly by exploring interpersonal conflict as the workplace stressor in question.

According to the effort-recovery model, extended effort at work requires a period of recovery afterwards in order for an individual's psychobiological systems to return to the prestressor level. In the context of this study, interpersonal conflict at work acts as a work stressor that will engage psychological and physiological processes. Over time, this activation will be associated with impairments in well-being and health. Therefore, recovery is necessary for alleviating the negative outcomes associated with work stressors. In addition, specific recovery experiences outside of work may buffer against the negative impacts of interpersonal conflict. Thus, though there may be detrimental outcomes associated with interpersonal conflict at work, engaging in various recovery experiences may help protect an individual's systems that are called into action as a response to this work stressor. The different recovery experiences (i.e., psychological detachment, relaxation, mastery, control, social activities, and positive work reflection) may affect the relationship between interpersonal conflict and employee outcomes to varying degrees, though all except for negative work reflection are expected to reduce the 
negative relationship. Negative work reflection, however, may exacerbate the negative association between interpersonal conflict and well-being, because individuals are expending more time and energy ruminating on negative work experiences. Specifically, those recovery experiences that are primarily related to positive psychological or social processes should be most effective in alleviating negative impacts of interpersonal conflict. Thus, for employees with higher levels of positive recovery experiences, the negative relationship between interpersonal conflict and well-being will be weaker than for employees with low levels of recovery experiences. A visual depiction of the following hypotheses can be found in Figure 1.

Psychological detachment as a moderator. Employees that are subject to high levels of interpersonal conflict at work may ruminate about the experience even after leaving the workplace, particularly if the interpersonal conflict is especially salient or increasingly negative. They may continue to think about what they should have said in response to a rude comment, or contemplate ways to retaliate against the perpetrator. For these reasons, it may be especially important that victims of interpersonal conflict at work seek to psychologically detach from work. Detaching from work in general, including from any conflict that may have taken place during the day, will allow employees to more effectively recover, thereby lessening any negative impacts of the conflict. As individuals psychologically detach from work, the psychobiological systems that were activated as a result of interpersonal conflict are no longer engaged. Psychological detachment-by definition-limits rumination about a particular work conflict, and may allow employees 
to focus on regaining emotional resources that were lost as a result of the conflict. This assumption is in line with the effort-recovery model (Meijman \& Mulder, 1998), which states that recovery is necessary after extended effort at work. If recovery does not take place, an individual may need to engage in various compensatory strategies that draw on additional resource reserves.

On the other hand, those individuals who are unable to detach from work while at home may have a more difficult time recovering, and will therefore experience higher levels of negative outcomes associated with interpersonal conflict at work. By failing to disengage from work stressors, particularly interpersonal conflict, an individual will continue to use emotional and physical resources that were already called upon during the time of the conflict. This resource loss will become apparent in impaired well-being and health. Thus, I hypothesize that psychological detachment from work during nonwork time will help reduce negative associations between interpersonal conflict at work and employee well-being.

Hypothesis 1: Psychological detachment will moderate the negative relationship between interpersonal conflict and employee well-being. Specifically, for employees high in detachment, interpersonal conflict will be less strongly related to well-being than for employees low in detachment.

Relaxation as a moderator. Interpersonal conflict at work often elicits anger and frustration in employees (Keenan \& Newton, 1985). Therefore, seeking out relaxing activities after work should allow employees to manage the strong emotions they felt 
while at work. Relaxation during nonwork time helps employees regulate their mood. In accordance with mood regulation theory, relaxation serves as a diversionary strategy to reduce negative affect that may have been elicited throughout the workday as a result of interpersonal conflict. By engaging in relaxation experiences, negative affect (e.g., anger, anxiety) is decreased and a lower activation positive affect (e.g., serenity) is elicited. Drawing on the effort-recovery model, taking time to relax allows for the recovery of resources that were lost while at work. Specifically, emotional and cognitive resources that were lost while dealing with conflict are restored during relaxation.

Keeping with propositions of mood regulation theory and the effort-recovery model, individuals who take time to relax after work will be more successful at restoring lost resources, which will help reduce the negative relationship between interpersonal conflict at work and well-being. In contrast, failing to relax after work hinders the psychobiological systems that were called into action during work from recovering, which is associated with continued resource loss. As individuals fail to recover, they are less able to deal with subsequent interpersonal conflict at work. Therefore, those low in relaxation during nonwork time should experience lowered levels of well-being as a result of interpersonal conflict at work compared to those high in relaxation.

Hypothesis 2: Relaxation will moderate the negative relationship between interpersonal conflict and employee well-being. Specifically, for employees with high levels of relaxation, interpersonal conflict will be less strongly related to well-being than for employees with low levels of relaxation. 
Mastery experience as a moderator. According to the COR theory, emotional and psychological responses to interpersonal conflict may deplete an individual's resources, becoming apparent in lower levels of well-being. Resource loss is particularly salient to individuals. In keeping with COR theory, individuals attempt to gain resources as a way to increase self-esteem and prevent future resource loss. Most, if not all, individuals seek to avoid losing resources. To counteract this, engaging in activities that build new resources or replenish existing ones may be helpful. In this respect, engaging in mastery experiences may allow for the development of new resources, which in turn can help counteract the loss of resources due to interpersonal conflict at work. By engaging in mastery experiences, individuals may learn new skills, such as sewing or rock-climbing. These new resources should help buffer against the negative outcomes of future threats to resources or actual resource losses. Accordingly, I hypothesize that individuals who engage in a higher level of mastery experiences outside of work should experience fewer negative associations between interpersonal conflict at work and wellbeing. In contrast, those low in mastery experiences will have fewer resources to utilize when dealing with interpersonal conflict at work, and will therefore experience increased negative associations between interpersonal conflict at work and well-being.

Hypothesis 3: Mastery experiences will moderate the negative relationship between interpersonal conflict and employee well-being. Specifically, for employees high in mastery, interpersonal conflict will be less strongly related to well-being than for employees low in mastery. 
Nonwork control as a moderator. In keeping with COR theory, control over nonwork experiences allows an individual to independently select experiences that will allow for the most gains in resources. In gaining resources, individuals will be more able to handle future threats to their resources and actual resource losses. As a result, control experiences should allow employees to offset possible negative outcomes associated with interpersonal conflict.

Additionally, interpersonal conflict, in the sense that it is occasionally unwarranted and thrust upon the victim, may leave the employee with feelings of frustration concerning the lack of control they have in dealing with that particular interaction. Therefore, control experiences outside of the workplace may offset the lack of control one feels within the context of interpersonal conflict. According to Fox and Spector's (1999) model of frustration-aggression, workplace aggression is often the result of thwarted workplace goals, which causes frustration within employees. If this frustration does not have an outlet, it may result in further instances of interpersonal conflict, either in the form of retaliation from the victim, or conflict perpetrated by the victim towards another target. Utilizing control experiences outside of work may allow victims of interpersonal conflict to deal with feelings of frustration associated with workplace interpersonal conflict.

Thus, those individuals who are able to engage in a high level of control over their recovery experiences should experience weaker negative associations between interpersonal conflict and well-being because exercising control allows them to regain 
many of their resources. Conversely, those individuals who are unable to exert control over their recovery experiences will be less likely to regain their resources, and therefore will experience stronger negative associations between interpersonal conflict and wellbeing.

Hypothesis 4: Control will moderate the negative relationship between interpersonal conflict and employee well-being. Specifically, for employees high in control, interpersonal conflict will be less strongly related to well-being than for employees low in control.

Social activities as a moderator. Social activities can be used as a way to recover from work stressors. Additionally, engaging in social activities of one's choosing may allow for access to social support (Viswesvaran et al., 1999). Seeking out social support from one's family and friends may allow for the regeneration of emotional resources that were called upon and lost while dealing with interpersonal conflict at work (Sonnentag, 2001).

According to COR theory, an individual will seek to protect and maintain their resources, as well as build new resources. By engaging in social activities, individuals are able to regain emotional and cognitive resources, which will halt the process of resource loss, and bolster an individual against future resource losses. It is also possible that certain social activities may result in the building of new resources. For example, when individuals join a social group they expand their social network and in such cases build new resources, which are known to be beneficial for feelings of self-worth (Hobfoll \& 
Lilly, 1993). Engaging in social activities may also serve as a diversionary strategy (in line with mood regulation theory) that serves to distract an individual from interpersonal conflict at work.

Thus, in the context of COR theory and mood regulation theory, individuals who are able to engage in higher levels of positive social activities will be able to halt the process of resource loss associated with interpersonal conflict, and will therefore experience weaker relationships between interpersonal conflict and well-being. In contrast, those that are less able to engage in social activities outside of work may have more difficulty halting the process of resource loss and therefore experience stronger negative associations between interpersonal conflict and well-being.

Hypothesis 5: Social activities will moderate the negative relationship between interpersonal conflict and employee well-being. Specifically, for employees high in social activities, interpersonal conflict will be less strongly related to wellbeing than for employees low in social activities.

Work reflection as a moderator. Work reflection during nonwork time can be either a positive or negative experience for an employee dealing with interpersonal conflict at work. Positive work reflection allows an individual to focus on the aspects of their job that he or she enjoys, which presumably would not include whatever instances of interpersonal conflict that may have been encountered at work. Positively reflecting on work may encourage individuals to set goals for themselves and focus on advancing at work, while keeping negative aspects of the job in perspective. Therefore, positive work 
reflection should weaken the negative relationship between interpersonal conflict and employee well-being.

As positive work reflection may result in the creation of positive work-related goals, it is possible that such an activity may be used as a way to gain new work-related resources such as self-efficacy. This would be in line with COR theory, as individuals in this case seek to gain new resources. It is also likely that positive work reflection may be used as an engagement strategy of mood regulation in which an individual actively confronts workplace issues, and in this case utilizes potential stressors to build new resources and work-related goals. As such, those individuals who are able to focus on the positive aspects of work will be less likely to experience negative associations between interpersonal conflict and well-being.

Hypothesis 6: Positive work reflection will moderate the negative relationship between interpersonal conflict and employee well-being. Specifically, for employees high in positive work reflection, interpersonal conflict will be less strongly related to well-being than for employees low in positive work reflection.

Negative work reflection, on the other hand, involves focusing on negative aspects of the workplace that an individual is frustrated with, upset by, or would like to change. With regard to interpersonal conflict, this would involve ruminating on the experienced conflict and the emotions resulting from it. This rumination may not involve any proactive strategies to confront and deal with interpersonal conflict at work, but instead may be focused on the negative feelings the conflict elicits in the employee. As a 
result, negative work reflection may actually call upon additional cognitive and emotional resources, which would further exacerbate the negative association between interpersonal conflict and well-being.

In the context of mood regulation theory, individuals who engage in negative work reflection may in fact be utilizing an engagement strategy to change their mood. However, unlike positive work reflection, negative work reflection is less likely to result in increased positive affect and the creation of work goals. Instead, those who engage in negative work reflection may continue to lose resources that were called upon while confronting interpersonal conflict at work. By failing to halt this process of resource loss, individuals who engage in negative work reflection are more likely to experience a stronger negative relationship between interpersonal conflict at work and well-being. Thus, I hypothesize that negative work reflection will moderate the relationship between interpersonal conflict and employee well-being.

Hypothesis 7: Negative work reflection will moderate the negative relationship between interpersonal conflict and employee well-being. Specifically, for employees high in negative work reflection, interpersonal conflict will be more strongly related to well-being than for employees low in negative work reflection. 


\section{Method}

\section{Procedure}

This study utilized archival data collected as part of a larger study on recovery experiences and employee well-being by Dr. Charlotte Fritz. Participants were recruited from seven U.S. colleges and universities. Once schools agreed to participate in the study, recruitment e-mails were sent to potential participants. Survey packets were sent out to 299 non-academic employees and included an introduction letter, three surveys, and three stamped, preaddressed return envelopes. A raffle flier was also included in the packet, and participants were entered into a raffle for restaurant gift certificates for each survey they returned, for a maximum of three raffle entries per participant.

Of the three surveys that were included in the packet, the participant was asked to

fill out one. The target employee reported information on their experience of interpersonal conflict during work as well as on their own recovery experiences during non-work time over the previous few weeks. The target employee was then asked to choose one coworker who knew his or her work well and ask this coworker to fill out a second survey pertaining to the target employee's work environment (including interpersonal conflict). Lastly, the third survey was to be given to the target employee's significant other or close friend, and pertained to the target employee's well-being.

Thus, for the purposes of the current study, data were analyzed using the target employee's report of interpersonal conflict, the target employee's report of recovery 
experiences, and the significant other's report of well-being. Additional analyses were conducted using coworker-reported interpersonal conflict. These additional analyses consisted of a replication of the current study's hypotheses using coworker-reported interpersonal conflict instead of self-reported interpersonal conflict. This was done to determine if coworkers' report of interpersonal conflict could potentially be useful in predicting negative well-being outcomes. This particular data analysis strategy was used to reduce issues relating to common method bias (Podsakoff, MacKenzie, Lee, \& Podsakoff, 2003).

The target employee's self-report of interpersonal conflict at work was seen as being most appropriate for data analysis since it is often an individual's own perceptions of the severity of conflict that leads to detrimental health outcomes. Individual differences may account for one employee reacting more strongly than another to the same perceived conflict. In addition to the perceptions of the severity of conflict, individuals may differ in their perceptions of whether or not a conflict actually occurred at all. In examining the relationships between interpersonal conflict and employee wellbeing, I am most interested in capturing workplace interpersonal conflict that the target actually perceived as occurring, as these conflicts are most likely to impact their subsequent well-being. The coworker's report of interpersonal conflict levels may potentially be useful as well, provided there is a match between the perceptions of the coworker and that of the target employee. The types of interpersonal conflict being measured in this study are directly observable, so in addition to being able to see overt 
displays of conflict, such as arguments or rude comments, a coworker may also be able to perceive and assess the target employee's reaction to the conflict. It is possible that the coworker may also not perceive that a conflict took place if the coworker does not see a reaction from the target employee. As this latter analysis strategy is exploratory in nature, these assumptions will need to be interpreted in light of the results of this study.

Regarding the measure of recovery experiences, the report of the target employee will be used for analysis. Quality of recovery experiences vary across individuals, are targeted at restoring internal resources, and thus, are very subjective experiences. Due to the internal nature of such processes, it is difficult to assess the quality of these recovery experiences using data from other sources.

Finally, the measures of employee well-being (job satisfaction, burnout, life satisfaction, and general health) will be analyzed using significant other reports. Lowered well-being (or conversely, high levels of well-being) should affect one's relationships, and in turn be noticeable to those especially close to the individual, which in this case would include their significant other-especially given the focus on more "chronic" levels of well-being in the current study. Similar data analysis strategies have been used in recent recovery-related research. For example, Fritz and colleagues (2010b) used significant other reports of emotional exhaustion and life satisfaction in their examination of the role of psychological detachment during nonwork time. Specifically, they found that higher levels of detachment (self-report) were related to lower levels of emotional exhaustion and higher levels of life satisfaction (significant other report). 


\section{Participants}

Of the 299 participants that were recruited, 172 returned surveys (57\% response rate), 65 of which were left out of the analyses due to missing data or missing significant other or coworker reports. The final 107 participants consisted of 91 women (85\%) and 16 men $(15 \%)$. The average age of the participants was 45 years $(S D=10.71)$. Mean job tenure was 10 years $(S D=8.96)$. Of the 107 participants, $45 \%$ held supervisory positions. Some of the jobs included in the sample were administrative assistant, coordinator of programs, director, web developer, and library associate. Regarding educational level, $39 \%$ were college graduates, $30 \%$ held a master's degree, and 5\% had earned a doctoral degree.

\section{Measures}

A subset of the measures gathered as part of the larger study will be used for the current study. A copy of those measures can be found in Appendix A. All of the measures ask participants to refer to the past few weeks as a time frame for their responses. All Cronbach's alphas (see Table 1) refer to the scales as used in the current study.

Interpersonal conflict. The Interpersonal Conflict at Work Scale (ICAWS; Spector \& Jex, 1998) was administered to target employees and coworkers to assess target employees' level of interpersonal conflict at work. The scale consisted of four items on a 5-point Likert scale, ranging from 1 (rarely) to 5 (very often). A sample item from the scale was "How often did he/she get into arguments with others at work?" The 
coworker report of this scale will be used for data analysis. Cronbach's alpha for this scale was .78.

Recovery experiences. Measures of recovery experiences were administered to target employees. Psychological detachment, mastery, control, and relaxation were measured with the Recovery Questionnaire (Sonnentag \& Fritz, 2007). Each of these subscales was measured with four items on a 5-point rating system, ranging from 1 (not at all) to 5 (always). Psychological detachment measured a participant's frequency of mentally and physically distancing oneself from work, and included sample items such as "I forgot about my work" $(\alpha=.84)$. Mastery items measured an individual's engagement in challenging activities and learning experiences. This subscale included sample items such as "I learned new things" $(\alpha=.93)$. Control items measured an individual's ability to choose their own recovery experiences, and included items such as "I felt like I could decide for myself what to do" $(\alpha=.79)$. Relaxation assessed an individual's experience of a low activation and positive affect state and was measured with items such as "I kicked back and relaxed" $(\alpha=.82)$.

Positive work reflection, negative work reflection, and social activities were measured using adapted measures from an earlier study by Sonnentag and Fritz (2005). Each of these experiences was measured with three items on a 5-point rating scale, ranging from 1 (not at all) to 5 (always). Positive work reflection measured the amount of time an individual spent thinking about the positive aspects of their work. Items included: "It became clear to me what I like about my work," "I contemplated the positive sides to 
my work," and "I considered the positive aspects of my work" $(\alpha=.83)$. Negative work reflection assessed how often individuals spent time thinking about negative aspects of their work. Items included: "I considered the negative aspects of my work," "I was aware of what is negative about my work," and "It became clear to me what I don't like about my work" $(\alpha=.88)$. Lastly, social activities assessed the amount of time individuals spent engaging in social experiences with other individuals. Items included "I spent time with nice people," "I took care of my relationships," and "I did things together with other people" $(\alpha=.68)$.

Job Satisfaction. Job satisfaction and all other well-being measures are significant-other reports. The short version of the Job Satisfaction Scale (Brayfield \& Rothe, 1951; Judge, Locke, Durham, \& Kluger, 1998) was used to assess job satisfaction. The scale consisted of five items on a 5-point rating scale, ranging from 1 (strongly disagree) to 5 (strongly agree). A sample item from this scale was "Most days he/she was enthusiastic about his/her work" $(\alpha=.76)$.

Burnout. The Oldenburg Burnout Inventory (Demerouti, Bakker, Nachreiner, \& Schaufeli, 2001) was used to assess emotional exhaustion and disengagement as two dimensions of burnout. The scale consisted of sixteen items on a 4-point rating scale ranging from 1 (totally disagree) to 4 (totally agree). The exhaustion subscale consisted of eight items. A sample item from this subscale was "After work, he/she needed more time to relax than in the past to become fit again" $(\alpha=.84)$. The disengagement subscale was also measured with eight items. A sample item from this subscale was "He/She 
tended to think less during his/her work and just executed it mechanically" $(\alpha=.83)$. For each of the subscales, four of the eight items were reverse coded.

Life Satisfaction. To measure life satisfaction, Diener and colleagues' (1985) five item scale was used with a 5-point rating scale ranging from 1 (strongly disagree) to 5 (strongly agree). A sample item from this scale was "In most ways his/her life is close to his/her ideal" $(\alpha=.87)$.

General Health. A short version of the Subjective Health Complaints Inventory (Ursin, Endresen, \& Ursin, 1988) was used to measure the participant's level of general health. The scale consists of 17 items on a 4-point rating scale ranging from 1 (not at all) to 4 (serious). Sample items included "headache/migraine," "anxiety," and "sleep problems/tiredness" $(\alpha=.68)$.

Control Variables. In the current study, age, gender, employee negative affectivity, and job status (supervisory vs. nonsupervisory) will be used as control variables. Each control variable was selected based on a theoretical rationale, however, preliminary analyses were conducted in order to determine if each of the proposed control variables were significantly related to the outcome variables in question.

Employee age was included as a control variable because of its established relationships with several of the outcome variables. For example, older employees tend to report higher levels of satisfaction with their jobs (Siu et al., 1999) and lower levels of 
burnout (Brewer \& Shapard, 2004). Age has also previously been positively correlated to physical well-being (Siu et al., 1999). Age was assessed with one single-item measure.

Employee gender was also considered as a control variable based on past literature. It may be that female employees have additional nonwork stressors (e.g., family responsibilities such as childcare) that lead to resource drain above and beyond that caused by workplace interpersonal conflict. Additionally, at least one meta-analysis has indicated possible gender differences in both life and job satisfaction, with women often reporting higher levels of satisfaction than men (Kossek \& Ozeki, 1998). Employee gender was assessed with one single-item measure, with males being coded as 1 , and females coded as 2 .

Employee negative affectivity (NA) was considered as a control variable as well, as it reflects stable and pervasive mood states. Individuals high in negative affectivity are likely to consistently experience significant levels of distress and dissatisfaction. Watson and Pennebaker (1989) demonstrated that NA is positively correlated with self-reports of subjective health complaints, though uncorrelated with actual objective health outcomes. This study controls for NA in an attempt to assess the negative impacts of interpersonal conflict above and beyond those impacts interpreted by individuals high in trait NA. Negative affectivity was measured with the ten-item negative affect scale taken from the Positive and Negative Affect Schedule (Watson, Clark, \& Tellegen, 1988). Participants were asked to rate the extent to which they generally experienced several mood states on 
a five-point rating scale, ranging from 1 (very slightly or not at all) to 5 (extremely). Sample items include, "afraid," "distressed," and "hostile."

Lastly, job status was considered as a control variable in the current study because one's status as a supervisor has the potential to protect them from becoming a victim of interpersonal conflict at work. Lower level employees may be more likely to come into conflict with coworkers because of the lack of power differential among these employees. However, a supervisor may find themselves the victim of fewer direct workplace conflicts. Job status was assessed with a single-item question, and was coded as $1=$ supervisory and $2=$ nonsupervisory. 


\section{Results}

Hierarchical regression analyses were used to test the proposed hypotheses. This analysis is most appropriate for the current study, as it allows for the assessment of whether or not the relationship between two variables varies according to the level of some third variable (Tabachnik \& Fidell, 2007).

\section{Preliminary Analyses}

Prior to hypothesis testing, preliminary analyses were conducted to ensure that the data conformed to assumptions of multiple regression (Tabachnick \& Fidell, 2007), including that no univariate and multivariate outliers were present. Data were found to meet all assumptions of regression, and so no transformations were necessary. Means, standards deviations, intercorrelations, and reliabilities can be found in Table 2.

Generally, both self-reported and coworker-reported interpersonal conflict were related to decreased life and job satisfaction and increased burnout. Overall, recovery experiences were associated with higher well-being. Psychological detachment, control, negative work reflection, and social activities demonstrated the strongest correlations with wellbeing outcomes.

In addition to checking that the assumptions of hierarchical regression were met, preliminary analyses were conducted to assess whether or not any dependency existed in the data due to job status (supervisory vs. non-supervisory). Independent-samples $t$ tests were conducted to evaluate whether or not differences existed between supervisors and 
non-supervisors on all study variables. No significant differences were detected, and as a result of these analyses, supervisors and non-supervisors were assessed together in further analyses.

Additionally, preliminary analyses were conducted to determine the necessity of each of the proposed control variables (age, gender, employee negative affectivity, and job status). Control variables were retained based on their relationships with study variables and their theoretical importance. An examination of correlations between all study variables demonstrated that age and job status were not significantly related to dependent variables, and gender (male $=1$, female $=2$ ) was only negatively associated with job satisfaction. In terms of predictor variables, gender was associated with social activities, while age was positively associated with positive work reflection and negatively associated with self-reported interpersonal conflict. Employee negative affectivity was associated with every study variable with the exception of relaxation. These control variables were retained in further analyses given their theoretical importance and use in past literature (e.g., Fritz et al., 2010b; Park, Fritz, \& Jex, 2011), as well as to account for the correlations mentioned. Education level was also considered as a potential additional control variable, but was not included in further analyses as it was not significantly associated with any dependent variables, and has not typically been associated with the well-being outcomes included in the current study. 


\section{Hypothesis Testing}

The current study hypothesized that recovery experiences would moderate the relationships between workplace interpersonal conflict and employee well-being. Both the independent variable (interpersonal conflict) and moderating variables (each of the recovery experiences) were grand mean centered so as to avoid issues of multicollinearity (Tabachnick \& Fidell, 2007). Centering the variables also prevents the problem of evaluating one main effect at an extreme value of the other main effect (Howell, 2010). In an attempt to mitigate issues of sufficient power, all interactions were entered into different regression models, rather than analyzing all interactions in the same model.

All seven hypotheses proposed that recovery experiences (psychological detachment, relaxation, nonwork control, mastery experiences, social activities, positive work reflection, and negative work reflection) would moderate the relationship between workplace interpersonal conflict and employee well-being. A total of thirty five regression analyses were conducted to test Hypotheses 1-7. Results of these regression analyses can be found in Tables 3-16. For each analysis, the well-being outcome in question was regressed onto interpersonal conflict and each recovery experience individually. Control variables (i.e., age, gender, employee negative affectivity, and job status) were entered into Step 1 of the regression analysis. The centered workplace interpersonal conflict variable was entered in the second step, followed by the centered recovery experience (e.g., psychological detachment) in Step 3. Finally, the interaction 
term (e.g., psychological detachment x job satisfaction) was entered in the final step of the regression model.

Results are discussed below by hypothesis. All results indicate findings after controlling for age, gender, job status, and employee negative affectivity. Hypotheses 1-7 tested moderator relationships. Significant $(p<.05)$ relationships are graphed.

\section{Hypothesis 1}

Overall, no significant moderator effects were detected for psychological detachment, providing no support for Hypothesis 1. Psychological detachment was shown to be significantly related to exhaustion, $\beta=-.28, t(100)=-2.95, p=.004$ and life satisfaction, $\beta=.28, t(104)=2.92, p=.004$. Psychological detachment explained a significant proportion of variance in both exhaustion, $\Delta R^{2}=.07, F(6,93)=6.52, p<.001$ and life satisfaction, $\Delta R^{2}=.07, F(6,97)=5.65, p<.001$. Results of hierarchical regression analyses are presented in Tables 3 and 4. Results for work-related well-being outcomes (job satisfaction, disengagement, and exhaustion) are found in Table 3, while results for general well-being outcomes (life satisfaction and health complaints) are found in Table 4.

\section{Hypothesis 2}

As seen in Table 5, one significant moderator effect for relaxation was detected. The interaction term between relaxation and interpersonal conflict was significant for exhaustion, $\beta=.23, t(99)=2.28, p=.03$. The interaction between relaxation and 
interpersonal conflict explained a significant amount of variance in exhaustion, $\Delta R^{2}=.04$, $F(7,92)=5.37, p<.001$. This interaction is graphed in Figure 2. Employees with low levels of relaxation had similar levels of exhaustion regardless of the amount of reported workplace interpersonal conflict. Those with high levels of relaxation had significantly lower levels of exhaustion under conditions of low workplace interpersonal conflict than those with low levels of relaxation. Interestingly, at high levels of workplace interpersonal conflict, those with high levels of relaxation experienced slightly more exhaustion than those with low relaxation.

No other significant moderator effects were detected for relaxation, thus, limited support was found for Hypothesis 2. However, relaxation was significantly related to life satisfaction, $\beta=.31, t(104)=3.56, p=.001$. Relaxation also explained a significant proportion of the variance in life satisfaction, $\Delta R^{2}=.09, F(6,97)=6.51, p<.001$. Results are presented in Tables 5 and 6. Results for work-related well-being outcomes are found in Table 5, while results for general well-being outcomes are found in Table 6.

\section{Hypothesis 3}

No significant moderator effects were detected for mastery experiences, providing no support for Hypothesis 3. However, mastery experiences were significantly related to disengagement, $\beta=.24, t(91)=2.46, p=.016$ and health complaints, $\beta=.27, t(96)=$ $2.93, p=.004$. Mastery explained a significant amount of the variance in disengagement, $\Delta R^{2}=.05, F(6,84)=5.68, p<.001$ and health complaints $\Delta R^{2}=.07, F(6,89)=6.38, p<$ .001. Results are presented in Tables 7 and 8. Results for work-related well-being 
outcomes are found in Table 7, while results for general well-being outcomes are found in Table 8.

\section{Hypothesis 4}

No significant moderator effects were detected for nonwork control, providing no support for Hypothesis 4. However, nonwork control was significantly related to exhaustion, $\beta=-.22, t(98)=-2.26, p=.026$, and life satisfaction, $\beta=.44, t(102)=5.04, p$ $<.001$. Nonwork control explained a significant amount of the variance in exhaustion, $\Delta R^{2}=.04, F(6,91)=5.38, p<.001$ and life satisfaction, $\Delta R^{2}=.17, F(6,95)=8.93, p<$ .000. Results are presented in Tables 9 and 10. Results for work-related well-being outcomes are found in Table 9, while results for general well-being outcomes are found in Table 10.

\section{Hypothesis 5}

No significant moderator effects were detected for social activities, providing no support for Hypothesis 5. However, social activities were found to be significantly related to exhaustion, $\beta=-.20, t(100)=-2.03, p=.047$ and life satisfaction, $\beta=.30, t(104)=$ $3.07, p=.003$. Social activities explained a significant proportion of the variance in exhaustion, $\Delta R^{2}=.03, F(6,93)=5.53, p<.001$ and life satisfaction, $\Delta R^{2}=.07, F(6,97)$ $=5.84, p<.001$. Results are presented in Tables 11 and 12. Results for work-related well-being outcomes are found in Table 11, while results for general well-being outcomes are found in Table 12. 


\section{Hypothesis 6}

No significant moderator effects were detected for positive work reflection, providing no support for Hypothesis 6. Positive work reflection was found to be significantly related to job satisfaction, $\beta=.24, t(101)=2.68, p=.009$. Positive work

reflection explained a significant proportion of the variance in job satisfaction, $\Delta R^{2}=.05$, $F(6,94)=7.46, p<.001$. Results are presented in Tables 13 and 14. Results for workrelated well-being outcomes are found in Table 13, while results for general well-being outcomes are found in Table 14.

\section{Hypothesis 7}

No significant moderator effects were detected for negative work reflection, providing no support for Hypothesis 7. Negative work reflection was found to be significantly related to job satisfaction, $\beta=-.38, t(102)=-3.90, p<.001$, exhaustion, $\beta=$ $.34, t(100)=3.30, p=.001$, and health complaints, $\beta=.24, t(98)=2.19, p=.031$. Negative work reflection explained a significant proportion of the variance in job satisfaction, $\Delta R^{2}=.10, F(6,95)=9.53, p<.001$, exhaustion, $\Delta R^{2}=.08, F(6,93)=6.99$, $p<.001$, and health complaints, $\Delta R^{2}=.04, F(6,91)=5.60, p<.001$. Results are presented in Tables 15 and 16. Results for work-related well-being outcomes are found in Table 15, while results for general well-being outcomes are found in Table 16. 


\section{Additional Analyses}

Hypotheses 1-7 were re-analyzed using coworker reports of interpersonal conflict, in an effort to understand whether or not coworkers' reports of interpersonal conflict in the workplace are useful in drawing associations with employee well-being. It is interesting to note that coworker reports of workplace interpersonal conflict were only moderately correlated with self-reports of workplace interpersonal conflict, $r(106)=.38$, $p<.001$.

Using coworker reports of workplace interpersonal conflict provided slightly different results than self-reported interpersonal conflict did in the current study. The only recovery experience that appeared as a significant moderator of the relationship between workplace interpersonal conflict and employee well-being was mastery experiences. Mastery experiences were a significant moderator of the relationship between workplace interpersonal conflict and both dimensions of burnout: exhaustion, $\beta$ $=-.19, t(98)=-2.02, p=.046$, and disengagement, $\beta=-.29, t(91)=-3.32, p=.001$. The interaction term between mastery experiences and interpersonal conflict explained a significant proportion of the variance in both exhaustion, $\Delta R^{2}=.03, F(7,90)=4.62, p<$ .001 , and disengagement, $\Delta R^{2}=.09, F(7,83)=6.69, p<.001$. The results of these hierarchical regressions can be found in Table 22. Interactions are graphed in Figures 3 and 4. For both exhaustion and disengagement, employees with high levels of mastery experiences exhibited a negative relationship with disengagement—as workplace interpersonal conflict increases, these employees show lower levels of disengagement 
and exhaustion. Conversely, those employees with low levels of mastery experiences show higher levels of disengagement and exhaustion as workplace interpersonal conflict increases. Finally, the significant results from Hypothesis 2 (in which relaxation was a significant moderator of the relationship between workplace interpersonal conflict and exhaustion) were not replicated using coworker reports of workplace interpersonal conflict.

In addition to conducting further analyses using coworker reports of interpersonal conflict, all main analyses were conducted without controlling for employee negative affectivity. As employee negative affectivity was significantly associated with every study variable with the exception of relaxation, the additional analyses were conducted to determine if its inclusion as a control variable was suppressing associations between interpersonal conflict, recovery experiences, and employee well-being. Results of these analyses included replications of two out of three of the significant interaction terms utilizing both self and coworker reports of interpersonal conflict. These further analyses did not replicate the findings concerning mastery experiences as a moderator of the relationship between coworker-reported interpersonal conflict and employee exhaustion.

Three additional moderator effects were detected after removing employee negative affectivity from analyses. These include: psychological detachment as a moderator of coworker-reported interpersonal conflict and employee exhaustion, $\beta=-.22$, $t(101)=-2.13, p=.036$ (Figure 5) and disengagement, $\beta=-.25, t(94)=-2.29, p=.024$ 
(Figure 6); and relaxation as a moderator of coworker-reported interpersonal conflict and life satisfaction, $\beta=.23, t(105)=-2.35, p=.021$ (Figure 7). 


\section{Discussion}

The current study provided an examination of the moderating role of recovery experiences in the relationship between workplace interpersonal conflict and employee well-being. Overall, limited support was found for the hypotheses presented in this study. It was proposed that recovery experiences (i.e., psychological detachment, relaxation, mastery, nonwork control, positive work reflection, negative work reflection, and social activities) would moderate the relationships between workplace interpersonal conflict and both general and work-related employee well-being. Relaxation during nonwork time was found to buffer the negative relationship between workplace interpersonal conflict and employee exhaustion; however, the specific nature of this relationship was somewhat unexpected. Those employees who engaged in higher levels of relaxation outside of work displayed lower levels of exhaustion than those who engaged in little relaxation outside of work when workplace interpersonal conflict was low. This relationship is in line with the current study's hypotheses, and demonstrates that relaxation during nonwork time may halt resource loss, as well as potentially encourage the restoration of lost resources under low levels of work stressors. It is particularly interesting, though, that under high levels of workplace interpersonal conflict, employees with high levels of relaxation experienced similar exhaustion levels as those with low relaxation levels. It may be that in cases of exceedingly high workplace interpersonal conflict, employees are actually spending a portion of their relaxation time ruminating about how to resolve work conflicts. An alternative explanation would be that employees who do spend more time 
relaxing in these high conflict situations are failing to address the sources of conflict in an attempt to resolve them. Hypotheses regarding psychological detachment, nonwork control, mastery experiences, positive work reflection, negative work reflection, and social activities as moderators of the relationship between workplace interpersonal conflict and employee well-being were not supported.

Additional analyses using coworker reports of interpersonal conflict indicated that mastery experiences moderated the negative relationship between interpersonal conflict and both disengagement and exhaustion. Employees who engaged in low levels of mastery experiences showed increased levels of both disengagement and exhaustion as workplace interpersonal conflict increased. This is in line with earlier recovery research, which suggests that failing to engage in mastery experiences outside of work is associated with a lack of resources indicated by lower well-being (Sonnentag \& Fritz, 2007). However, employees with high levels of mastery experiences showed a decrease in both disengagement and exhaustion as levels of workplace interpersonal conflict increased. This was contrary to the hypothesis that individuals high in recovery experiences would demonstrate a weaker positive relationship between interpersonal conflict and burnout than those low in recovery experiences. There are several possible explanations for these results. It may be that more active recovery processes, such as mastery experiences, are more effective in dealing with high levels of workplace interpersonal conflict, a stressor related to anxiety, depression, and burnout (De Dreu et al., 2004), than less active recovery processes such as psychological detachment. Under 
high levels of workplace interpersonal conflict, employees may be drawing more heavily upon their nonwork mastery experiences in order to make up for the resources lost at work due to conflicts with coworkers, supervisors, or customers. It is also possible that coworker reports of interpersonal conflict are capturing only a portion of those instances of workplace interpersonal conflict assessed through self-reports. For example, coworkers may not have been aware of every instance of conflict the target employee experienced at work, or may have only been reporting on exceptionally salient instances of conflict (e.g., ongoing arguments).

Surprisingly, under low levels of workplace interpersonal conflict employees with high levels of mastery experiences experienced higher levels of disengagement and exhaustion than those with low levels of mastery experiences. Further research should be done in an attempt to replicate and examine the nature of these findings. The findings of the current study run contradictory to earlier findings examining mastery as a moderator (Siltaloppi et al., 2009; Kinnunen et al., 2010). These recent studies examined stressors such as lack of job control and job insecurity, and have found that mastery experiences buffered the negative associations between these stressors and employee well-being outcomes. It may be that mastery experiences play a different role in the recovery process when taking into account interpersonal conflict as the workplace stressor. In considering possible explanations for the findings of the current study, it may be helpful to return to the ego depletion model. Depending on the nature of the specific mastery experiences 
undertaken, it may be that these mastery experiences are drawing upon, instead of replenishing, the same internal resource taxed by workplace interpersonal conflict.

Though there were few moderator effects detected in the current study, several main effects were detected that are in line with and support past research on recovery from work. Specifically, psychological detachment and nonwork control were both associated with lower levels of exhaustion and higher levels of life satisfaction. Relaxation was also found to be positively associated with life satisfaction. These results replicate earlier findings by Sonnentag and Fritz (2007). The current study also found relationships between social activities and lower levels of exhaustion and higher levels of life satisfaction. While social activity during nonwork time has previously been linked to general well-being (Fritz \& Sonnentag, 2005), the current study links social activity to additional measures of well-being. Positive work reflection was positively related to job satisfaction, again providing an additional linkage to employee well-being. Lastly, negative work reflection was associated with lower levels of job satisfaction and higher levels of exhaustion and health complaints. Earlier findings have also linked negative work reflection to higher health complaints and exhaustion (Fritz \& Sonnentag, 2006).

While three significant moderating relationships were found, the rest of the proposed hypotheses were not supported. There are several possible reasons for the absence of significant findings for these additional relationships. First, there may be insufficient power to detect the effects. The current study utilized a fairly small sample size, which may have limited the ability to find significant moderator effects. 
Alternatively, it may be the case that other processes are involved in the relationship between interpersonal conflict and well-being. For example, an individual's choice of coping strategy may also play a role in terms of the outcomes they experience. The amount of social support an individual experiences (distinct from the concept of social activities) may also help to buffer the relationship between interpersonal conflict and employee well-being. Additionally, it may be the case that certain recovery experiences are more effective than others in alleviating negative outcomes associated with interpersonal conflict.

As mentioned, it is likely that coping strategies also play a role in the relationship between interpersonal conflict, recovery experiences, and well-being outcomes. In validating the Recovery Experience Questionnaire, Sonnentag and Fritz (2007) point out the similarities between coping and recovery experiences, though they conclude that the concepts are not identical. Lazarus and Folkman (1984) have described coping as "constantly changing cognitive and behavioral efforts to manage specific external and/or internal demands that are appraised as taxing or exceeding the resources of the person" (p. 141). Based on this definition, as compared to recovery experiences, coping refers to the way an individual deals with stressors, while recovery refers to the way in which internal resources are restored. Sonnentag and Fritz (2007) demonstrate that correlations between coping styles and recovery experiences are generally low and mostly nonsignificant. The results of the current study suggest that the proposed model may fit for coping, though not for recovery. It may also be that different pathways exist between 
coping and recovery experiences and well-being outcomes. For example, coping may be designed to act as a buffer of these relationships, while recovery may impact well-being more directly through the rebuilding of internal resources. This is consistent with the current study's demonstration of several significant relationships between recovery experiences and employee well-being, which is in line with past recovery from work research (e.g., Fritz \& Sonnentag, 2005; 2006; Sonnentag \& Fritz, 2007). It may also offer an explanation for the lack of significant findings concerning recovery as a moderator of the relationship between workplace interpersonal conflict and employee well-being.

Furthermore, it is important to note that, to the author's knowledge, this is the first study to examine recovery experiences as a moderator of the relationship between interpersonal conflict and well-being outcomes. The literature on recovery experiences as moderators is quite limited to date, and existing studies include the examination of job stressors such as a lack of job control (Siltaloppi et al., 2010) job insecurity (Kinnunen et al., 2010), and job demands (Sonnentag et al., 2010). It may be that recovery experiences play a different role in the experience of relationship-based work stressors such as interpersonal conflict. The main effects of recovery experiences found in the current study suggest that engaging in recovery during nonwork time does have an impact on employee well-being. However, it may be that this relationship is occurring in addition to, or outside of, the impacts of interpersonal conflict on employee well-being. It is also possible that interpersonal conflict draws on another set of internal resources that are not 
as readily replenished by recovery experiences. Finally, as mentioned previously, it may be that additional mechanisms, such as coping strategies or social support, are playing a role in the relationship between interpersonal conflict, recovery, and well-being.

\section{Implications}

In terms of practical implications, it would be premature to suggest specific recovery-based interventions to lessen the effects of workplace interpersonal conflict, particularly since several of the current findings run contrary to the expected relationships between recovery experiences, workplace interpersonal conflict, and employee wellbeing. That being said, numerous recent studies have demonstrated the positive impacts of recovery from work (e.g., Fritz \& Sonnentag, 2005; 2006; Sonnentag \& Fritz, 2007; Fritz et al., 2010a; 2010b; Sonnentag et al., 2008; 2010) and the current study should not be seen as discounting the impacts of this stream of research. Indeed, many of the main effects found in the current study support and extend this line of research. For these reasons, recovery experiences should be encouraged by organizations and sought after by employees looking to increase both well-being and performance capabilities.

In terms of implications for research on recovery from work, the counterintuitive findings presented in this study suggest that recovery experiences may have differential outcomes depending on the type of work stressor. As mentioned in the general discussion, few studies on recovery have focused on the role of recovery experiences as moderators, and thus it would be wise to continue this line of research. Further research in this area would be useful in identifying the unique contributions of recovery 
experiences in lessening the impacts of various work stressors. As recovery research turns towards examining the effects of recovery-based workplace interventions, distinguishing the specific contributions of individual recovery experiences becomes increasingly important. One recent quasi-experimental study examined the effects of a recovery-based intervention and found beneficial effects for recovery experiences, recovery related self-efficacy, sleep quality, perceived stress, and state negative affect (Hahn, Binnewies, Sonnentag, \& Mozja, 2011). While this study demonstrated effects of a training program, work stressors prior to the intervention were not measured. Incorporating results of the current study and previous studies of recovery experiences as moderators (Siltaloppi et al., 2009; Kinnunen et al., 2010), would further extend this new line of research on recovery based interventions by identifying work stressors most likely to be affected by such interventions.

\section{Contributions and Limitations}

The current study offers several contributions to the literature on recovery from work. Strengths of this study include an extension of previous recovery research, including an answer to the call of Sonnentag and Fritz (2007) for further research on the moderating role of recovery experiences. Several recent studies have begun work on this direction of research (Siltaloppi et al., 2009; Kinnunen et al., 2010; Sonnentag et al., 2010), though this is the first known study to examine the moderating role of recovery experiences in the relationship between interpersonal conflict and employee well-being. Interpersonal conflict has been identified as an important work stressor that is associated 
with negative outcomes for its victims (Spector \& Jex, 1998), though much of the research on interpersonal conflict has focused on the antecedents and outcomes of this work stressor without offering strategies for reducing its potential negative effects.

In addition to these contributions, coworker and significant other reports of study variables were used in both an effort to alleviate issues of common method bias, but also to extend the current literature on recovery and interpersonal conflict. Significant other reports of well-being have been used successfully in recovery research (e.g., Fritz et al., 2010b), and the current study provides an additional example of the use of this form of survey data. By including coworker reports of interpersonal conflict, a comparison could be made between self-report and coworker reports of this construct to contribute to the understanding of whether or not coworker reports were a sufficient measurement of employee interpersonal conflict. The results of the current study suggest that coworker reports should not be discounted, though they may be identifying differing relationships between work stressors, recovery, and well-being than those studies utilizing self-reports of interpersonal conflict.

While this study does make several important contributions, it is important to also consider its limitations. For example, the cross-sectional nature of the data does not allow for inferences of causality. While past research (e.g. Stoetzer et al., 2009) would suggest that increased interpersonal conflict leads to lower well-being, from the current data it is also possible that lowered well-being may contribute to increased workplace interpersonal conflict or lower levels of recovery experiences. The issue of reverse 
causality is an important one, as it may be that employees with lower levels of well-being have fewer resources available with which to regulate negative emotions, which in turn may be associated with higher instances of conflict with coworkers. COR theory would suggest that these individuals may experience loss spirals, in which resource losses lead to continued future resource loss. If future longitudinal studies were to find that lowered well-being was predictive of increased interpersonal conflict, these loss spirals may contribute to the understanding of this process. Future studies should examine similar processes with longitudinal designs so as to allow for a clearer understanding of possible causal processes. The current study has adopted an "intervention" approach, in that the primary focus lies in whether or not recovery experiences can lessen negative associations between workplace interpersonal conflict and employee well-being.

However, if future longitudinal studies find that lower well-being also causes interpersonal conflict at work, additional studies adopting a "prevention" approach would be warranted, in which the aim would be to increase employee well-being, in hopes of reducing the levels of interpersonal conflict at work.

On a related note, the measure of interpersonal conflict used in the current study does not measure the source of the conflict. Instead, the levels of interpersonal conflict can be seen as a composite score of any conflict the employee came into contact with while at work, be it from supervisors, coworkers, or customers. Due to the inability to separate sources of conflict from the data at hand, it is impossible to know whether or not interpersonal conflict experienced with a certain group of people (e.g., supervisors) may 
have impacted well-being outcomes more strongly than conflict with other individuals at work. It is also possible that recovery experiences are particularly useful in mitigating interpersonal conflict with certain individuals at work. In general, the sample utilized in the current study had a relatively low base rate of workplace interpersonal conflict, which may somewhat account for the lack of significant findings.

Additionally, the current study uses a relatively small sample size, which may have resulted in lower than preferred statistical power. However, each hypothesis was analyzed in separate regression models in an attempt to mitigate the issue of power. Nevertheless, numerous models were analyzed, and as such, future studies would be wise to consider utilizing larger sample sizes. Using larger sample sizes would allow for a greater breadth of analyses, as well as the examination of more complex models.

The current sample consists of administrative university staff, which may have unique job characteristics, such as the interdependence of work tasks, and differ in the frequency of experienced interpersonal conflict from more service-based occupations. It would be helpful to examine various occupations in order to explore the generalizability of these findings to different populations. Finally, while the data was collected from seven different institutions, grouping data was not available with which to test a possible nested structure. Though several significant relationships were still detected assessing the sample as one group, it is possible that testing for group differences across institutions may have provided additional interpretations. For example, the amount of workplace 
interpersonal conflict or recovery experiences may have differed across institutions due to organizational climate or policies.

\section{Future Research}

In considering the contributions and limitations of the current study, several recommendations can be made for future research in the area of recovery from work. As the results of the current study differ somewhat from the recent findings regarding recovery experiences as moderators (e.g., particularly concerning mastery experiences), future studies examining the role of recovery experiences as moderators should take into consideration the severity of the workplace stressor, as this may play a role in the types of recovery experiences that are useful in buffering negative associations with well-being. In doing so, it would be possible to determine whether certain recovery experiences are more useful in lessening the effects of certain workplace stressors. This knowledge would prove useful in furthering research designed to evaluate recovery-based interventions (Hahn et al., 2011).

In considering the construct of interpersonal conflict, future studies should explore whether or not the size of one's work group could play a role in the effects of interpersonal conflict. In large work groups, employees may be able to seek social support from other coworkers, while those in small work groups may see stronger negative impacts of interpersonal conflict with the few coworkers they have. Collecting data on the size of participants' work groups in future studies would help to address this question. Additionally, collecting data on the source of conflict could prove fruitful, as 
previous research has shown differential associations with well-being outcomes across sources of conflict (Frone, 2000).

As mentioned in the limitations section, it would be helpful to employ longitudinal designs in future research in order to further examine the directionality of relationships between work stressors, recovery experiences, and employee well-being. Additionally, future studies should consider using larger sample sizes and sampling from a wide variety of occupations. In particular, it may be helpful to examine occupations with higher base rates of workplace interpersonal conflict, such as customer-service based occupations or nursing. Finally, research on recovery from work has traditionally relied upon subjective measures of employee well-being. Future studies should consider using objective measures of well-being, such as blood pressure, actigraphy data, or cortisol levels. 


\section{Conclusion}

The current study contributes to the literature on recovery from work by examining the moderating role of recovery experiences in the relationship between workplace interpersonal conflict and employee well-being. Both relaxation and mastery experiences were found to act as moderators of the relationship between interpersonal conflict and employee burnout, though the directions of these relationships warrant further research. Many of the main effects detected in the current study both support and extend the current recovery literature. As interpersonal conflict has previously been linked to numerous negative well-being outcomes, it is important that future research continue to examine possible strategies for helping employees cope with this stressor. Continued research can result in practical recommendations to organizations for providing interventions, policies, and practices that will address the impacts of interpersonal conflict in the workplace. 
Table 1

Table of Variables and Measurement Scales

\begin{tabular}{|c|c|c|c|c|}
\hline Variable & Author & $\begin{array}{l}\text { Number } \\
\text { of } \\
\text { Items }\end{array}$ & Scale & $\begin{array}{l}\text { Cronbach's } \\
\text { alpha }\end{array}$ \\
\hline \multicolumn{5}{|l|}{ Job Stressor $^{1,2}$} \\
\hline Interpersonal Conflict & Spector \& Jex, 1998 & 4 & $1-5$ & .78 \\
\hline \multicolumn{5}{|l|}{ Recovery $^{1}$} \\
\hline $\begin{array}{l}\text { Psychological } \\
\text { Detachment } \\
\text { Mastery } \\
\text { Control } \\
\text { Relaxation } \\
\text { Social Activities } \\
\text { Positive Work } \\
\text { Reflection } \\
\text { Negative Work } \\
\text { Reflection }\end{array}$ & Sonnentag \& Fritz, 2007 & 25 & $1-5$ & $\begin{array}{l}.84 \\
.93 \\
.79 \\
.82 \\
.68 \\
.83 \\
.88\end{array}$ \\
\hline \multicolumn{5}{|l|}{ Well-Being $^{3}$} \\
\hline Life Satisfaction & Diener et al., 1985 & 5 & $1-5$ & .87 \\
\hline $\begin{array}{l}\text { Burnout } \\
\text { Exhaustion } \\
\text { Disengagement }\end{array}$ & Demerouti et al., 2003 & $\begin{array}{l}8 \\
8\end{array}$ & $\begin{array}{l}1-4 \\
1-4\end{array}$ & $\begin{array}{l}.84 \\
.83\end{array}$ \\
\hline \multirow[t]{2}{*}{$\begin{array}{l}\text { General Health } \\
\text { Job Satisfaction }\end{array}$} & $\begin{array}{l}\text { Ursin, Endresen, \& Ursin, } \\
1988\end{array}$ & 17 & $1-4$ & .68 \\
\hline & $\begin{array}{l}\text { Brayfield \& Rothe, } 1951 \\
\text { Judge et al., } 1998\end{array}$ & 5 & $1-5$ & .76 \\
\hline \multicolumn{5}{|l|}{ Control Variable ${ }^{1}$} \\
\hline Negative Affectivity & $\begin{array}{l}\text { Watson, Clark, \& Tellegen, } \\
1988\end{array}$ & 10 & $1-5$ & .84 \\
\hline
\end{tabular}




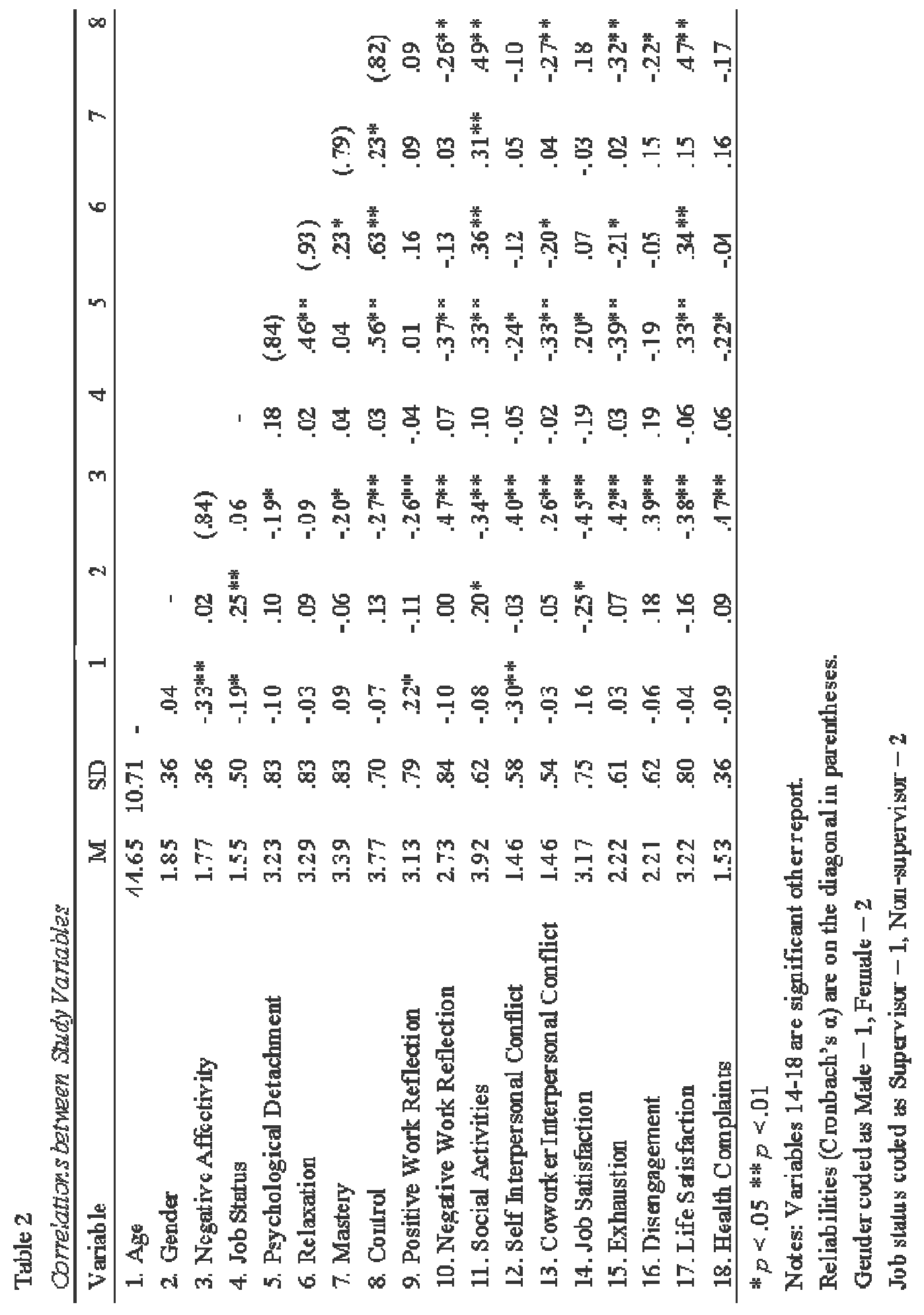




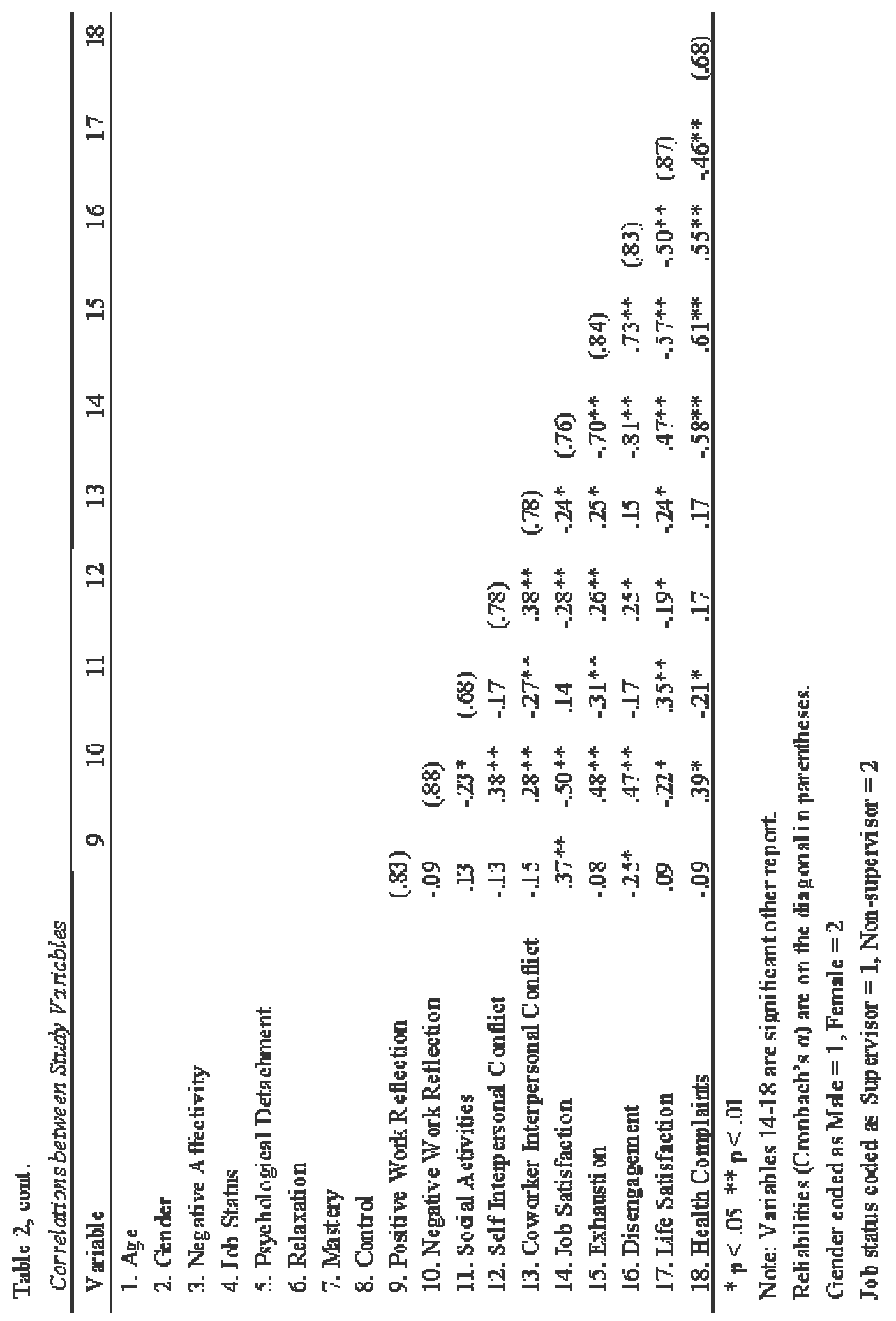




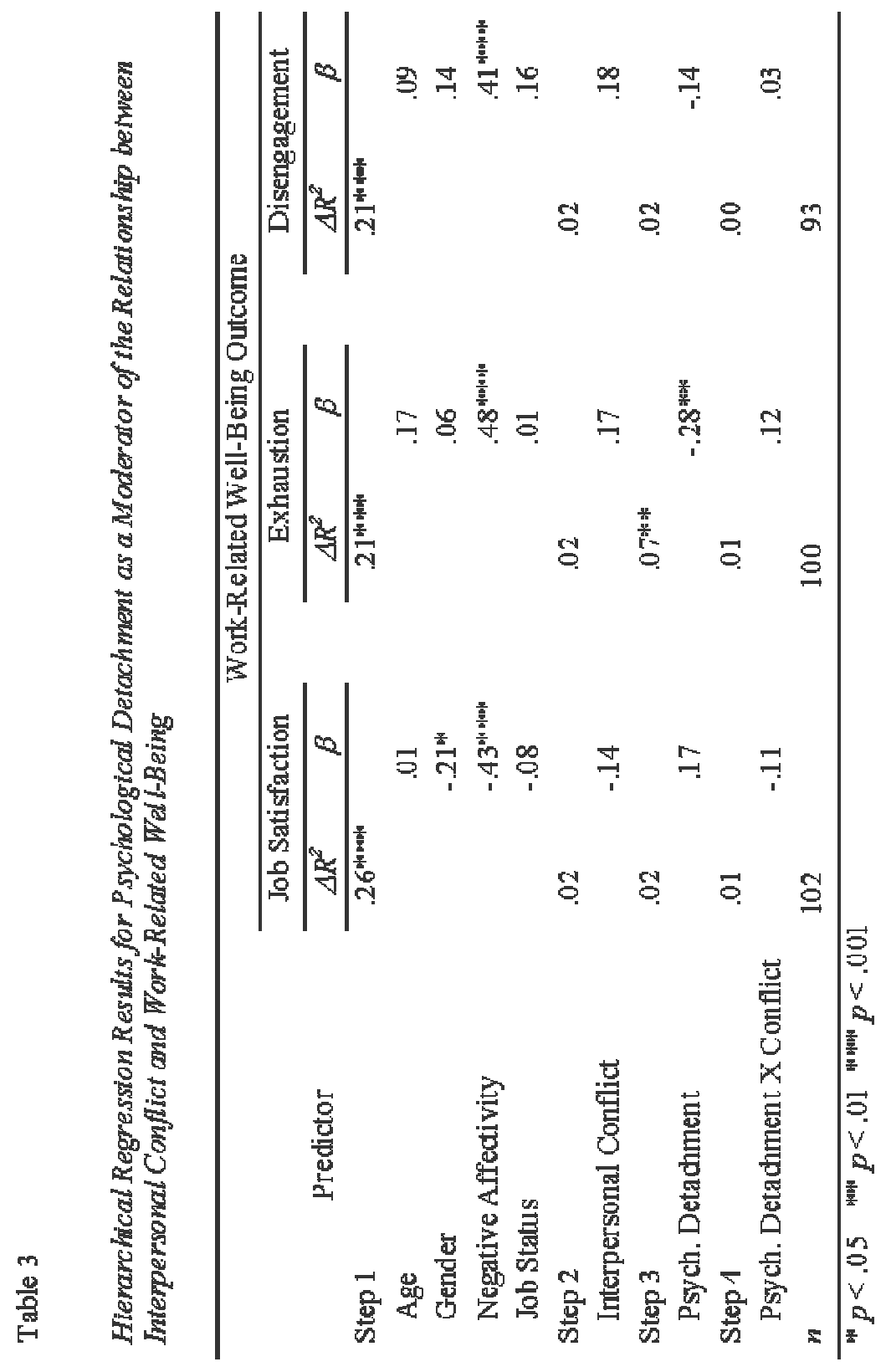




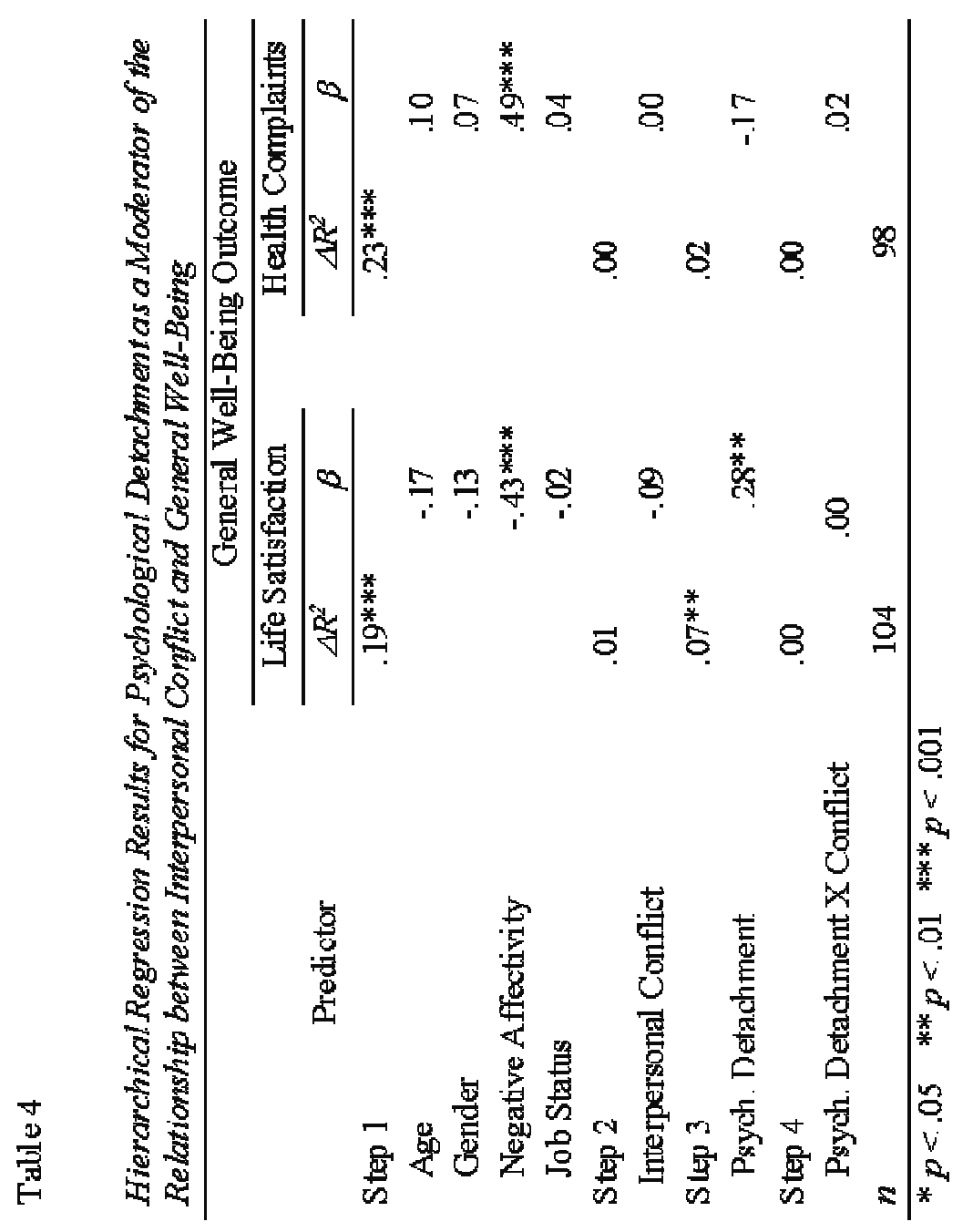




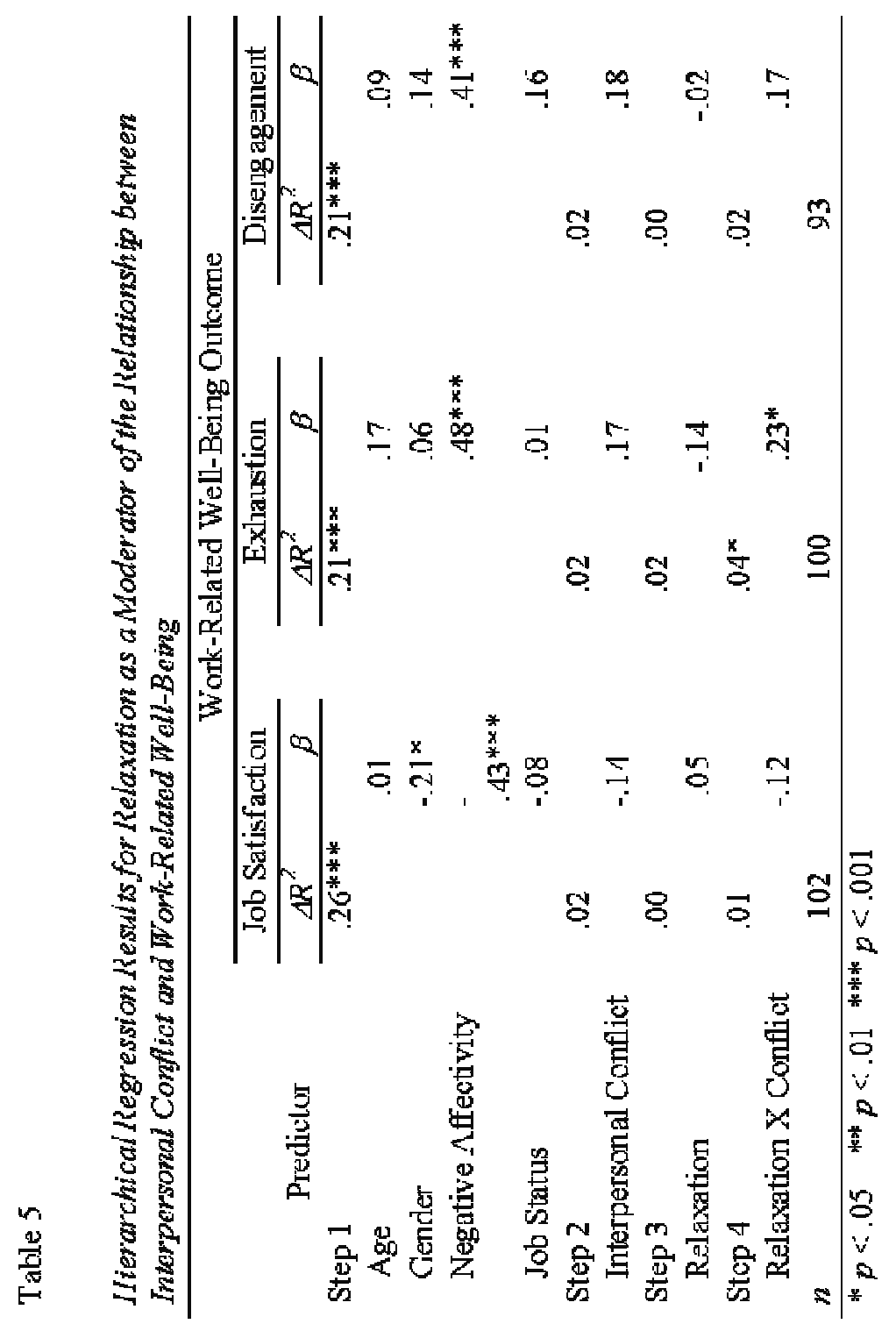




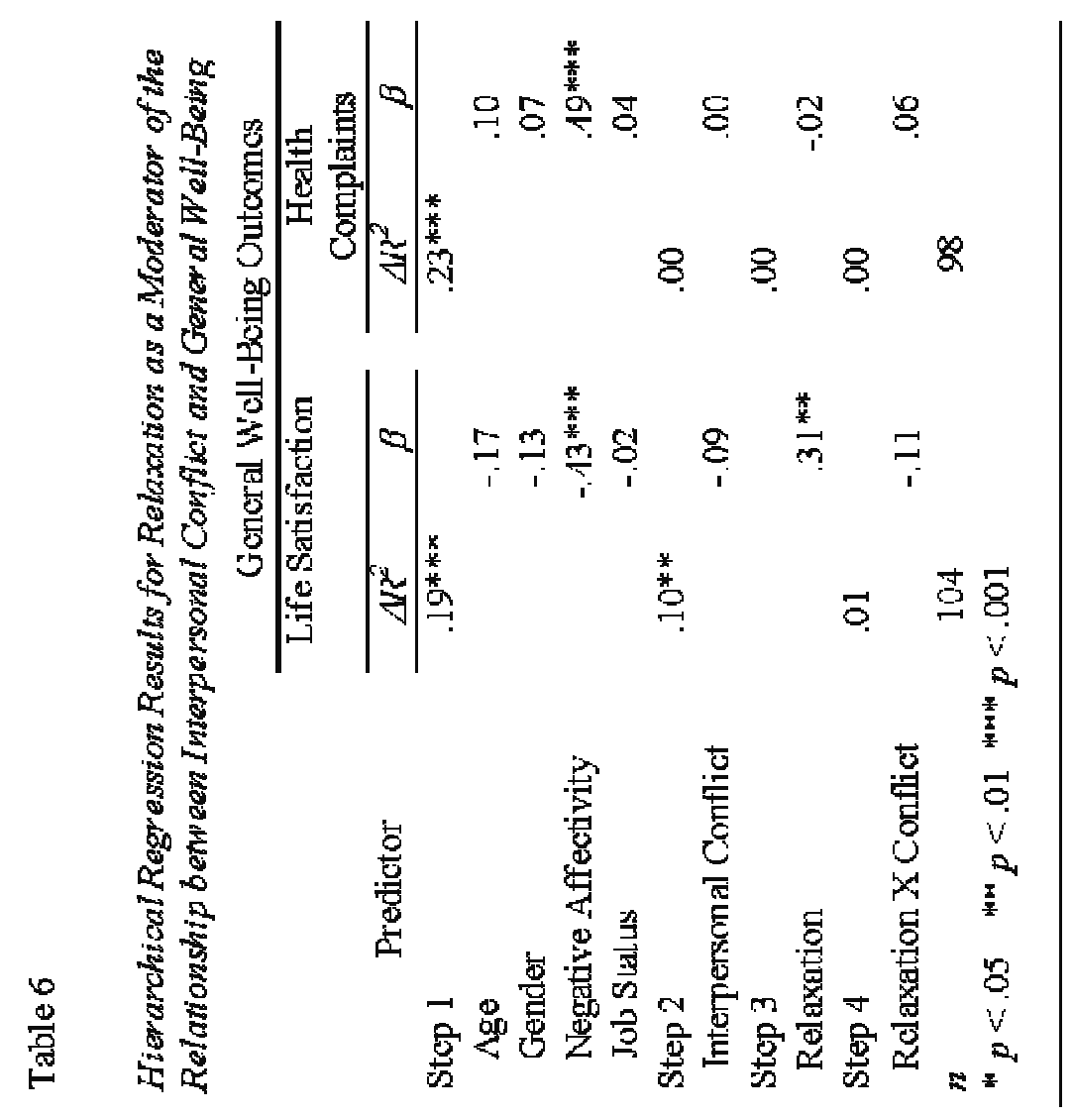




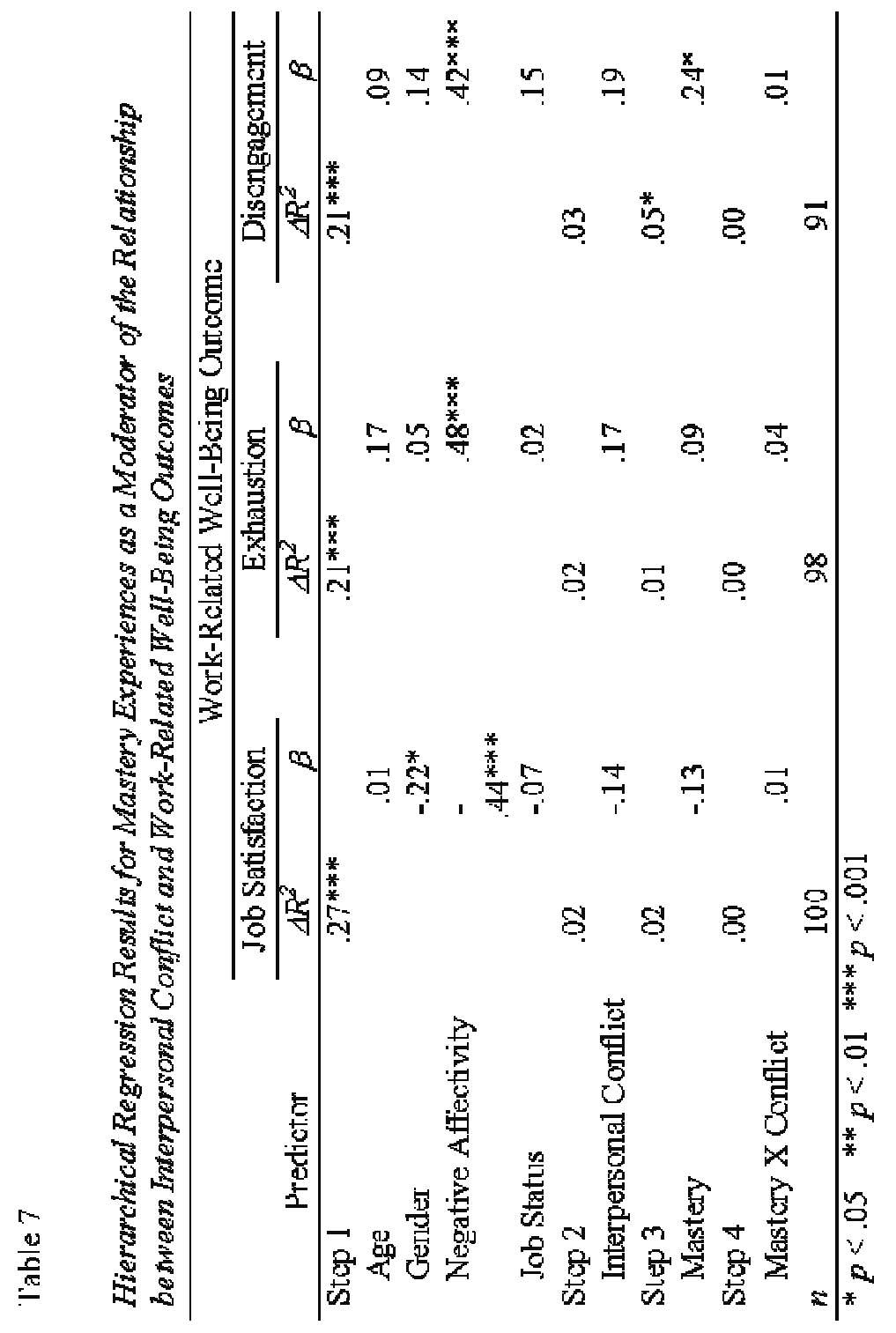




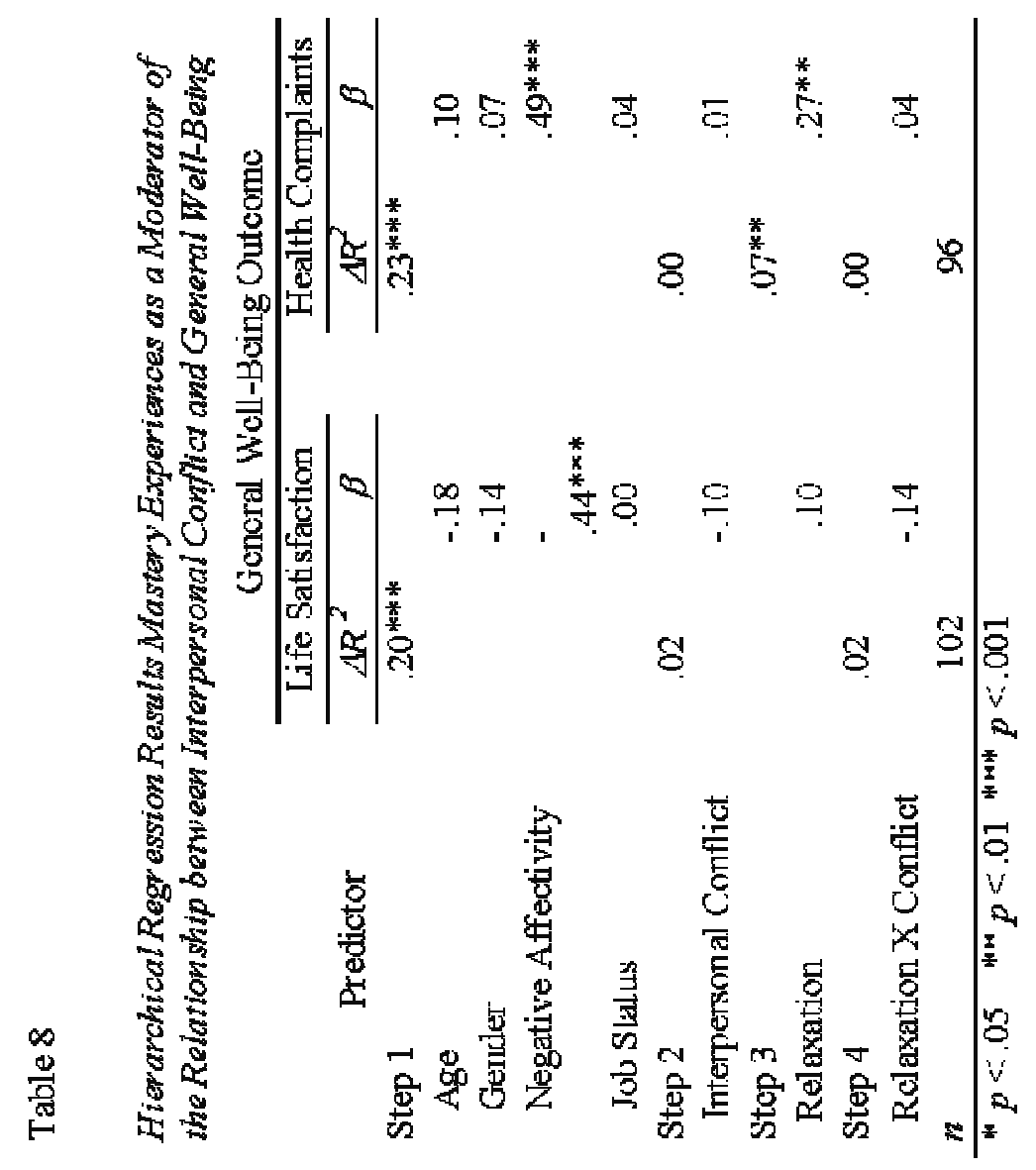




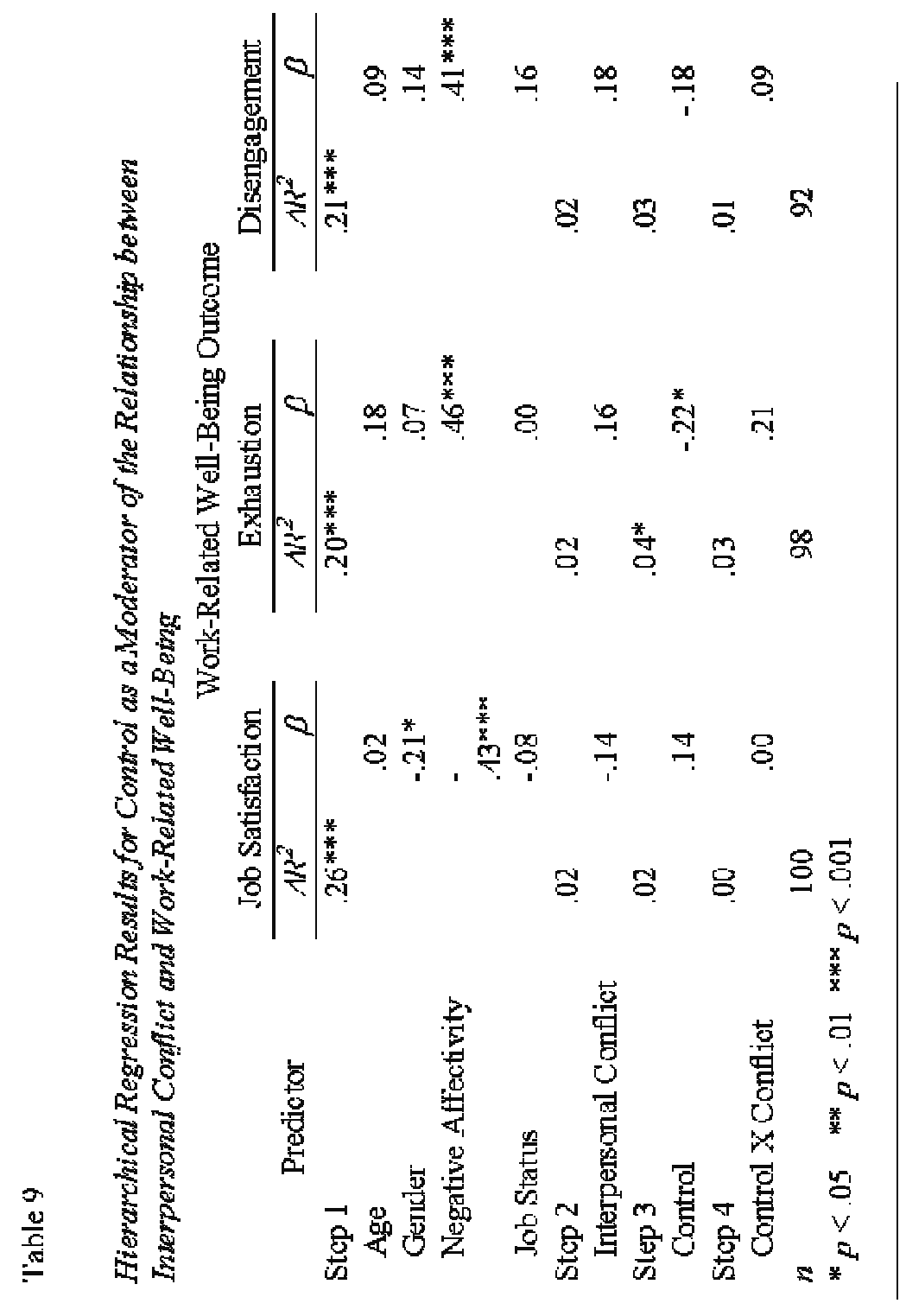




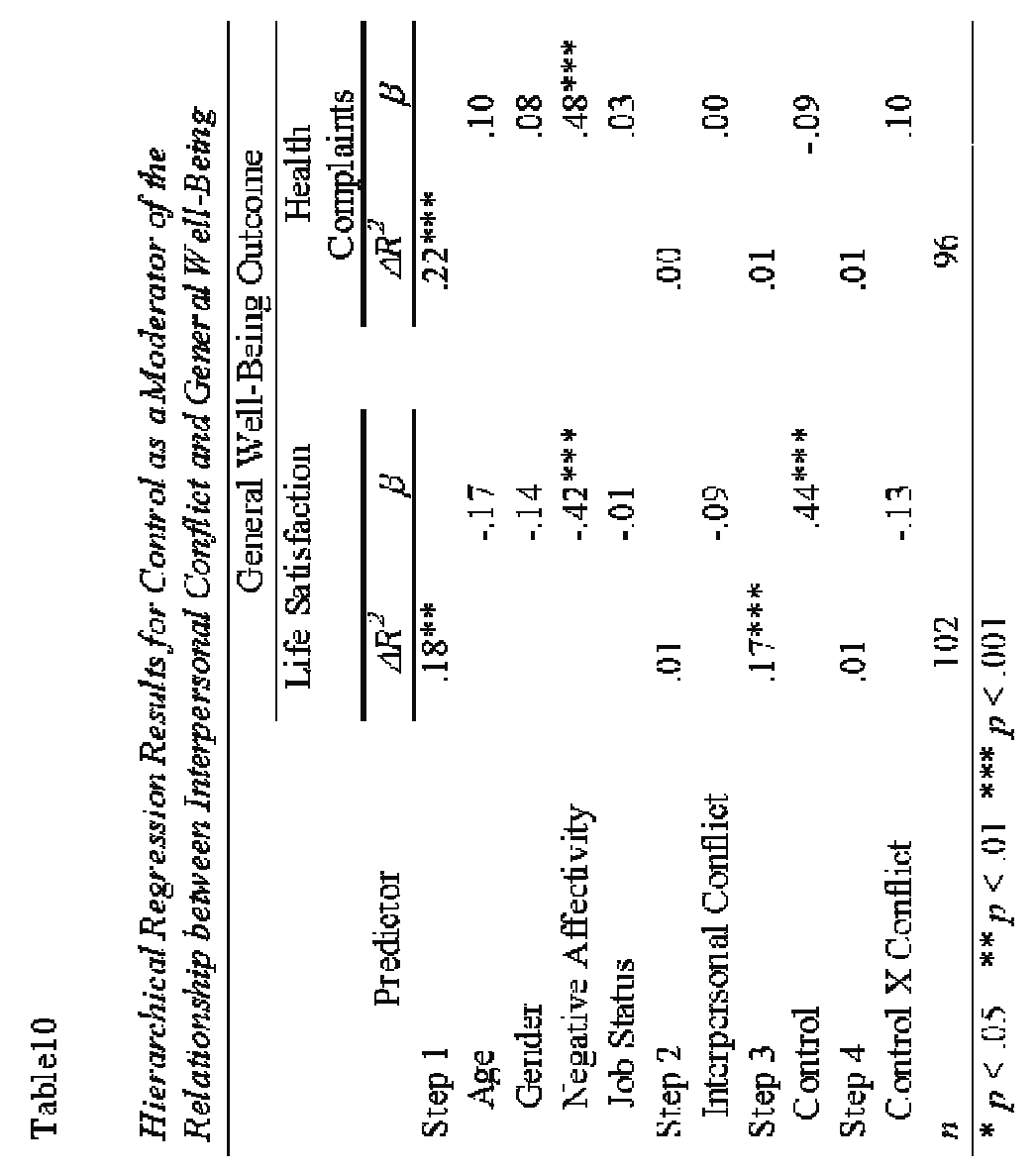




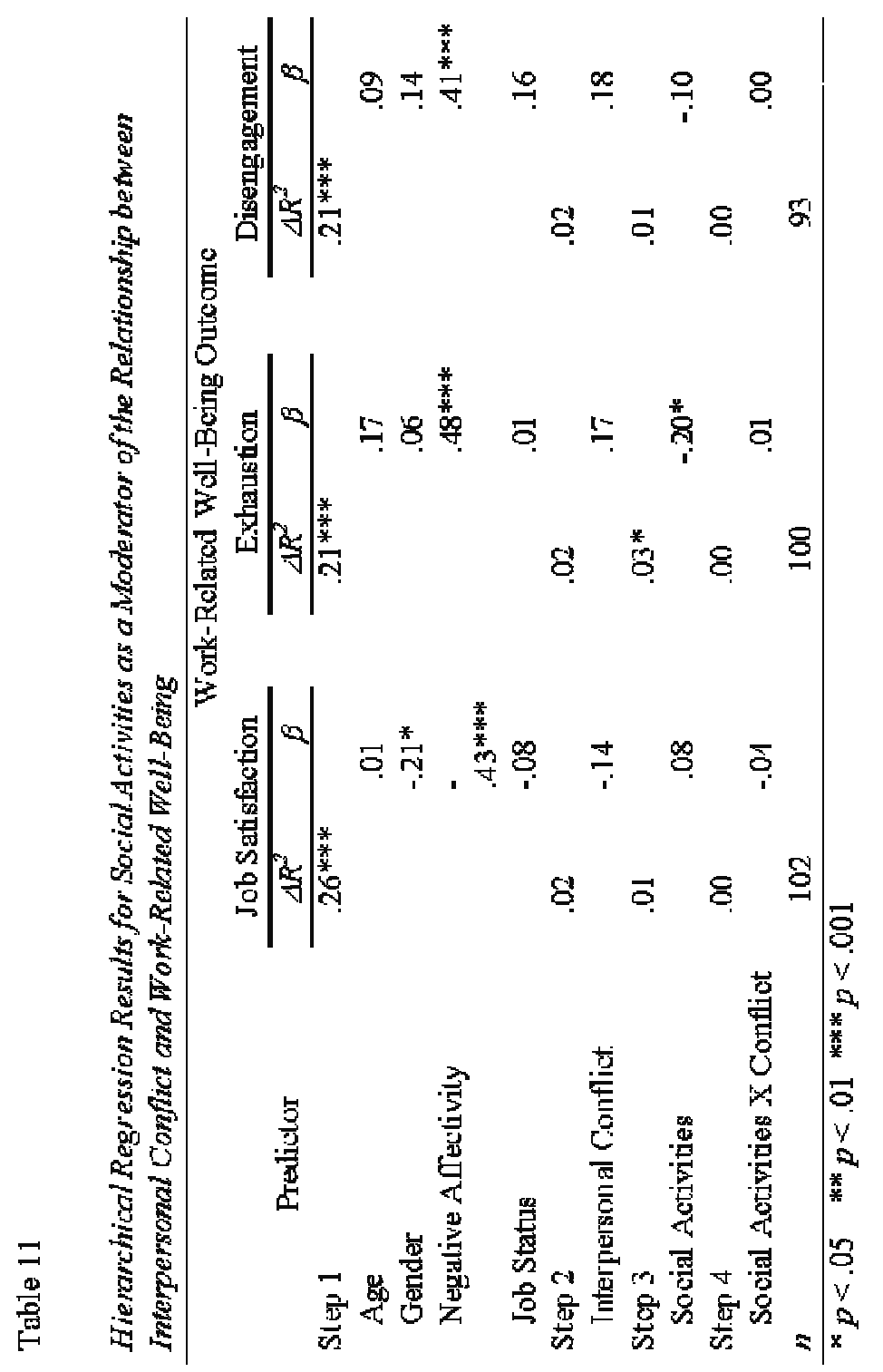




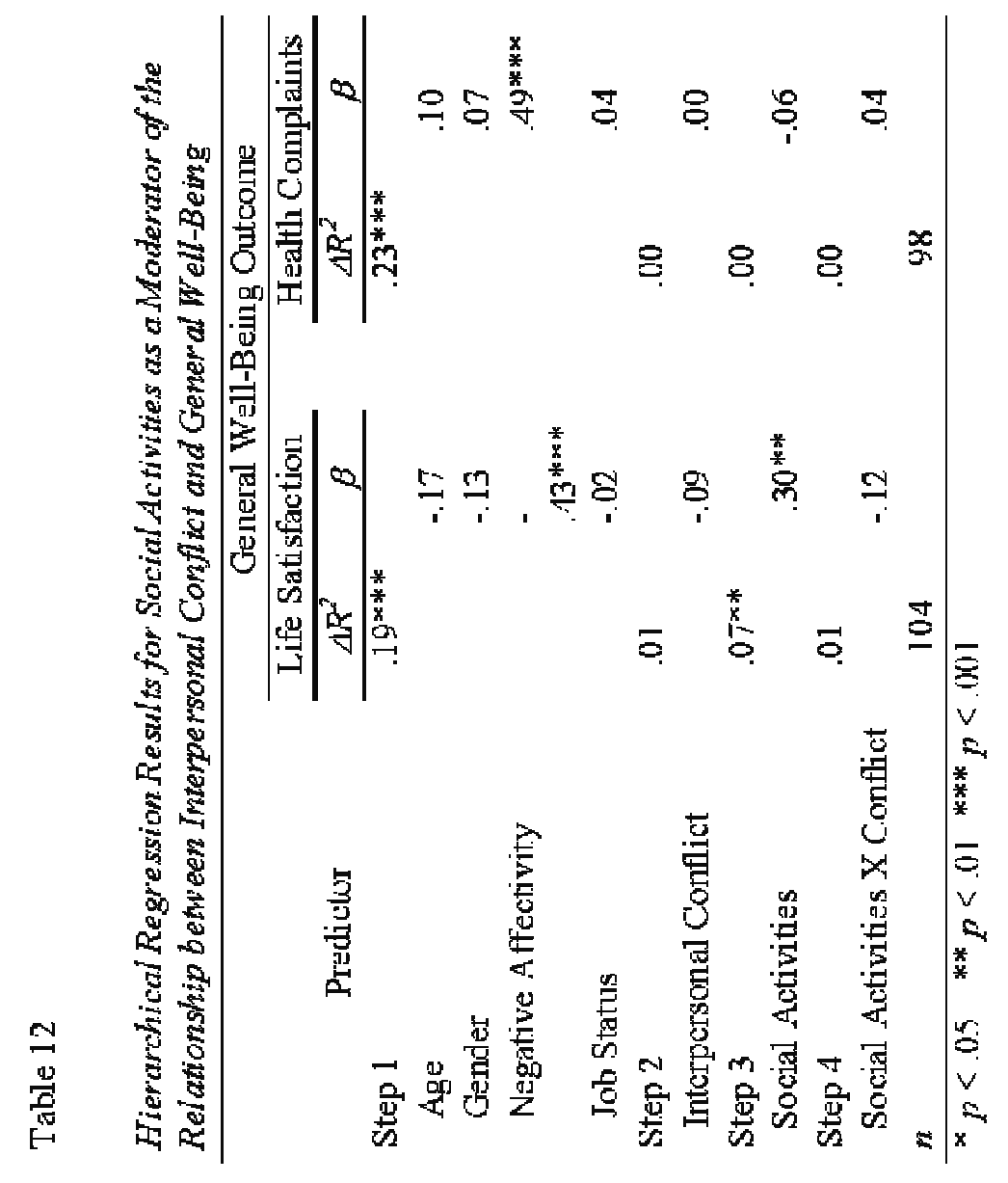




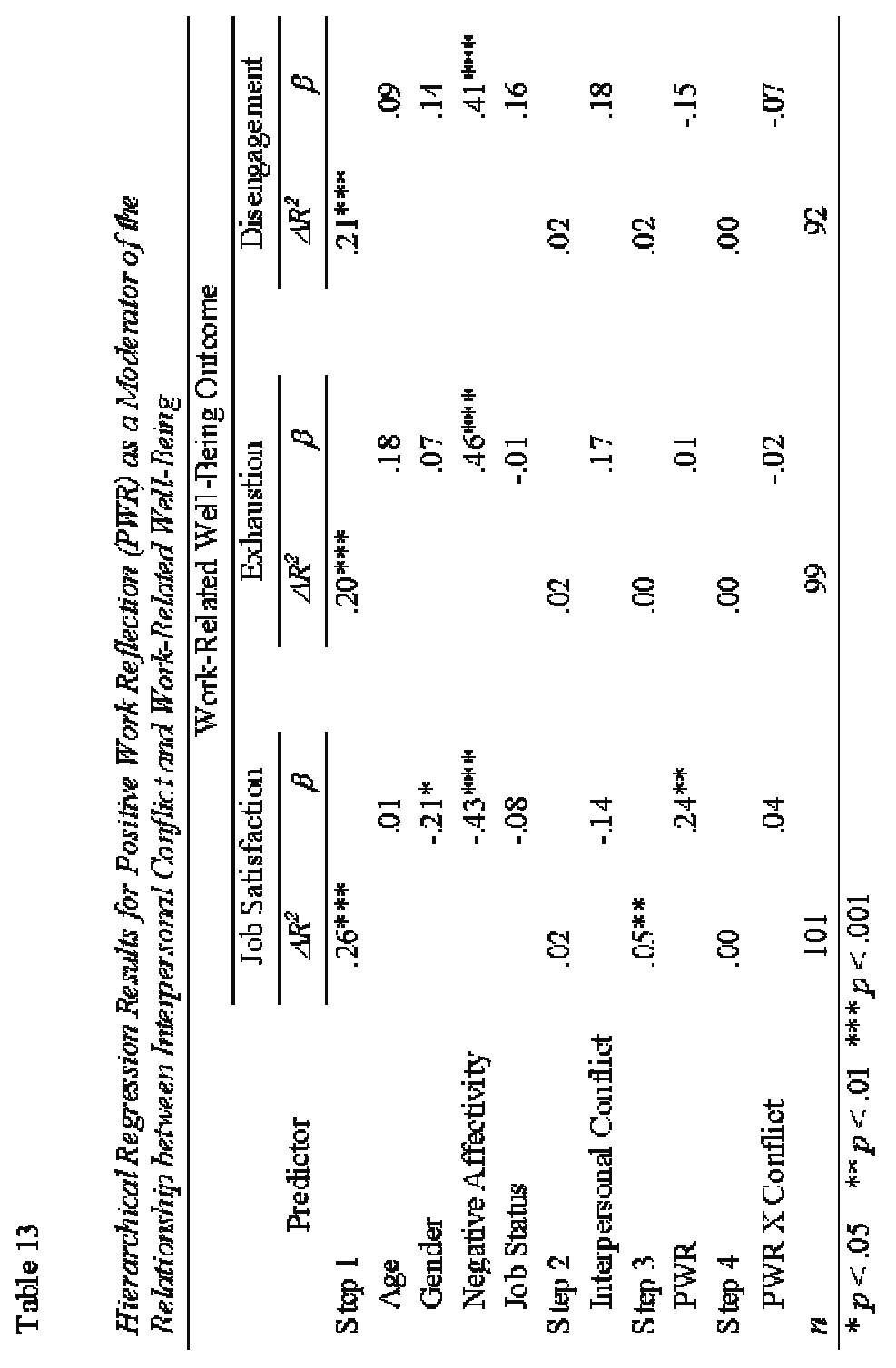




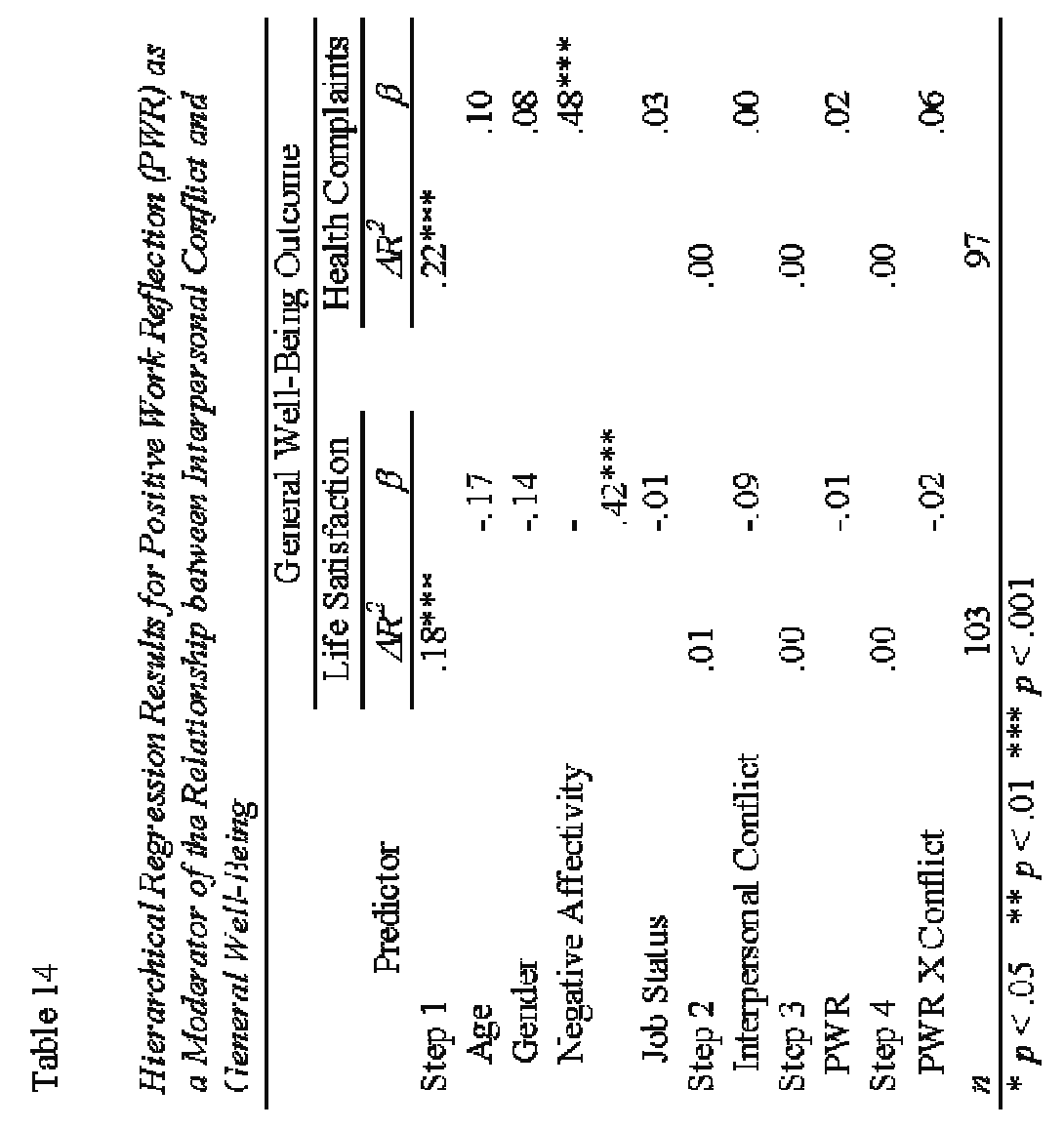




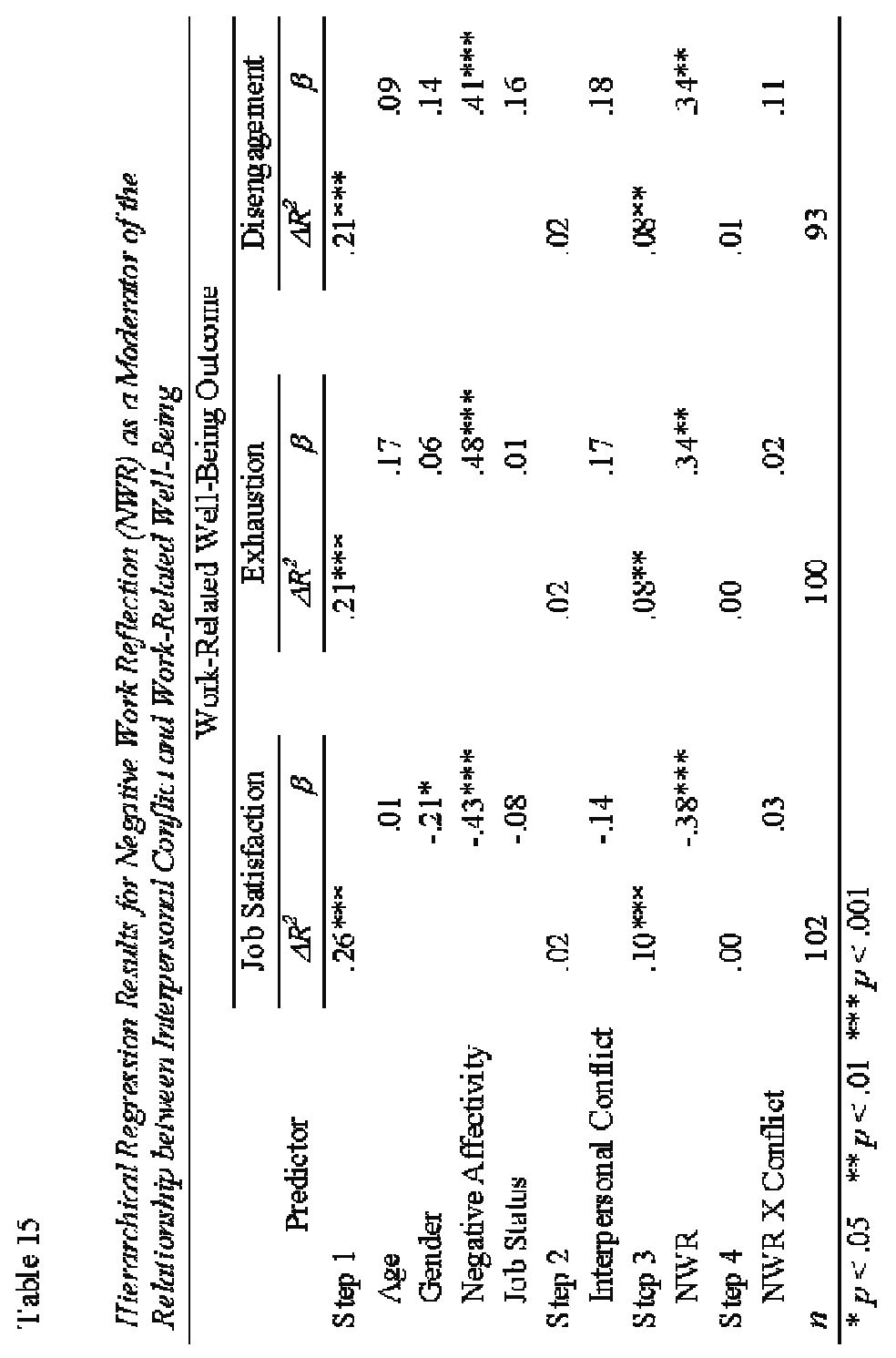




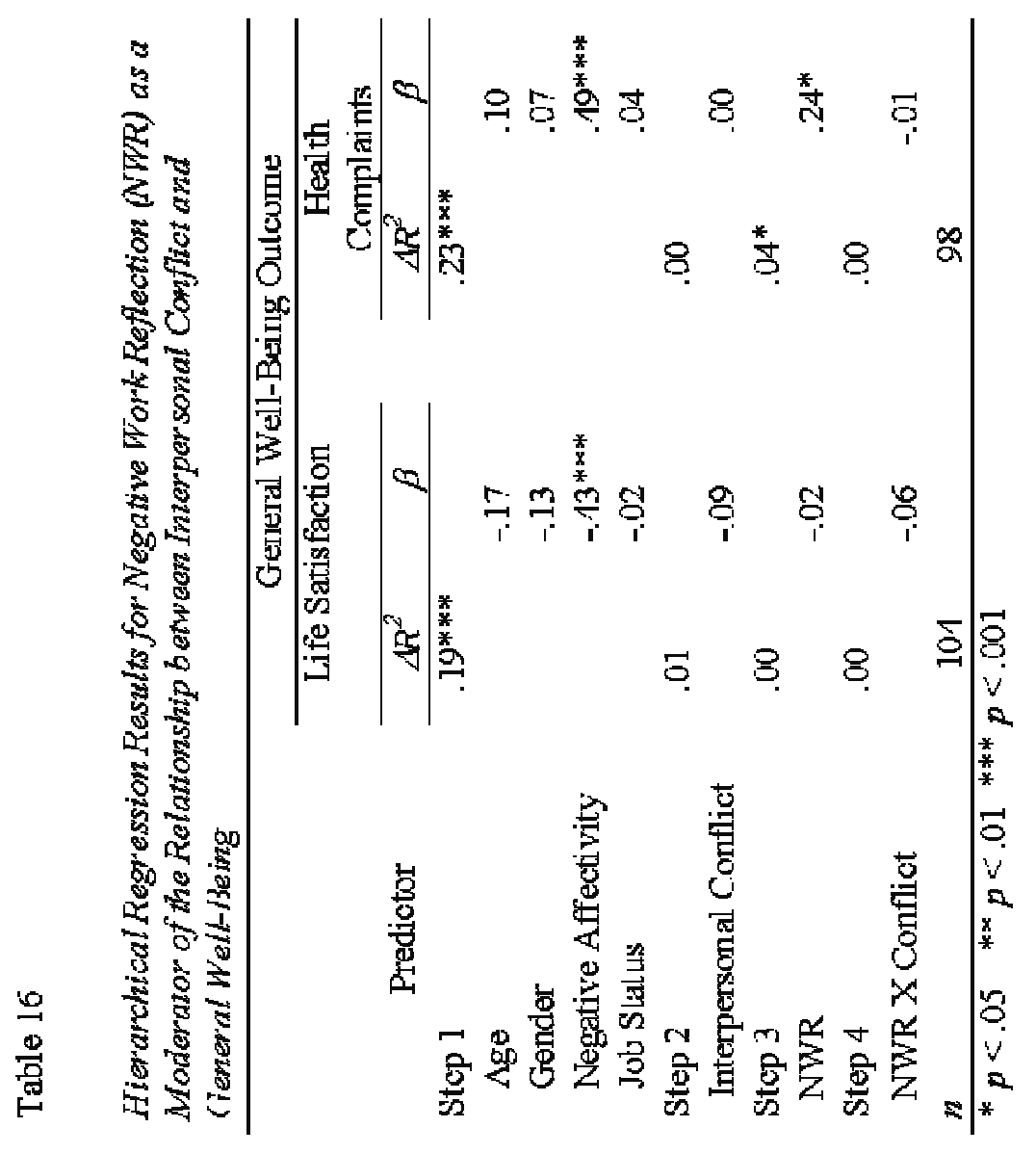




$\frac{\text { Work Stressor }}{\text { Interpersonal }}$
Conflict

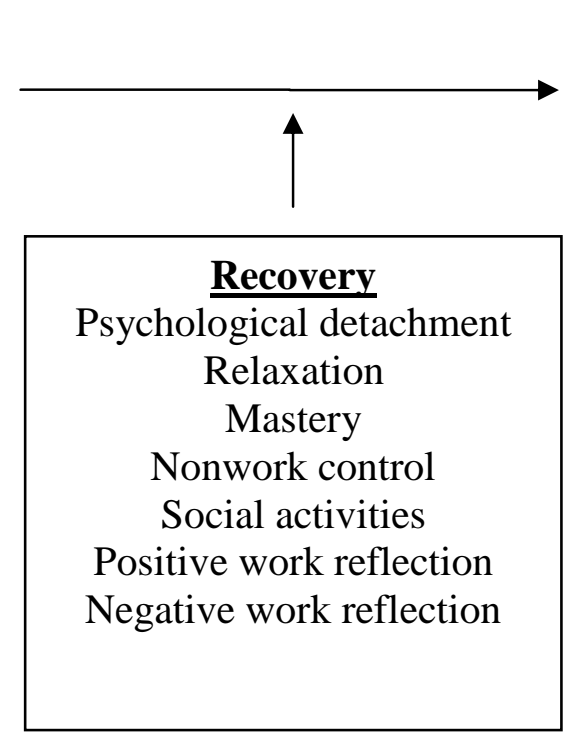

\begin{tabular}{|c|}
\hline Well-Being \\
Work-related \\
Job satisfaction \\
Burnout \\
General \\
Life satisfaction \\
Health Complaints \\
\hline
\end{tabular}

Figure 1. Hypothesized model of relationships between interpersonal conflict and wellbeing with recovery experiences as moderators. 


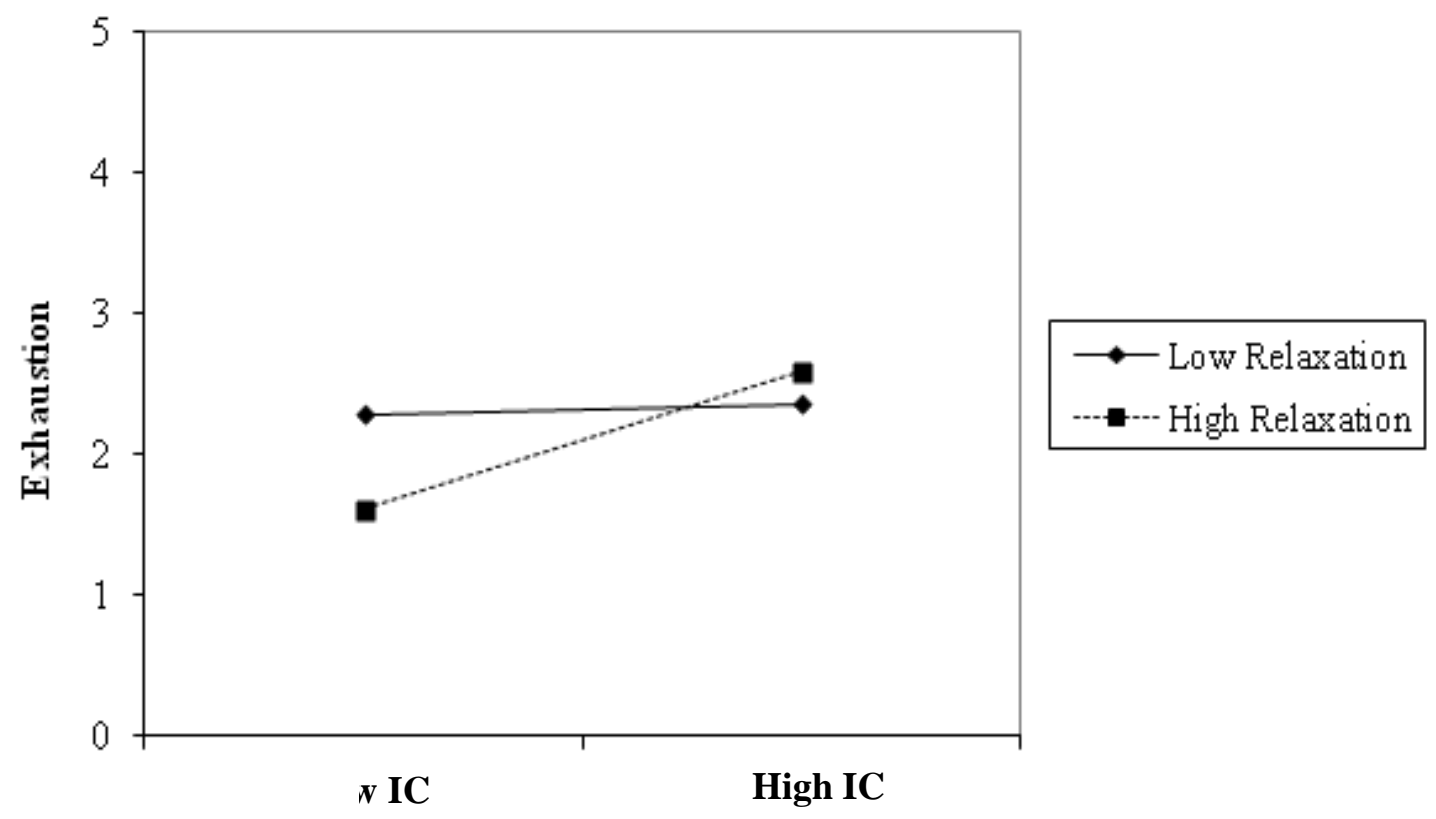

Figure 2. Relaxation as a Moderator of the Relationship between Self-Reported Interpersonal Conflict and Exhaustion 


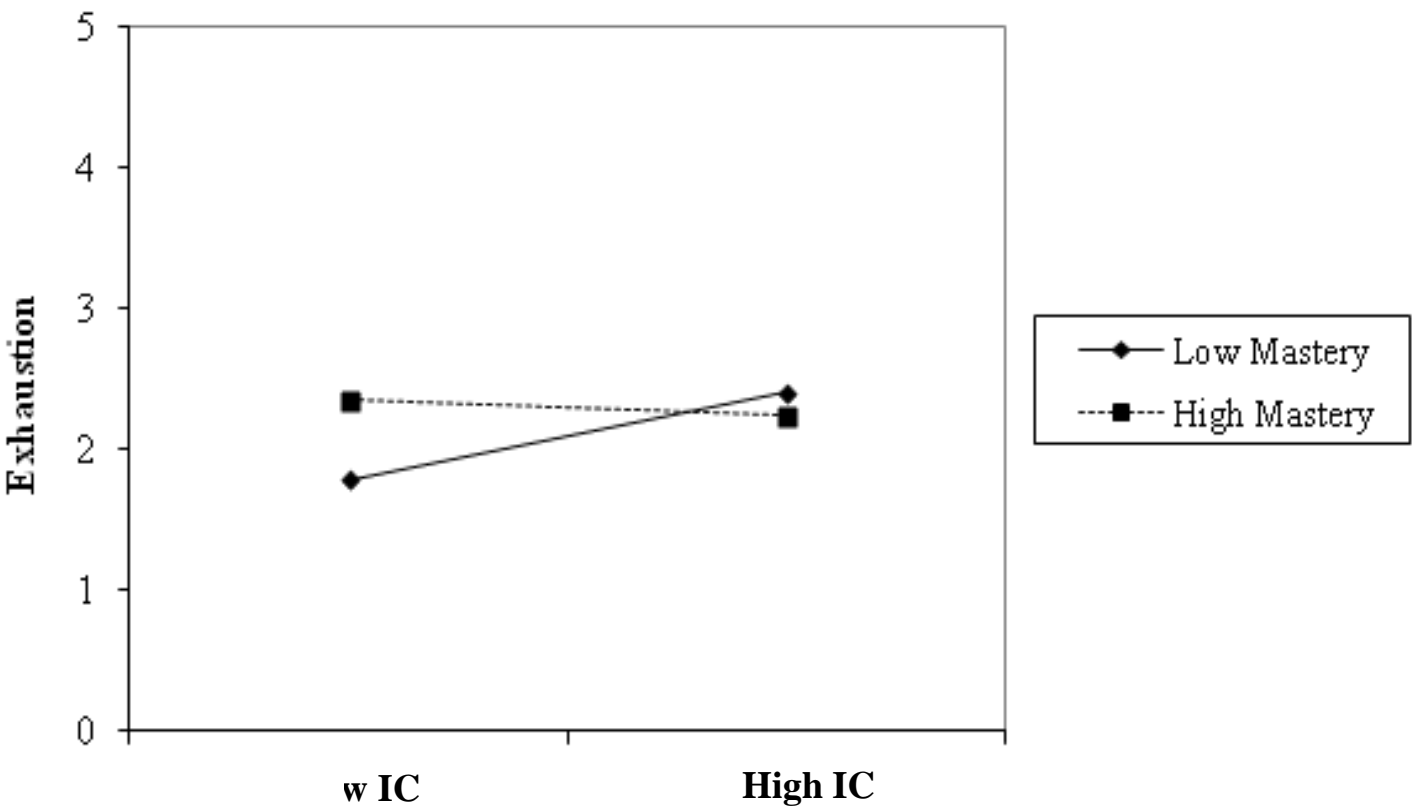

Figure 3. Additional Analyses: Mastery Experiences as a Moderator of the Relationship between Coworker-Reported Interpersonal Conflict and Exhaustion 


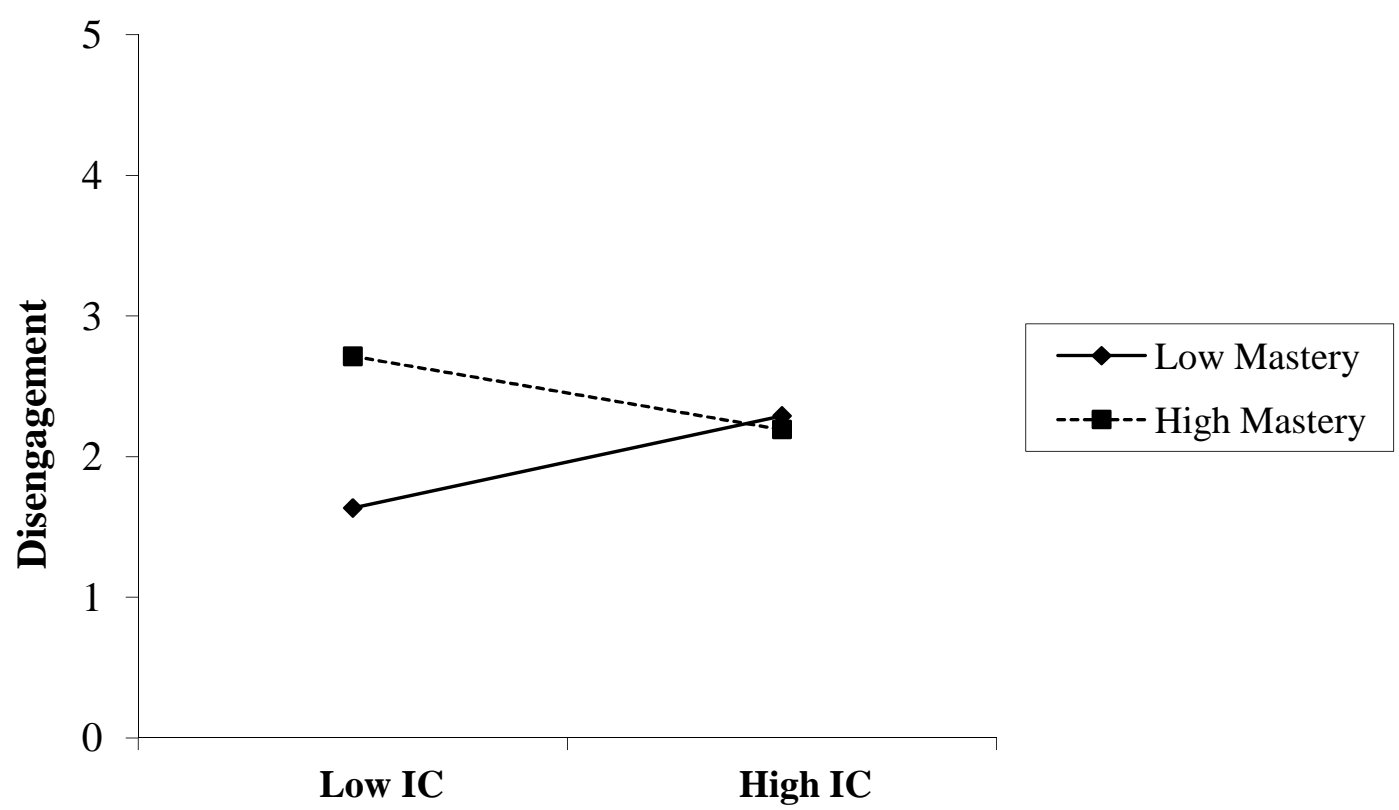

Figure 4. Additional Analyses: Mastery Experiences as a Moderator of the Relationship between Coworker-Reported Interpersonal Conflict and Disengagement 


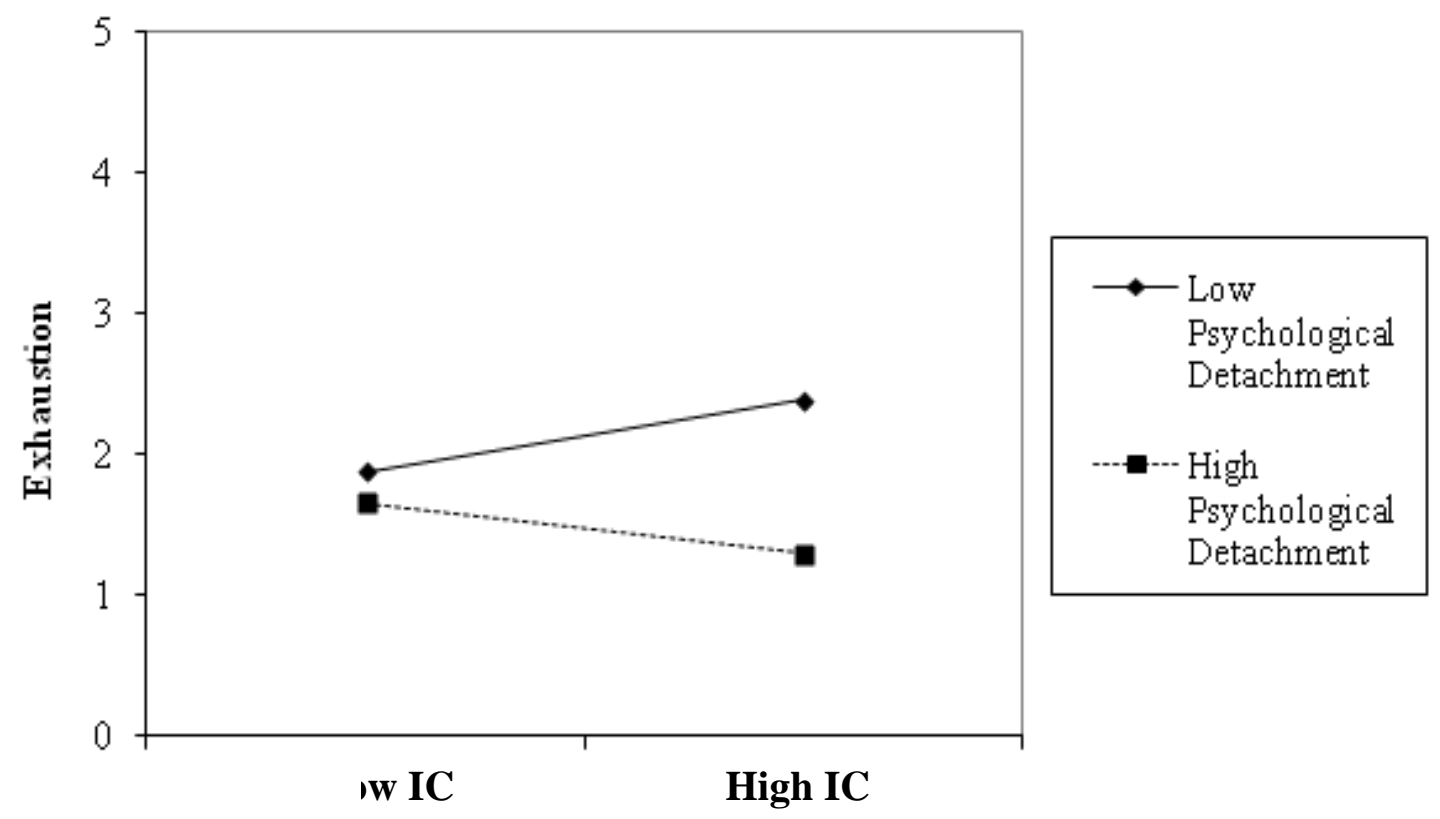

Figure 5. Additional Analyses: Psychological Detachment as a Moderator of the Relationship between Coworker-Reported Interpersonal Conflict and Exhaustion (Controlling for Age, Gender, and Job Status) 


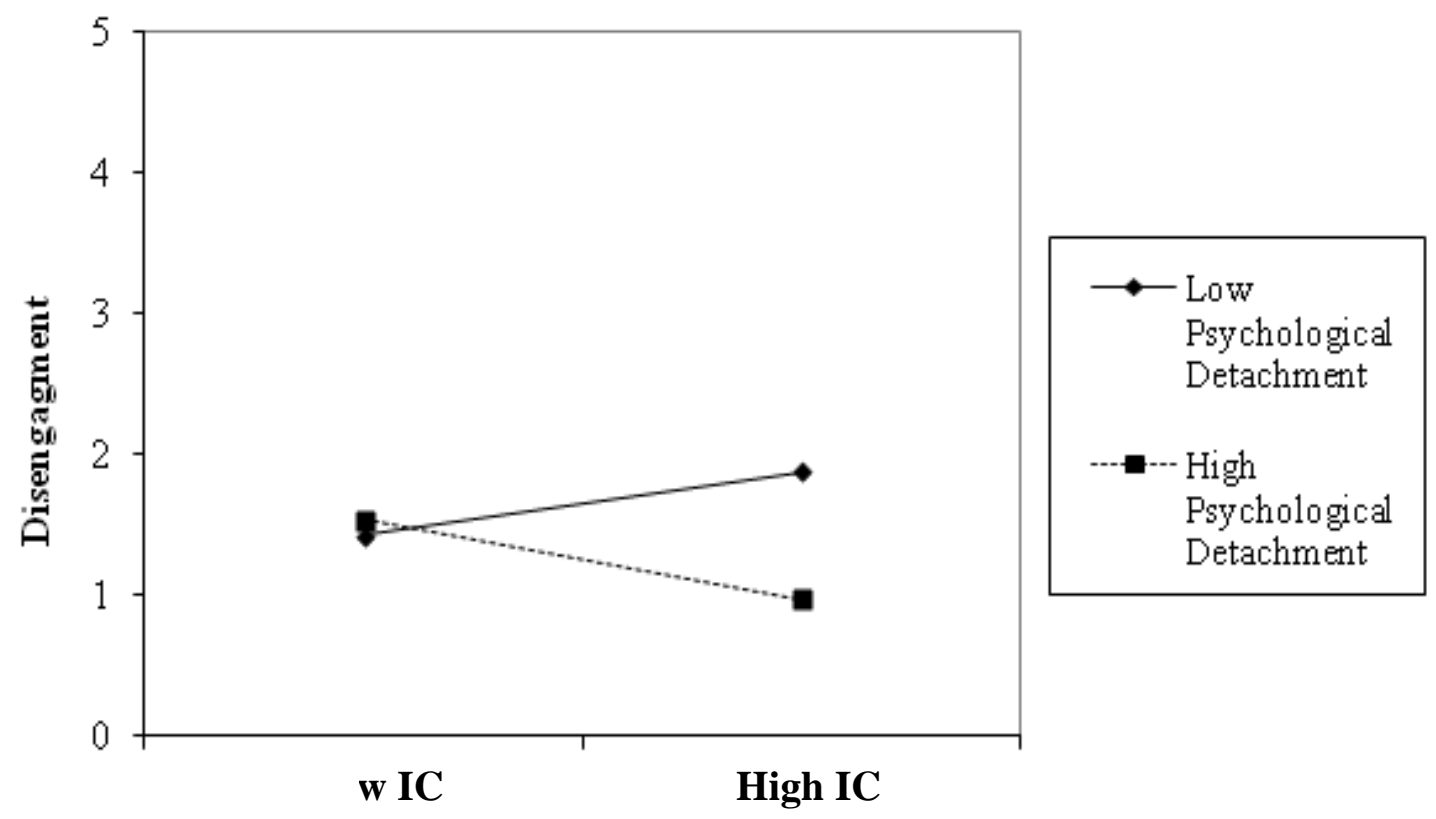

Figure 6. Additional Analyses: Psychological Detachment as a Moderator of the Relationship between Coworker-Reported Interpersonal Conflict and Disengagement (Controlling for Age, Gender, and Job Status) 


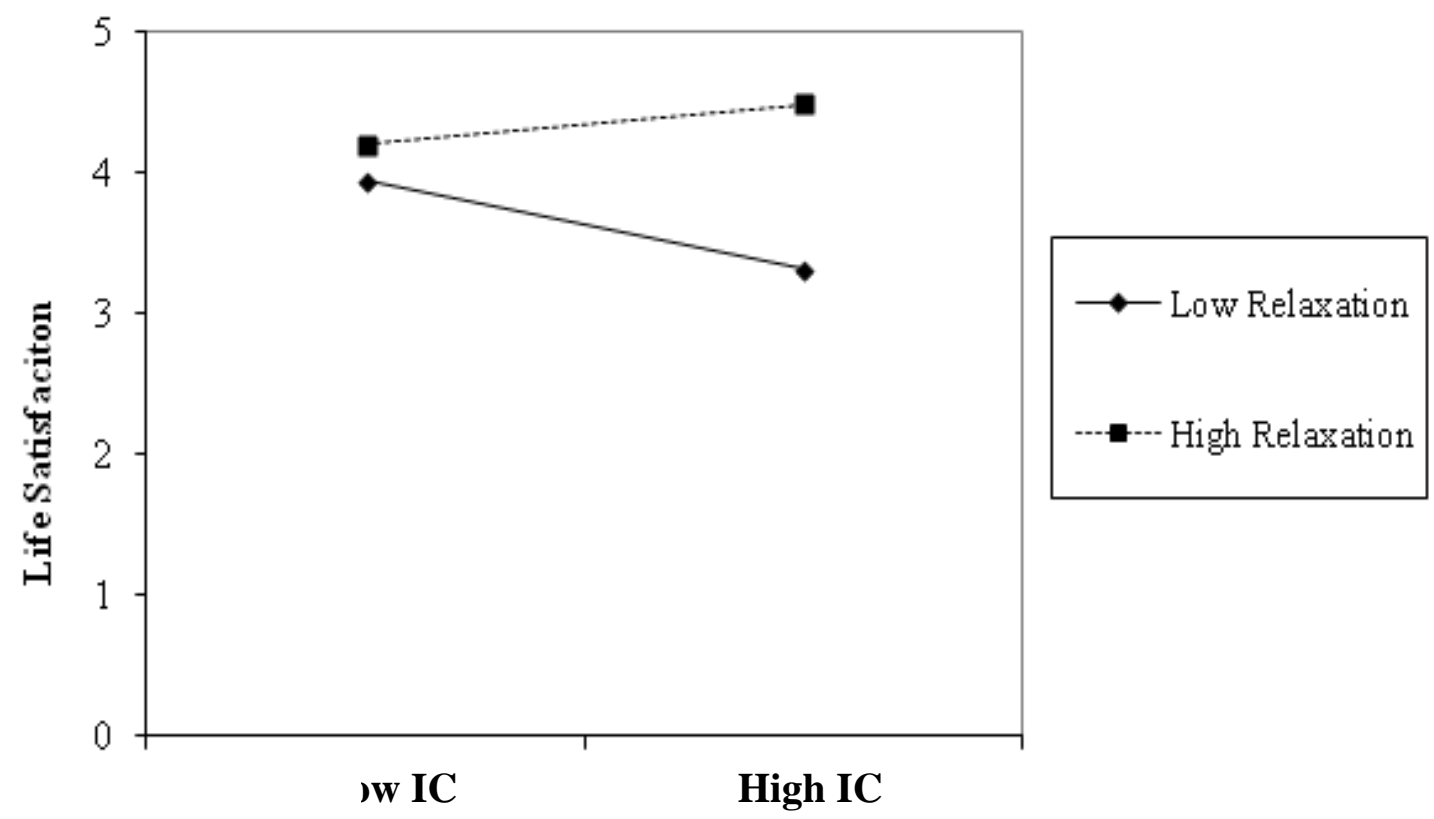

Figure 7. Additional Analyses: Relaxation as a Moderator of the Relationship between Coworker-Reported Interpersonal Conflict and Life Satisfaction (Controlling for Age, Gender, and Job Status) 


\section{References}

Arkin, R. M. (1981). Self-presentational styles. In J. T. Tedeschi (Ed.), Impression management theory and social psychological research (pp. 311-333). New York: Academic Press.

Bandura, A. (1997). Self-efficacy: The exercise of control. New York: Freeman.

Barki, H., \& Hartwick, J. (2004). Conceptualizing the construct of interpersonal conflict. The International Journal of Conflict Management, 15, 216-244.

Barling, J., Dupre, K. E., \& Kelloway, E. K. (2009). Predicting workplace aggression and violence. Annual Review of Psychology, 60, 671-692.

Baumeister, R. F., Bratslavsky, E., Muraven, M., \& Tice, D. M. (1998). Ego depletion: Is the active self a limited resource? Journal of Personality and Social Psychology, $74,1252-1265$.

Bowling, N. A., Beehr, T. A. (2006). Workplace harassment from the victim's perspective: A theoretical model and meta-analysis. Journal of Applied Psychology, 91, 998-1012.

Brasher, E. E., \& Chen, P. Y. (1999). Evaluation of success criteria in job search: A process perspective. Journal of Occupational and Organizational Psychology, 72, $57-70$.

Brayfield, A., \& Rothe, H. (1951). An index of job satisfaction. Journal of Applied Psychology, 35, 307-311. 
Brewer, E. W. \& Shapard, L. (2004). Employee burnout: A meta-analysis of the relationship between age or years of experience. Human Resource Development Review, 3, 102-123.

Cheek, J. M., \& Buss, A. H. (1981). Shyness and sociability. Journal of Personality and Social Psychology, 41, 330-339.

Cohen, S., \& Wills, T. A. (1985). Stress, social support, and the buffering hypothesis. Psychological Bulletin, 98, 310-357.

Cohen-Charash, Y., \& Spector, P. E. (2001). The role of justice in organizations: A metaanalysis. Organizational Behavior and Human Decision Processes, 86, 278-321.

Cooper, C.L. \& Marshall, J. (1976). Occupational sources of stress: a review of the literature relating to coronary heart disease and mental ill health. Journal of Occupational Psychology, 49, 11-28.

Danna, K. \& Griffin, R.W. (1999). Health and well-being in the workplace: a review and synthesis of the literature. Journal of Management, 25, 357-84.

De Dreu, C. K. W., Van Dierendonck, D., \& Best-Waldhober, M. D. (2004a) Conflict at work and individual well-being. In M. J. Schabracq, J. A. M. Winnubst, \& C. L. Cooper (Eds.), The handbook of work and health psychology (pp. 495-515). West Sussex, England: John Wiley \& Sons Ltd.

De Dreu, C. K. W., Van Dierendonck, D., \& Dijkstra, M. T. (2004b). Looking back, looking ahead: Conflict at work and individual health and well-being. International Journal of Conflict Management, 15, 1-18. 
Demerouti, E., Bakker, A. B., Nachreiner, F., \& Schaufeli, W. B. (2001). The job demands-resources model of burnout. Journal of Applied Psychology, 86, 499512.

Demerouti, E., Bakker, A. B., Vardakou, I., \& Kantas, A. (2003). The convergent validity of two burnout instruments: A multitrait-multimethod analysis. European Journal of Psychological Assessment, 18, 296-307.

Diener, E., Emmons, R. A., Larsen, R. J., \& Griffin, S. (1985). The satisfaction with life scale. Journal of Personality Assessment, 49, 71-75.

Dohrenwend, B. S. (1978). Social status and responsibility for stressful life events. In C. D. Spielberger \& L. G. Sarason (Eds.), Stress and anxiety (Vol. 5, pp. 25-42). New York: Wiley.

Dollard, J., Doob, L.W., Miller, N. E., Mowrer, O. H. and Sears, R. R. (1939). Frustration and Aggression, Yale University Press, New Haven.

Edwards, J. R., \& Rothbard, N. P. (2000). Mechanisms linking work and family: Clarifying the relationship between work and family constructs. Academy of Management Review, 25, 178-199.

Etzion, D., Eden, D., \& Lapidot, Y. (1998). Relief from job stressors and burnout: Reserve service as a respite. Journal of Applied Psychology, 83, 577-585.

Faragher, E. B., Cass, M. \& Cooper, C. L. (2005). The relationship between job satisfaction and health: A meta-analysis. Occupational and Environmental Medicine, 62, 105-111. 
Fox, S. \& Spector, P. E. (1999). A model of work frustration-aggression. Journal of Organizational Behavior, 20, 915-931.

Fritz, C., \& Sonnentag, S. (2005). Recovery, health, and job performance: Effects of weekend experiences. Journal of Occupational Health Psychology, 10, 187-99.

Fritz, C., \& Sonnentag, S. (2006). Recovery, well-being, and performance-related outcomes: The role of workload and vacation experiences. The Journal of Applied Psychology, 91, 936-45.

Fritz, C., Sonnentag, S., Spector, P., \& McInroe, J. (2010a). The weekend matters: Relationships between stress recovery and affective experiences. Journal of Organizational Behavior, 31, 1137-1162.

Fritz, C., Yankelevich, M., Zarubin, A., \& Barger, P. (2010b). Happy, healthy, and productive: The role of detachment from work during nonwork time. Journal of Applied Psychology, 95, 977-983.

Frone, M. R. (2000). Interpersonal conflict at work and psychological outcomes: Testing a model among young workers. Journal of Occupational Health Psychology, 5, 246255.

Fuller, J. A., Stanton, J. M., Fisher, G. G., Spitzmuller, C., Russell, S. S., \& Smith, P. C. (2003). A lengthy look at the daily grind: Time series analyses of events, mood, stress, and satisfaction. Journal of Applied Psychology, 88, 1019-1033. 
Grandey, A. A. (2000). Emotion regulation in the workplace: A new way to conceptualize emotional labor. Journal of Occupational Health Psychology, 5, 95110.

Greenberg, J. \& Baron, R. A. (2008). Behavior in organizations. Upper Saddle River, NJ: Pearson Prentice Hall.

Greenhaus, J. H., \& Beutell, N. J. (1985). Sources of conflict between work and family roles. Academy of Management Review, 10, 76-88.

Griffin, J. M., Fuhrer, R., Stansfeld, S. A., \& Marmot, M. (2002). The importance of low control at work and home on depression and anxiety: Do these effects vary by gender and social class? Social Science \& Medicine, 54, 783-798.

Hackman, J. R., \& Oldham, G. R. (1976). Motivation through the design of work: Test of a theory. Organizational Behavior and Human Performance, 16, 250-279.

Hahn, V. C., Binnewies, C., Sonnentag, S., \& Mojza, E. J. (2011). Learning how to recovery from job stress: Effects of a recovery training program on recovery, recovery-related self-efficacy, and well-being. Journal of Occupational Health Psychology, 16, 202-216.

Halbesleben, J. R. B., \& Demerouti, E. (2005). The construct validity of an alternative measure of burnout: Investigating the English translation of the Oldenburg Burnout Inventory. Work and Stress, 19, 208-220. 
Hammer, L. B., \& Zimmerman, K. L. (2010). Quality of Work Life. In S. Zedeck (Ed.), Handbook of I/O Psychology. Vol. 3. Washington, DC: American Psychological Association.

Harder, J. K., Schmidt, F. L., \& Hayes, T. L. (2002). Business-unit-level relationship between employee satisfaction, employee engagement, and business outcomes: A meta-analysis. Journal of Applied Psychology, 87, 268-279.

Harrison, D. A., Newman, D. A., \& Roth, P. L. (2006). How important are job attitudes? Meta-analytic comparison of integrative behavioral outcomes and time sequences. Academy of Management Journal, 49, 305-325.

Hershcovis, M. S. (2011). Incivility, social undermining, bullying...Oh My! A call to reconcile constructs within workplace aggression research. Journal of Organizational Behavior, 32, 499-519.

Hershcovis, M. S., \& Barling, J. (2009). Towards a multi-foci approach to workplace aggression: A meta-analytic review of outcomes from different perpetrators. Journal of Organizational Behavior, 31, 24-44.

Hobfoll, S. E. (1989). Conservation of Resources: A New Attempt at Conceptualizing Stress. American Psychologist, 44, 513-524.

Hobfoll, S. E., \& Lilly, R. S. (1993). Resource conservation as a strategy for community psychology. Journal of Community Psychology, 21, 128-148.

Hobfoll, S. E. (1998). Stress, culture, and community: The psychology and physiology of stress. New York: Plenum Press. 
Holmes, T. H., \& Rahe, R. H. (1967). The social readjustment rating scale. Journal of Psychosomatic Research, 11, 213-218.

Howell, D. C. (2010). Statistical Methods for Psychology. Belmont, CA: Wadsworth.

Hulin, C. L., \& Judge, T. A. (2003). Job attitudes. In W. C. Borman, D. R. Ilgen, \& R. J. Klimoski (Eds.): Handbook of Psychology, Volume 12, Industrial and Organizational Psychology. New York: Wiley.

Jackson, S. E., \& Schuler, R. S. (1985). A meta-analysis and conceptual critique of research on role ambiguity and role conflict in work settings. Organizational Behavior and Human Decision Processes, 36, 16-78.

Jex, S. M., \& Beehr, T. A. (1991). Emerging theoretical and methodological issues in the study of work-related stress. Research in Personnel and Human Resources Management, 9, 311-365.

Judge, T. A. \& Bono, J. E. (2001). Relationship of core self-evaluations traits—-selfesteem, generalized self-efficacy, locus of control, and emotional stability-with job satisfaction and job performance: A meta-analysis. Journal of Applied Psychology, 86, 80-92.

Judge, T. A., Thoreson, C. J., Bono, J. E., \& Patton, G. K. (2001). The job satisfactionjob performance relationship: A qualitative and quantitative review. Psychological Bulletin, 127, 376-407.

Judge, T. A., \& Watanabe, S. (1993). Another look at the job satisfaction-life satisfaction relationship. Journal of Applied Psychology, 78, 939-948. 
Judge, T. A., Locke, E. A., Durham, C. C., \& Kluger, A. N. (1998). Dispositional effects on job and life satisfaction: The role of core evaluations. Journal of Applied Psychology, 83, 17-34.

Kahn, R. L.,Wolfe, D. M., Quinn, R. P., Snoek, D., \& Rosenthal, R. A. (1964). Organizational stress: Studies in role conflict and ambiguity. New York: Wiley.

Kalliath, T. J. (2001). Is the path to burnout and turnover paved by a lack of supervisory support? A structural equations test. New Zealand Journal of Psychology, 30, 72.

Keenan, A., \& Newton, T. J. (1985). Stressful events, stressors, and psychological strains in young professional engineers. Journal of Occupational Behavior, 6, 151-156.

Kinicki, A. J., McKee-Ryan, F. M., Schriesheim, C. A., \& Carson, K. P. (2002). Assessing the construct validity of the job descriptive index: A review and metaanalysis. Journal of Applied Psychology, 87, 14-32.

Kinnunen, U., Mauno, S., \& Siltaloppi, M. (2010). Job insecurity, recovery, and wellbeing at work: Recovery experiences as moderators. Economic and Industrial Democracy, 31, 179-194.

Kossek, E. E. \& Ozeki, C. (1998). Work-family conflict, policies, and the job-life satisfaction relationship: A review and directions for organizational behaviorhuman resources research. Journal of Applied Psychology, 83, 139-149.

Larsen, R. J. (2000). Toward a science of mood regulation. Psychological Inquiry, 11, $129-141$.

Lazarus, R. S. (1966). Psychological stress and the coping process. New York: McGrawHill. 
Lazarus, R. S. (1991). Psychological stress in the workplace. In P. L. Perrewe (Ed.), Journal of Social Behavior and Personality: Vol. 6. Handbook on job stress (special issue) (pp. 1-13). San Rafael, CA: Select Press.

Lazarus, R. S., \& Folkman, S. (1984). Stress, appraisal, and coping. New York: Springer.

Lyubomirsky, S., Caldwell, N. D., \& Nolen-Hoeksema, S. (1998). Effects of ruminative and distracting responses to depressed mood on retrieval of autobiographical memories. Journal of Personality and Social Psychology, 75, 166-177.

Maslach, C. (1982). Burnout: The cost of caring. Englewood Cliffs, NJ: Prentice-Hall, Inc.

McEwen, B.S. (1998). Protective and damaging effects of stress mediators. Seminars in Medicine of the Beth Israel Deaconess Medical Center, 338, 171-9.

Meijman, T. F., \& Mulder, G. (1998). Psychological aspects of workload. In P. J. D. Drenth, H. Theirry, \& C. J. Wolff (Eds.). Handbook of Work and Organizational Psychology: Work Psychology. East Sussex: Psychology Press.

Muraven, M., Tice, D. M., \& Baumeister, R. F. (1998). Self-control as limited resource: Regulatory depletion patterns. Journal of Personality and Social Psychology, 74, 774-789.

Nolen-Hoeksema, S. (1991). Responses to depression and their effects on the duration of depressive episodes. Journal of Abnormal Psychology, 100, 569-582. 
Park, Y., Fritz, C., Jex, S. M. (2011). Relationships between work-home segmentation and psychological detachment from work: The role of communication technology use at home. Journal of Occupational Health Psychology, 16, 457-467.

Parkinson, B., Totterdell, P., Briner, R. B., \& Reynolds, S. (1996). Changing moods: The psychology of mood and mood regulation. London: Longman.

Parkinson, B., \& Totterdell, P. (1999). Classifying affect-regulation strategies. Cognition and Emotion, 13, 277-303.

Pennebaker, J.W. (1982). The Psychology of Physical Symptoms. New York: SpringerVerlag.

Peters, L. H. and O'Connor, E. J. (1980). Situational constraints and work outcomes: The influences of a frequently overlooked construct. Academy of Management Review $5,391-397$.

Podsakoff, P. M., MacKenzie, S. B., Lee, J. Y., \& Podsakoff, N. P. (2003). Common method bias in behavioral research: A critical review of the literature and recommended remedies. Journal of Applied Psychology, 88, 879-903.

Rosenfield, S. (1989). The effects of women's employment: Personal control and sex differences in mental health. Journal of Health and Social Behavior, 30, 77-91.

Sarason, I. G., Johnson, J. H., \& Siegel, J. M. (1978). Assessing the impact of life changes: Development of the Life Experiences Survey. Journal of Consulting and Clinical Psychology, 46, 932-946. 
Schat, A. C. H., Frone, M. R., \& Kelloway, E. K. (2006). Prevalence of workplace aggression in the U. S. workforce. In E. K. Kelloway, J. Barling, \& J. J. Hurrell (Eds.). Handbook of workplace violence. Thousand Oaks, CA: Sage Publications.

Siltaloppi, M., Kinnunen, U., \& Feldt, T. (2009). Recovery experiences as moderators between psychosocial work characteristics and occupational well-being. Work and stress, 23, 330-348.

Siu, O., Lu, L., \& Cooper, C. L. (1999). Managerial stress in Hong Kong and Taiwan: A comparative study. Journal of Managerial Psychology, 14, 6-25.

Smith, P. C., Kendall, L. M., \& Hulin, C. L. (1969). The measurement satisfaction in work and retirement: A strategy for the study of attitudes. Chicago: Rand McNally.

Sonnentag, S. (2001). Work, recovery activities, and individual well-being: A diary study. Journal of Occupational Health Psychology, 6, 196-210.

Sonnentag, S., \& Bayer, U.-V. (2005). Switching off mentally: Predictors and consequences of psychological detachment from work during off-job time. Journal of Occupational Health Psychology, 10, 393-414.

Sonnentag, S., Binnewies, C., \& Mojza, E. J. (2008). Did you have a nice evening? A day-level study on recovery experiences, sleep, and work-relevant affect. Journal of Applied Psychology, 93, 674-684. 
Sonnentag, S., Binnewies, C., \& Mojza, E. J. (2010). Staying well and engaged when demands are high: The role of psychological detachment. Journal of Applied Psychology, 95, 965-976. doi: 10.1037/a002003

Sonnentag, S., \& Fritz, C. (2007). The Recovery Experience Questionnaire: Development and validation of a measure for assessing recuperation and unwinding from work. Journal of Occupational Health Psychology, 12, 204-21.

Sonnentag, S., Kuttler, I., \& Fritz, C. (2010). Job stressors, emotional exhaustion, and need for recovery: A multi-source study on the benefits of psychological detachment. Journal of Vocational Behavior, 76, 355-365.

Spector, P. E. (1978). Organizational frustration: A model and review of the literature. Personnel Psychology, 31, 815-829.

Spector, P. E. (1986). Perceived control by employees: A meta-analysis of studies concerning autonomy and participation at work. Human Relations, 11, 1005-1016.

Spector, P. E. (1987). Interactive effects of perceived control and job stressors on affective reactions and health outcomes for clerical workers. Work and Stress, 1, $155-162$.

Spector, P. E. (1998). A control theory of the job stress process. In C. L. Cooper (Ed.), Theories of organizational stress (pp. 153-169). Oxford, UK: Oxford Univ. Press. Spector, P. E. (2006). Industrial and Organizational Psychology: Research and Practice Hoboken, NJ: Wiley. 
Spector, P. E., Dwyer, D. J., \& Jex, S. M. (1988). Relation of job stressors to affective, health, and performance outcomes: A comparison of multiple data sources. Journal of Applied Psychology, 73, 11-19.

Spector, P. E. \& Jex, S. (1998). Development of four self-report measures of job stressors and strain: Interpersonal conflict at work scale, organizational constraints scale, quantitative workload inventory, and physical symptoms inventory. Journal of Occupational Health Psychology, 3, 356-367.

Spielberger, C. D., Reheiser, E. C. and Sydeman, S. J. (1995). Measuring the experience, expression, and control of anger. In: Kassinove, H. (Ed.) Anger Disorders: Definitions, Diagnosis, and Treatment, Taylor \& Francis, Washington, DC. Stoetzer, U., Ahlberg, G., Johansson, G., Bergman, P., Hallsten, L., Forsell, Y., Lundberg, I. (2009). Problematic interpersonal relationships at work and depression: A Swedish prospective cohort study. Journal of Occupational Health, 51, 144-151.

Stone, A. A., Kennedy-Moore, E., \& Neale, J. M. (1995). Association between daily coping and end-of-day mood. Health Psychology, 14, 341-349.

Tabachnik, B. G., \& Fidell, L. S. (2007). Using multivariate statistics: Fifth edition. Boston: Pearson Education, Inc.

Thayer, R. E., Newman, J. R., \& McClain, T. M. (1994). Self-regulation of mood: Strategies for changing a bad mood, raising energy, and reducing tension. Journal of Personality and Social Psychology, 67, 910-925. 
Ursin, H., Endresen, I. M., \& Ursin, G. (1988). Psychological factors and self-reports of muscle pain. European Journal of Applied Physiology and Occupational Physiology, 57, 282-290.

Viswesvaran, C., Sanchez, J. I., \& Fisher, J. (1999). The role of social support in the process of work stress: A meta-analysis. Journal of Vocational Behavior, 54, $314-334$.

Watson, D., Clark, L.A., \& Tellegen, A. (1988). Development and validation of brief measures of positive and negative affect: The PANAS scales. Journal of Personality and Social Psychology, 54, 1063-1070.

Watson, D., \& Pennebaker, J. W. (1989). Health complaints, stress, and distress: Exploring the central role of negative affectivity. Psychological Review, 96, 234254.

Weiss, H. M. (2002). Deconstructing job satisfaction: Separating evaluations, beliefs, and affective experiences. Human Resource Management Review, 12, 173-194.

Weiss, H. M., \& Cropanzano, R. (1996). Affective events theory: A theoretical discussion of the structure, causes, and consequences of affective experiences at work. In: B. M. Staw \& L. L. Cummings (Eds.) Research in organizational behavior: An annual series of analytical essays and critical reviews, 18, 1-74.

Westman, M. (1999, August). Gain and loss spirals: Applying Hobfoll's COR theory to respite research. Paper presented at the Academy of Management meeting, Chicago, IL. 
Westman, M. \& Eden, D. (1997). Effects of a respite from work on burnout: Vacation relief and fade-out. Journal of Applied Psychology, 82, 516-527. 
Appendix:

Survey Items

Negative Affectivity (Self-Report)

Instructions: Please rate the extent to which you experience the following moods in general.

1. Afraid

2. Upset

3. Distressed

4. Jittery

5. Nervous

6. Ashamed

7. Guilty

8. Irritable

9. Hostile

10. Scared

Response options: $(1=$ Very slightly or not at all, $2=$ A little, $3=$ Moderately, $4=$ Quite a bit, 5 = Extremely)

Interpersonal Conflict at Work (Coworker-Report)

Instructions: During the past few weeks, how often did the following occur in your job?

1. How often did he/she get into arguments with others at work?

2. How often did other people yell at him/her at work?

3. How often were people rude to him/her at work?

4. How often did other people do nasty things to him/her at work?

Response options: $(1=$ Never, $2=$ Rarely, $3=$ Sometimes, $4=$ Quite Often, $5=$ Extremely often)

Recovery Experiences (Self-Report \& Coworker-Report)

Instructions: Please tell us about your leisure time during the past few weeks. During off work time in the past few weeks...

Psychological Detachment:

1. I forgot about work.

2. I didn't think about work at all.

3. I distanced myself from work.

4. I got a break from the demands of work. 
Relaxation:

1. I kicked back and relaxed.

2. I did things that were relaxing.

3. I used the time to relax.

4. I took time for leisure.

Mastery:

1. I learned new things.

2. I sought out mental challenges.

3. I did things that challenged me.

4. I did something to broaden my horizons.

Control:

1. I felt like I could decide for myself what to do.

2. I decided my own schedule.

3. I determined for myself how I spent my time.

4. I took care of things the way that I wanted them done.

Positive Work Reflection:

1. It became clear to me what I like about my work.

2. I contemplated the positive sides to my work.

3 . I considered the positive aspects of my work.

Negative Work Reflection:

1. I considered the negative aspects of my work.

2. I was aware of what is negative about my work.

3. It became clear to me what I don't like about my work.

Social Activities:

1. I spent time with nice people.

2. I did things together with other people.

3. I took care of my relationships.

Response Options: $(1=$ Not At All, $2=$ Rarely, $3=$ Sometimes, $4=$ Most of the Time, $5=$ Always)

Well-Being (Significant Other Report)

Job Satisfaction:

Instructions: Please mark the extent to which you agree or disagree with the following statements regarding how you felt about your job in the past few weeks:

1. Most days he/she was enthusiastic about my work.

2. He/She felt fairly satisfied with my present job. 
3. Each day at work seemed like it would never end for him/her.

4. He/She found real enjoyment in his/her work.

5. He/She considered his/her job rather unpleasant.

Response Options: ( 1 = Strongly Disagree, $2=$ Disagree, $3=$ Neither Agree Nor Disagree, 4 = Agree, 5 = Strongly Agree)

\section{Burnout:}

Instructions: Please answer the following items (from 1 to 4 ) with regard to the past few weeks.

Exhaustion:

1. There were days that he/she felt already tired before he/she went to work.

2. After his/her work, he/she now needed more time to relax than in the past to become

fit again.

3. He/She could stand the pressure of his/her work very well.

4. During his/her work, he/she often felt emotionally drained.

5. After his/her work, he/she usually felt still totally fit for his/her leisure activities.

6. After his/her work, he/she usually felt worn out and weary.

7. He/She could manage the amount of work well.

8. When he/she worked, he/she usually felt vital.

Disengagement:

1. He/She always found new and interesting aspects in his/her work.

2. It happened more and more often that he/she talked about my work in a derogatory way.

3. He/She tended to think less during his/her work and just execute it mechanically.

4. He/She experienced his/her work as a real challenge.

5. He/She believes that, with the time, one loses the internal relationship with one's work.

6. Sometimes he/she felt really sick about his/her work tasks.

7. He/She could not imagine another occupation for himself/herself.

8 . He/She got more and more engaged in his/her work.

Response Options: $(1=$ Totally Disagree, 2 = Somewhat Disagree, 3 = Somewhat Agree,

$$
4=\text { Totally Agree) }
$$




\section{Life Satisfaction:}

Instructions: Using the 1-5 scale below, indicate your agreement with each item by circling that item. Please be open and honest in your responding. Describe how satisfied you were with your life during the past few weeks.

1. In most ways his/her life was close to his/her ideal.

2. The conditions of his/her life were excellent.

3. He/She was satisfied with his/her life.

4. So far he/she has gotten the important things he/she wanted in life.

5. If he/she could have lived his/her life over, he/she would change almost nothing.

Response Options: $(1=$ Strongly Disagree, $2=$ Disagree, $3=$ Neither Agree Nor Disagree, $4=$ Agree, $5=$ Strongly Agree)

General Health:

Instructions: Please answer the following items (from 1 to 4) with regard to the extent to which you experienced these symptoms during the past few weeks.

1. Cold, flu

2. Back pain

3. Arm pain

4. Leg pain

5. Headache/Migraine

6. Anxiety

7. Sadness/depression

8. Sleep problems/Tiredness

9. Extra heartbeats

10. Heat flushes

11. Dizziness

12. Stomach discomfort

13. Heartburn

14. Diarrhea/Constipation

15. Breathing difficulties

16. Allergies

17. Chest pain

Response Options: $(1=$ Not at All, $2=$ A Little, $3=$ Some, $4=$ Serious $)$ 